Florida International University FIU Digital Commons

\title{
Comparison of Synthetic Versus Organic Herbicides/Insecticides on Arbuscular Mycorrhizal Fungi in Abelmoschus esculentus
}

Ariel Freidenreich

Florida International University, afrei006@fiu.edu

DOI: $10.25148 /$ etd.FIDC000723

Follow this and additional works at: https://digitalcommons.fiu.edu/etd

Part of the Agricultural Science Commons, Agriculture Commons, Biology Commons, and the Environmental Microbiology and Microbial Ecology Commons

\section{Recommended Citation}

Freidenreich, Ariel, "Comparison of Synthetic Versus Organic Herbicides/Insecticides on Arbuscular Mycorrhizal Fungi in Abelmoschus esculentus" (2016). FIU Electronic Theses and Dissertations. 2601.

https://digitalcommons.fiu.edu/etd/2601 


\title{
FLORIDA INTERNATIONAL UNIVERSITY
}

Miami, Florida

\section{COMPARISON OF SYNTHETIC VERSUS ORGANIC HERBICIDES/INSECTICIDES ON ARBUSCULAR MYCORRHIZAL FUNGI \\ IN ABELMOSCHUS ESCULENTUS}

\author{
A thesis submitted in partial fulfillment of the \\ requirements for the degree of \\ MASTER OF SCIENCE \\ in \\ ENVIRONMENTAL STUDIES \\ by
}

Ariel Freidenreich

2016 
To: Dean Michael R. Heithaus

College of Arts, Sciences and Education

This thesis, written by Ariel Freidenreich and entitled Comparison of Synthetic Versus Organic Herbicides/Insecticides on Arbuscular Mycorrhizal Fungi in Abelmoschus esculentus, having been approved in respect to style and intellectual content, is referred to you for judgment.

We have read this thesis and recommend that it be approved.

DeEtta Mills

Leonard J. Scinto

Krishnaswamy Jayachandran, Major Professor

Date of Defense: June 14, 2016

The thesis of Ariel Freidenreich is approved.

Dean Michael R. Heithaus

College of Arts, Sciences, and Education

Andrés G. Gil

Vice President for Research and Economic Development and Dean of the University Graduate School

Florida International University, 2016 


\section{ACKNOWLEDGMENTS}

I would like to thank my major advisor, Dr. Krish Jayachandran, for his continuous guidance and support throughout my graduate career. His expertise in agriculture and soil science has helped me tremendously in my field and laboratory work. I wish to thank Dr. Leonard Scinto for his time in advising me in statistical analysis and data interpretation. I would also like to thank Dr. DeEtta Mills for graciously allowing my research to take place on her property along with her guidance in the development of my thesis research.

I am very thankful for the mentorship of Dr. Pushpa Soti who dedicated countless hours training me in the soil and microbiology laboratories. I thank Diana Johnson for assisting with AQ2 training. Additionally, I would like to thank Robert Barnum for allowing me to use his land for my research along with his invaluable farming advice. I thank Eduardo Perez, Chinya and Nyala Bully, Christopher Williams, Michael Hubbard, Conrad Freidenreich, and Dylan Safra for their help in setting up my research plots and sampling assistance. I thank Tyler Stout for assistance with Statistics. I thank my laboratory manager Eric Betancourt for the many hours he dedicated assisting in sample collection and processing. I thank Dr. Mahadev Bhat and Stephany Alvarez-Ventura for their assistance and guidance through my time in the Agroecology Program.

I want to thank my parents Abraham and Marcia Freidenreich for always encouraging me to keep moving forward even during tough times. I would also like to thank Guy DeSanctis for being there with me every step of the way throughout my entire academic career. Finally, I would like to thank the United States Department of Agriculture for funding my project USDA-NIFA-NNF 2013-38420-20499. 
ABSTRACT OF THE THESIS

\title{
COMPARISON OF SYNTHETIC VERSUS ORGANIC HERBICIDES/INSECTICIDES \\ ON ARBUSCULAR MYCORRHIZAL FUNGI
}

IN ABELMOSCHUS ESCULENTUS

\author{
by \\ Ariel Freidenreich \\ Florida International University, 2016 \\ Miami, Florida
}

Professor Krishnaswamy Jayachandran, Major Professor

Arbuscular mycorrhizal fungi (AMF) play a crucial role in improving the growth of a vast majority of plants. Past researchers have discovered that agricultural practices have a significant negative effect on the diversity of AMF. Arbuscular mycorrhizal fungi are reported to enhance plant nutrient uptake, stress tolerance, and soil aggregate formation which are key aspects of productive low-input farming. The objective of this study was to investigate the effects of four pesticides on the ability of AMF to colonize the roots of okra plants (Abelmoschus esculentus). The pesticides being tested include two synthetic chemicals (glyphosate and carbaryl) and two organic chemicals (neem oil and citrus oil). The tested parameters included crop yield, plant biomass, leaf matter CNP, and the percentage of mycorrhizal colonization in roots. The results of this study show that the organic chemicals had no significant effect on AMF colonization while the synthetic chemicals did have somewhat of a negative effect on colonization. 


\section{TABLE OF CONTENTS}

SECTION

PAGE

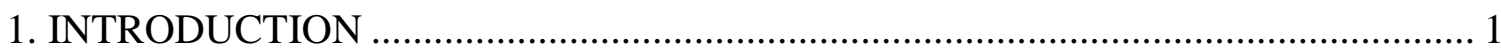

1.1 Significance of Research.................................................................................... 1

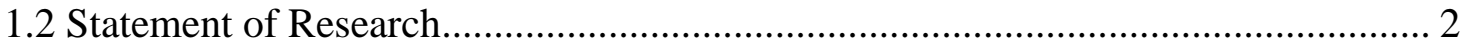

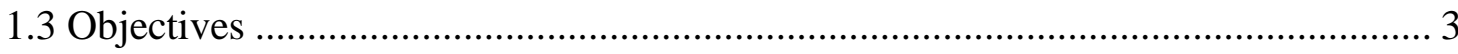

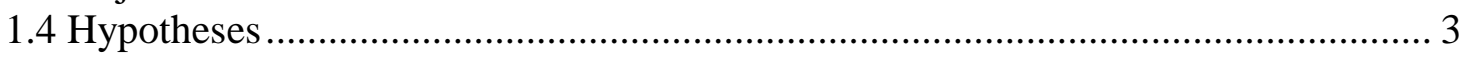

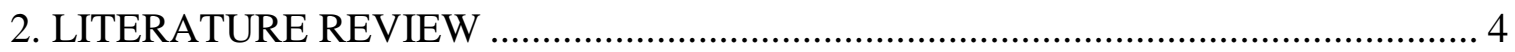

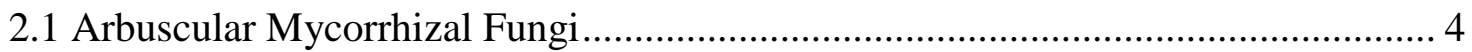

2.1.1 Mycorrhiza/Plant Relationship ................................................................... 4

2.1.2 Arbuscular Mycorrhizal Fungi Biology ………….......................................... 5

2.1.3 Benefits of Arbuscular Mycorrhizal Fungi ...................................................... 7

2.1.4 Effects of Pesticides on Arbuscular Mycorrhizal Fungi ................................... 9

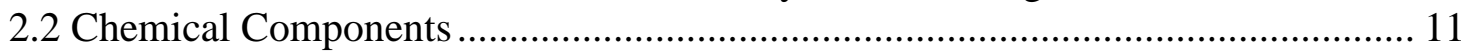

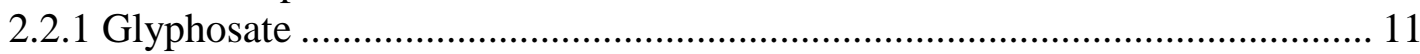

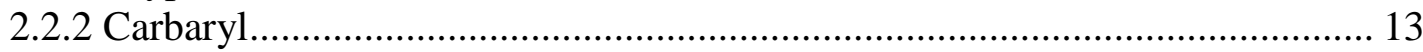

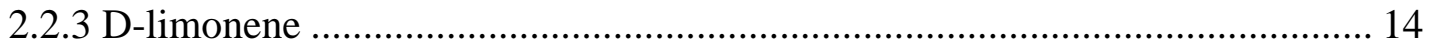

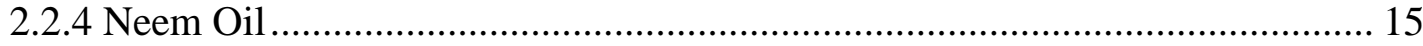

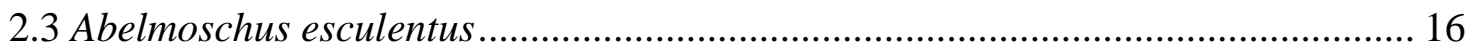

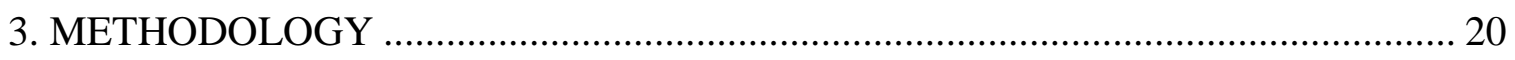

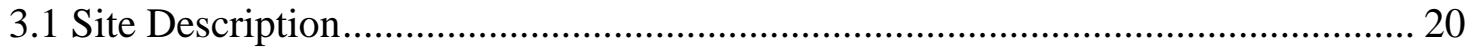

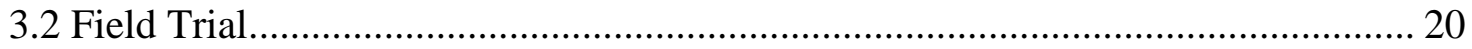

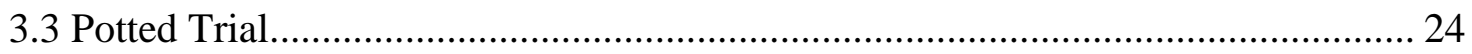

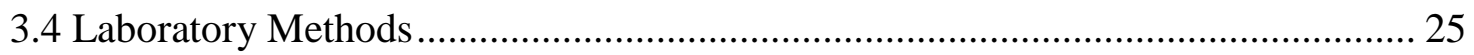

3.4.2 Total Carbon and Nitrogen (Soil and Leaf) ………….................................. 26

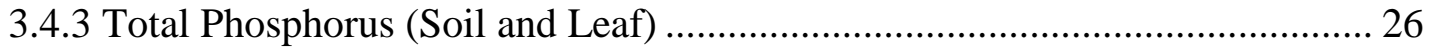

3.4.4 Soil Organic Matter Content ...................................................................... 27

3.4.5 Soil Moisture Content .................................................................................. 27

3.4.6 Clearing and Staining Root Samples for Arbuscular Mycorrhizal Fungi

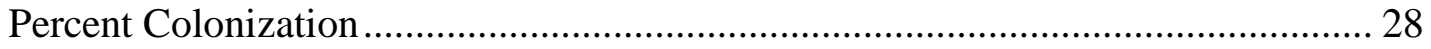

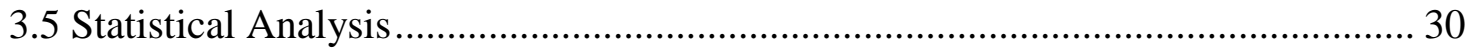

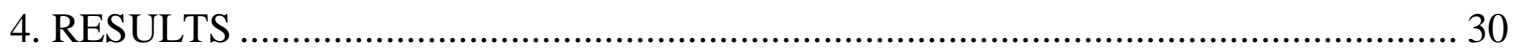

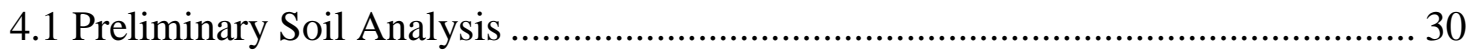

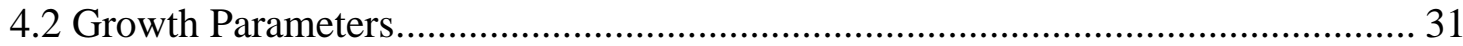

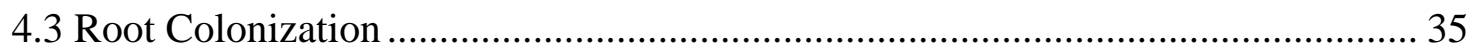

4.3.1 Root Colonization between Both Sites ....................................................... 35

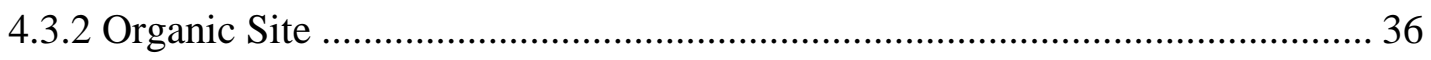

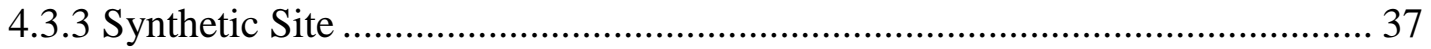

4.4 Phosphorus Concentration (Leaf Matter) ………….............................................. 38 


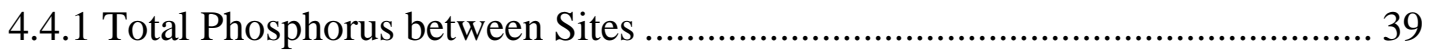

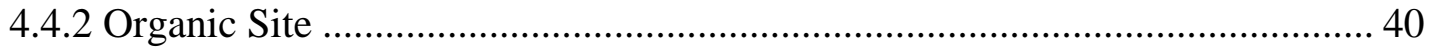

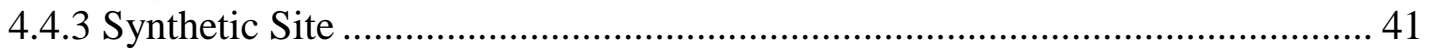

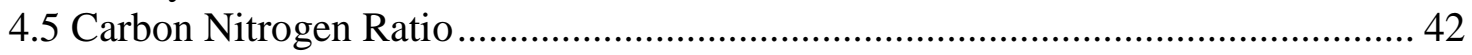

4.5.1 C:N ratio between Both Sites................................................................ 43

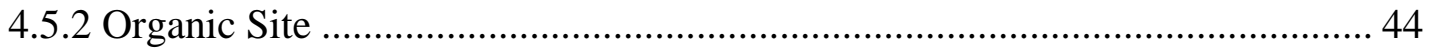

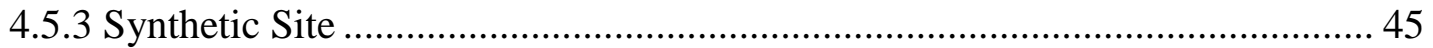

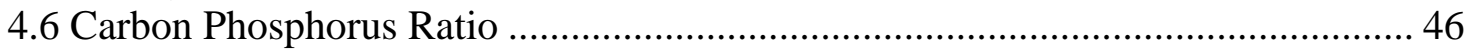

4.6.1 C:P Ratio Between Sites ........................................................................ 47

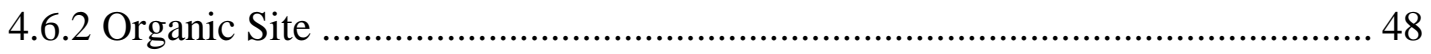

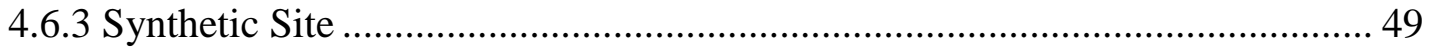

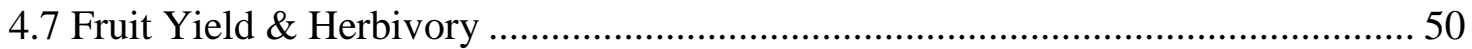

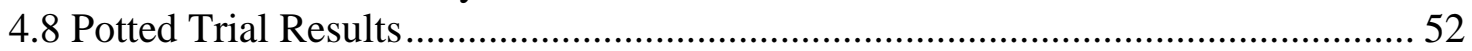

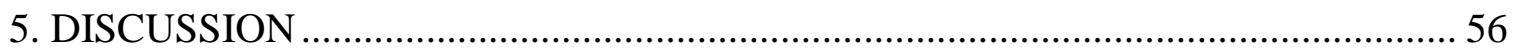

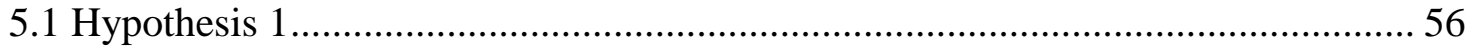

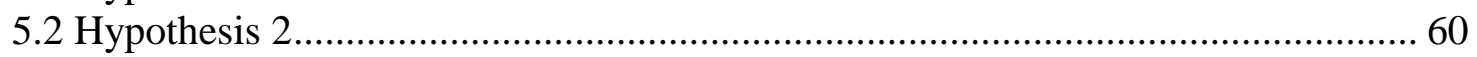

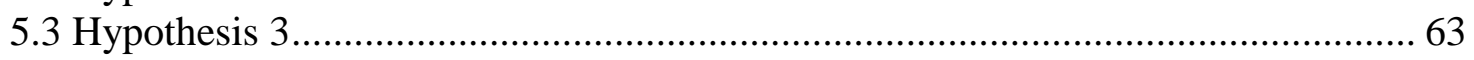

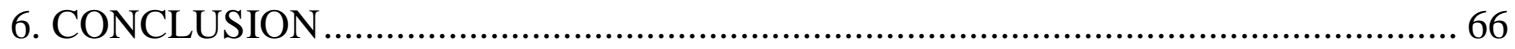

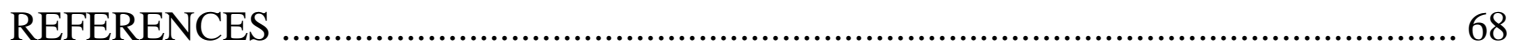

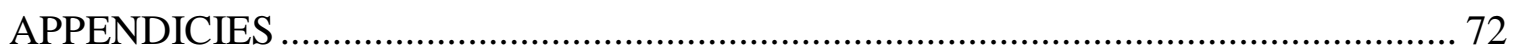




\section{LIST OF TABLES}

TABLE

PAGE

Table 1: Glyphosate growth inhibition on a variety of fungal species (Dill et al. 2010). 13

Table 2: A list of recommended insecticide sprays for South Florida and the pests they

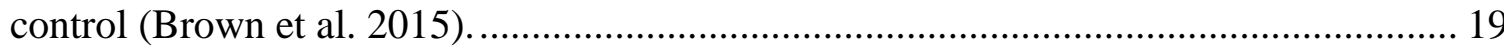

Table 3: Analyses performed on soil and root samples at the 3 sampling periods.......... 25

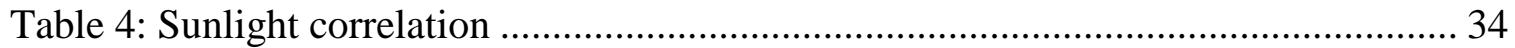

Table 5: Root colonization ANOVA results for $\mathrm{T}_{1} \& \mathrm{~T}_{2}$ for each site comparing the

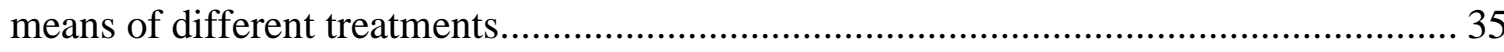

Table 6: Total phosphorus ANOVA results for $T_{1} \& T_{2}$ for each site comparing the

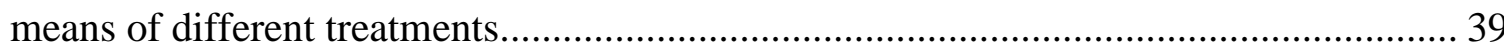

Table 7: C:N ratio ANOVA results for $\mathrm{T}_{1} \& \mathrm{~T}_{2}$ for each site comparing the means of

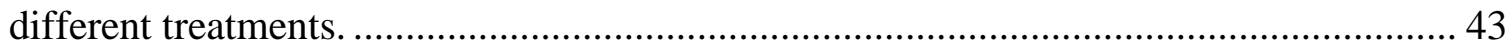

Table 8: C:P ratio ANOVA results for $\mathrm{T}_{1} \& \mathrm{~T}_{2}$ for each site comparing the means of different treatments. 


\section{LIST OF FIGURES}

FIGURE

PAGE

Figure 1: Mycorrhizal structures in root (Brundrett et al. 1996) .................................... 7

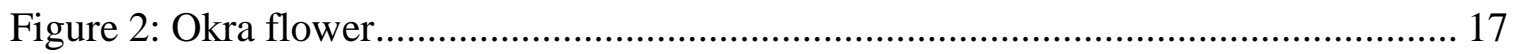

Figure 3: (a) Rototilling grass and surface soil (b) soil delivery (c) leveling out of soil.. 21

Figure 4: The finished plots with plastic separators ............................................ 22

Figure 5: Using soil meter to take field measurements............................................. 24

Figure 6: Example of mycorrhizal root colonization ............................................. 28

Figure 7: A close up example of vesicle and hyphae structures .................................. 29

Figure 8: A close up example of arbuscules inside the root ..................................... 29

Figure 9: A graph depicting the means of total dry weight biomass at each site

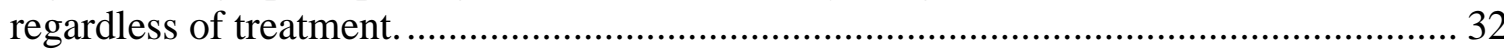

Figure 10: A graph depicting the means of stem and root dry weight biomass at each site regardless of treatment.

Figure 11: Sunlight intensity measurements from each of the three sampling dates at both sites.

Figure 12: A line graph depicting the relationship of mean root colonization percentage for both sites by sampling time (day) regardless of treatment.

Figure 13: A boxplot showing average root colonization percentage at the organic site with $\mathrm{T}_{1}$ and $\mathrm{T}_{2}$ averages combined.

Figure 14: A boxplot presenting average root colonization percentage at the synthetic site with $\mathrm{T}_{1}$ and $\mathrm{T}_{2}$ averages combined.

Figure 15: A line graph depicting the relationship of the mean total phosphorus concentrations for both sites regardless of treatment. 40

Figure 16: A boxplot depicting the average total phosphorus measurements at the organic site with $\mathrm{T}_{1}$ and $\mathrm{T}_{2}$ averages combined. 
Figure 17: A boxplot displaying the average total phosphorus measurements at the synthetic site with $\mathrm{T}_{1}$ and $\mathrm{T}_{2}$ averages combined.

Figure 18: A line graph depicting the relationship of the mean $\mathrm{C}: \mathrm{N}$ ratio for both sites regardless of treatment.

Figure 19: A boxplot showing the $\mathrm{C}: \mathrm{N}$ ratio between treatments at the organic site with $\mathrm{T}_{1}$ and $\mathrm{T}_{2}$ averages combined.

Figure 20: A boxplot displaying the $\mathrm{C}: \mathrm{N}$ ratio between treatments at the synthetic site with $\mathrm{T}_{1}$ and $\mathrm{T}_{2}$ averages combined.

Figure 21: A line graph depicting the relationship of the mean $\mathrm{C}: \mathrm{P}$ ratio (leaf matter) for both sites regardless of treatment.

Figure 22: A boxplot depicting the C:P ratio between treatments at the organic site with $\mathrm{T}_{1}$ and $\mathrm{T}_{2}$ averages combined.

Figure 23: A boxplot showing the C:P ratio between treatments at the synthetic site with $\mathrm{T}_{1}$ and $\mathrm{T}_{2}$ averages combined.

Figure 24: A bar graph depicting the fruit yield means at the organic and synthetic site at $\mathrm{T}_{2}$

Figure 25: Images displaying the intense herbivory at the Possum Trot organic site. .... 52

Figure 26: A boxplot showing the mean root colonization for each treatment in the potted trial with $T_{1}$ and $T_{2}$ averages combined.

Figure 27: A boxplot displaying the total phosphorus in $\mathrm{mg} g-1 \mathrm{dw}$ of the leaf samples from each treatment with $\mathrm{T}_{1}$ and $\mathrm{T}_{2}$ averages combined.

Figure 28: A boxplot displaying the $C: N$ ratio for the potted trial with $T_{1}$ and $T_{2}$ averages combined.

Figure 29: A boxplot depicting the $C: P$ ratio for the pot trial with $T_{1}$ and $T_{2}$ averages combined. 


\section{ABBREVIATIONS AND ACRONYMS}

AChE

$\mathrm{AM}$

AMF

$\mathrm{C}$

$\mathrm{cm}$

$\mathrm{C}: \mathrm{N}$

$\mathrm{C}: \mathrm{P}$

DIW

dw

EPSPS

FIU

g

$\mathrm{g} / 1$

HCL

IPM

1

MgSO4 Magnesium sulfate

mg g-1 Milligrams per gram

$\mathrm{ml}$

$\mathrm{mm}$

mol

$\mathrm{N}$

Celsius

Centimeter

Carbon to nitrogen

Deionized water

Dry weight

Gram

Grams per liter

Hydrochloric acid

Liter

Milliliter

Millimeter

Mole

Nitrogen
Acetyl cholinesterase enzyme

Arbuscular mycorrhiza

Arbuscular mycorrhizal fungi

Carbon to phosphorus

Enzyme 5-enolpyruvylshikimate-3-phosphate synthase

Florida International University

Integrated pest management 


$\begin{array}{ll}\text { OM\% } & \text { Organic matter percentage } \\ \text { OMRI } & \text { Organic Materials Review Institute } \\ \mathrm{P} & \text { Phosphorus } \\ \mathrm{pH} & \text { Power of hydrogen } \\ \mathrm{P}_{\mathrm{i}} & \text { Inorganic phosphate } \\ \mathrm{P} / 1 & \text { Phosphorus per liter } \\ \mathrm{USDA} & \text { United States Department of Agriculture } \\ \mathrm{Zn} & \text { Zinc } \\ \mu 1 & \text { Microliter } \\ \mu \mathrm{m} & \text { Micrometer }\end{array}$




\section{INTRODUCTION}

\subsection{Significance of Research}

Since the Green Revolution of the mid 1900's, conventional agriculture has dominated the world of food production. These types of high input agricultural methods have greatly increased crop yield through the use of synthetic fertilizer, irrigation technologies, chemical herbicide and pesticides, and improved crop varieties (Altieri, 1999). While these innovations increase food output, they have also caused land transformation, biodiversity loss, and ecosystem degradation along with health issues associated with the extensive use of chemicals in the food system (Altieri, 1999). Agriculture dominates land use today and will continue to as long as the world's population and demand for food continue to rise. Approximately $40 \%$ of the planet's arable landscape has been converted to agricultural land (Tanentzap et al. 2015).

It is estimated that 2.5 million tons of pesticide are applied to agricultural crops across the globe annually. Yet, the amount of substance that comes into contact or consumed by pests is a very small percentage of the amount applied. Most studies have shown that only around $0.3 \%$ of pesticide applied is actually reaching the target pest (van der Werf, 1996). The improper use of pesticides creates a situation where the majority of chemical substance is coming in contact with non-target organisms. In many cases, human health is considered top priority, and countless studies have been conducted to discover the effects of leaching pesticides into drinking water and residual pesticide left on agricultural products for human consumption. These topics have been an issue of public concern since the early 1960's with the release of Rachel Carson's Silent Spring. 
Soil quality is one of the most important factors in crop production and is often overlooked. Soil microbes are incredibly important for soil formation (decomposition) along with assisting in plant nutrient availability and uptake (van der Heijden et al. 2008). Arbuscular mycorrhizal fungi (AMF) are plant symbionts that can be found in soil systems worldwide. The presence of AMF can help to improve growth in a variety of different plants including some of today's mainstream crops (Druille et al. 2013). Arbuscular mycorrhizal fungi can assist plants in nutrient uptake, increase water availability, and help protect against plant pathogens. These beneficial characteristics of AMF make its presence beneficial for plant diversity and productivity along with vegetation community structure (Druille et al. 2013). Given the significant role that AMF plays in plant productivity, it is important to consider the effects of chemical pesticide and herbicide applications that occur regularly on conventional and organic farms.

\subsection{Statement of Research}

My thesis research project is designed to test the effects of four widely available pesticides on the root colonization of mycorrhizal fungi and overall plant fitness in Abelmoschus esculentus (Okra). I have tested two Organic Materials Review Institute (OMRI) certified products including one herbicide and one pesticide, along with two synthetic chemical products, one herbicide and one pesticide. The experiment conducted was designed to test the effects of these pesticides separated into groups of organic and synthetic, and then comparatively between the two groups. Additionally, this study considers the effect that time has on the applied treatments and mycorrhizal colonization of the roots. The research occurred at two separate field sites; one site received organic 
treatment, while the other received synthetic. Each site had four separate treatments. At the organic site, the treatments were split into NATRIA® Neem Oil application (insecticide), Avenger Organics@ Citrus oil application (herbicide), a combination of the two, and a control. At the synthetic site treatments were Sevin ${ }^{\circledR}$ (insecticide), Roundup® (herbicide), a combination of the two, and a control. Each of these treatments were applied to their own individual plot and each plot was sampled over three time periods.

\subsection{Objectives}

1. To determine the effects of synthetic herbicide (glyphosate) and insecticide (carbaryl) on presence of AMF relative to the control.

2. To determine if alternative organic weed (citrus oil) and pest (neem oil) control have an effect on the presence AMF relative to the control.

3. To determine if crop nutrient status and yield will be affected given the different treatments applied.

\subsection{Hypotheses}

1. Both the glyphosate and carbaryl treatments will have a negative effect on the mycorrhizae population and, in turn, leaf nutrients. The combination treatment of both glyphosate and carbaryl will have the most severe effect.

2. D- Limonene (citrus oil) and neem oil treatments will have little to no effect on the mycorrhizae population or leaf nutrients.

3. The synthetic chemical sprays will have a greater negative effect on the mycorrhizae population and colonization than the organic alternative sprays. 


\section{LITERATURE REVIEW}

\subsection{Arbuscular Mycorrhizal Fungi}

\subsubsection{Mycorrhiza/Plant Relationship}

The presence of soil microorganisms is essential for maintaining soil quality in the form of nutrient cycling and overall biogeochemical processes. The rhizosphere is the volume of soil influenced and adjacent to plant roots. A healthy microbial presence in the rhizosphere is critical for successful plant growth and productivity through providing available nutrients for uptake through the plant root (Jeffries et al. 2002). Mycorrhizal fungi are among these beneficial rhizosphere microorganisms.

Mycorrhizal fungi are beneficial plant symbionts. It is now known that mycorrhizal relationships are some of the most significant in terms of plant-microbe symbiosis. There are two types of mycorrhizal interaction. Ectomycorrhiza form between the roots of a plant; they establish themselves by penetrating roots intracellularly and work to replace the middle lamellae within the cortical cells of feeder roots (roots that absorb water and nutrients) (Tate, 2000). Ectomycorrhizae coagulate densely to form a mycelial net between cells and a continuous hyphal network over the surface of feeder roots (Tate, 2000). Therefore, the presence of ectomycorrhizae can be seen with the naked eye in most cases. This type of relationship occurs mainly in woody species (Lazaruk et al. 2005). On the other hand, endomycorrhizae penetrate the root and have the ability to grow inside the cell membrane. Arbuscular mycorrhizal fungi (AMF), a type of endomycorrhiza, are the most widespread and archaic type of mycorrhiza. It is now known that more than $80 \%$ of plant species have the ability to form relationships with AMF. Fossil records show that terrestrial plants evolved symbiotically with the aid 
of AMF. Therefore, it is clear that mycorrhizal relationships are directly related with diversity and productivity of present-day plant communities worldwide (Jeffries et al. 2002). Arbuscular mycorrhizal fungi are considered essential components of soil biota. They are naturally found in nearly every ecosystem across the planet and in agricultural cropping systems.

\subsubsection{Arbuscular Mycorrhizal Fungi Biology}

Arbuscular mycorrhizal fungi work by penetrating feeder roots through cortical cells forming structures of large vesicles and arbuscules (Tate, 2000). Arbuscular mycorrhizal fungi arise from three sources of inoculum: spores, hyphae, and infected root fragments (Smith \& Read, 2008). Spores are the most clearly defined source of inoculum and the only part of the fungus used for species identification. Density and diversity of spores can vary by environmental conditions. Even if spores are present, they may be dormant, have low rates of infectivity, or they are nonviable (Smith \& Read, 2008). Root fragments serve as an important source of inoculum in many soil types. It is possible that hyphae can regrow from previously infected root fragments which can be used to initiate colonization even if the host root is dead (Smith \& Read, 2008). Additionally, hyphal connections are also important because the hyphal network is able to survive and maintain infectivity through times where associated vegetation is dormant or, in some cases, even dead (Smith \& Read, 2008).

Once present in the soil, AMF takes steps to colonize the roots of a host plant and can occur from any of the three sources of inoculum. Colonization of roots is initiated once the inoculum (spore, hyphae, or infected root) gets close to the host; in some cases it has been observed that initiation may take place as far as $13 \mathrm{~mm}$ away through extended 
hyphae (Smith \& Read, 2008). Once hyphal contact is made with the root, adhesion occurs. Within the first three days of contact, swollen appressoria (a specialized cell used to infect a host) begin to form. If appressoria do not form, it indicates to the fungus that the selected host is not suitable for colonization. After the penetration of the root epidermis and formation of appressorium, hyphal branches begin to extend into the root's inner cortex and the mycorrhiza continues to grow longitudinally and fill intercellular spaces (Smith \& Read, 2008). These branches allow for the rise of arbuscules in the cells. Arbuscules are tree like structures that occur within the cortical cells of the host root. The presences of arbuscules are the main indicator for AMF colonization. Arbsucules within the plant root provide a large increase in contact surface area between the fungus and plant which has lead researchers to believe that they play a crucial role in soil-derived nutrient transfer of phosphorus $(\mathrm{P})$ and zinc $(\mathrm{Zn})$ to the host (Smith \& Read, 2008). After arbuscules are established, vesicles begin to develop. Vesicles are a storage system used by the fungus. They continually develop in the root even after arbuscules begin to deteriorate. In the later stages of colonization, arbuscules collapse beginning with the finest branches (Brundrett et al. 1996). Arbuscules are the most short-lived fungal structure; they begin senescence after only 4-10 days of establishment and activity. The arbuscule collapses and the plant cell returns back to its original state, available for recolonization in the future (Siddiqui et al. 2008).

Once the AMF has established itself in the root of a host, it can use external hyphae as a source of inoculum and continue to vigorously colonize the entire root system. When the AMF become established, the external mycelium begins to grow extensively (Smith \& Read, 2008). The growth of external mycelium is greatly important 
for the production of parent spores. Root system colonization is an interesting and dynamic process because the root and AMF continue to grow and develop at the same time. The root grows through the process of cell division, creating lateral roots through differentiation and elongation, while the fungus creates colonization units that continually grow throughout the root. Therefore, the percentage of root colonization, or the rate at which the root becomes colonized, is directly influenced by the growth of the root system and creation of fungal colonization cells (Smith \& Read, 2008).

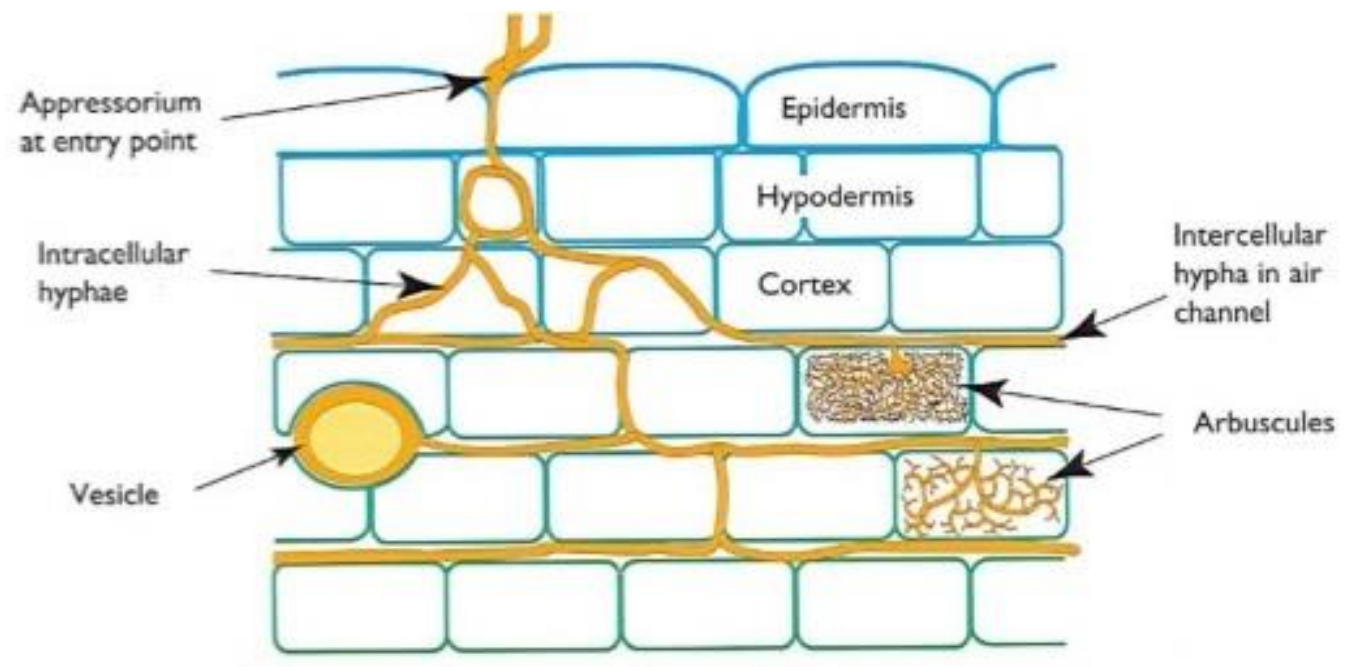

Figure 1: Mycorrhizal structures in root (Brundrett et al. 1996)

\subsubsection{Benefits of Arbuscular Mycorrhizal Fungi}

Mycorrhizae have a symbiotic and mutual relationship with many of the world's host plants. The most notable benefit of AMF is that they assist in extracting mineral nutrients from the soil and provide it to the plant. The host plant provides carbon to the fungus to keep them alive. The fungus benefits the host by providing minerals to the plant in the form of essential nutrients such as phosphorus $(\mathrm{P})$ and nitrogen $(\mathrm{N})$ (Siddiqui et al. 2008). Phosphorus is often a limiting nutrient for plants in most every environment. This 
nutrient is present in the soil in the form of orthophosphate which is inorganic and is only available to plants in that form. Phosphate limitation in soils is an age-old problem which severely effects modern agriculture's efficiency. Phosphorus is synthetically added to agricultural soils which solves the nutrient deficiency issues, but inadvertently creates environmental problems (Sawers et al. 2008). Arbuscular mycorrhiza phosphate attainment begins with the extension of extra-radical fungal hyphae. These hyphae extend beyond the colonized root to allow for exposure to greater soil volume. These hyphae uptake $\mathrm{P}_{\mathrm{i}}$ (inorganic phosphate). Phosphate is then transferred to the fungal vacuole where polyphosphate is formed. From there, hydrolization of the polyphosphate occurs and the substance is released to the apoplast. The phosphate is then guided across the arbuscular membrane and translocated to the vascular system of the plant making it available to all parts of the host (Sawers et al. 2008).

In addition to assisting plants with nutrient uptake, AMF can also act as a bioprotectant in the form of disease control. Many studies have shown that AMF colonization in the roots of plants susceptible to plant parasitic nematodes, fungal plant pathogens, and other plant pathogens can actually deter disease or help to heal faster (Akhtar et al. 2008). Colonization of AMF in the root system changes the roots morphologically through an increase in root surface area. The plants response to interactions with other organisms changes when the morphology of the root system is altered. Past research has shown that plants colonized by AMF exhibit strong vascular health and enhanced lignin production (Akhtar et al. 2008). This increase in heartiness allows the colonized plant to produce wound barriers quicker and recover from disease faster than non-mycorrhizal plants. Furthermore, studies on root-knot nematodes have 
revealed that AMF inoculated plants showed smaller root galls. Smaller galls are less ideal for nematode reproduction and result in smaller offspring that take longer to mature (Akhtar et al. 2008).

Mycorrhizal presence in soils has a strong positive effect on growth of AMF compatible plants. Because of these beneficial characteristics, farmers of agricultural crops have become more aware of the importance of beneficial fungal communities and practices that enhance reproduction and stability of AMF in the soil. With the increasing need for food, agricultural practices have evolved from small, low input operations into large, high input and high production systems. It is well known that the practices of conventional agriculture systems have negative effects on the land being cultivated as well as the surrounding environment. Common agricultural management practices include crop rotation, intensive tillage, synthetic pesticide and fertilizer application, genetically modified crop varieties, and the planting of strictly monoculture fields. Within the last few decades, questions have been raised as to how these conventional agricultural system are affecting human and environmental health. Sustainable and organic agriculture has since become popular in North America. The goal of these types of agriculture systems is to produce suitable yields while keeping environmental impacts to a minimum.

\subsubsection{Effects of Pesticides on Arbuscular Mycorrhizal Fungi}

There has been a good deal of research conducted on the effects of agricultural practices such as tillage systems, crop density, and fertilizer application on presence and colonization of AMF. However, there has been little published research on the effects of synthetic and organic herbicides and insecticides on AMF. Abd-Alla et al. (2000) tested 
the herbicides Brominal (BUCTRIL®, Bayer Crop Science) and Gramoxone ${ }^{\circledR}$ (Syngenta), and the insecticide Selecron ${ }^{\circledR}$ (Syngenta) on AMF colonization in multiple legume types in a potted study. They found that all tested pesticides negatively affected colonization. This pesticide interaction is attributed to negatively effecting the ability of spores to initiate colonization through the reduced production of AM cell wall degrading enzymes (Abd-Alla et al. 2000). Dodd and Jeffries, (1989) tested the effects of four herbicides (Avenge 630, Ceridor, Dicurane, and Harrier) in a greenhouse study using field application protocols and germination tests performed in petri dishes. They found that Dirurane, Dicurane, and Harrier had little to no effect on spore germination and root colonization, while Avenge significantly reduced spore germination, root colonization and number of spores present.

The studies mentioned above display that there is some type of observed effect of pesticides on the presence and colonization of AMF in agricultural settings. Therefore, it is pertinent to continue to research this topic as it pertains to popular modern day agricultural pesticides. The chemical glyphosate is the most widely used herbicide in the United States (Szekacs and Darvas, 2012). The frequent use of Roundup® can be attributed to the development of genetically modified crop varieties that have specific resistance to the active ingredient glyphosate. When these crop varieties are implemented, glyphosate may be sprayed liberally to kill weeds without fear of killing the crop itself. While glyphosate is very effective at killing weeds at a low cost and high efficiency, its effects on non-target organisms is still uncertain (Druille et al. 2013).

Druille et al. (2013) conducted a study looking at the effects of glyphosate on AMF spore viability and root colonization. Their results show that spore viability was 
significantly reduced in soils treated with glyphosate compared to untreated soils. The spore viability in untreated soil was actually 5 to 7 times higher than in the treated samples. Root colonization results showed similar effects. Soils treated with glyphosate harbored roots that had significantly lower colonization and reduced appearance of arbuscules and vesicles. Savin et al. (2008) conducted a greenhouse study showing the effects of glyphosate spray on root colonization of three different crops (maize, cotton, and soybeans). They found that glyphosate application decreased root colonization in maize, had no real effect on soybean, and increased colonization in cotton.

These studies along with Druille et al. (2013) show conflicting results of the impact of glyphosate on AMF colonization and viability. Therefore, additional research must be conducted to exhibit a more accurate display of the interaction between pesticide application and fungus. The research I conducted investigated the outcome of glyphosate

application on AMF along with testing three other substances; a synthetic insecticide with the active ingredient of carbaryl, an organic herbicide with the active ingredient of dlimonene, and an organic insecticide with an active ingredient of clarified hydrophobic extract of neem oil.

\subsection{Chemical Components}

\subsubsection{Glyphosate}

Glyphosate was made popular by Monsanto when it was first commercially introduced as the active ingredient in their herbicide Roundup $®$ in 1974 (Szekacs and Darvas, 2012). Originally, Roundup® was used strictly for landscaping purposes. However, with the introduction of genetically modified crops, specifically glyphosate 
resistant crops, Roundup ${ }^{\circledR}$ 's popularity spiked in the agricultural community beginning in 1992 (Cerdeira and Duke, 2006).

Glyphosate is a broad spectrum non-selective herbicide. It is used as a post emergence herbicide because it is thought to have little to no activity in soil. It is composed of an amino acid glycine in the form of a phosphonomethyl derivative (N(phosphonomethyl) glycine). Glyphosate works by inhibiting the enzyme 5enolpyruvylshikimate-3-phosphate synthase (EPSPS) (Dill et al. 2010). The active sites of the EPSPS is very high in plants but also exists in fungi and bacteria. Inhibiting EPSPS results in the deregulation of the shikimate pathway which reduces the creation of aromatic amino acids, hormones, and plant metabolites (Dill et al. 2010). Additionally, deregulation of the shikimate pathway results in a buildup of shikimic acid, which is an indicator of glyphosate toxicity. Most plants degrade glyphosate metabolically very slowly giving it time to move throughout the tissues (Cerdeira and Duke, 2006). Glyphosate is translocated through the plant by phloem transport which results in delivery to meristematic tissues in the shoots and roots (Dill et al. 2010).

Glyphosate works effectively to kill weeds because it inhibits the EPSPS enzyme. This enzyme is also present in fungi and bacteria. However, the chemical is recognized as having miniscule effect as a fungicide. Research conducted on the effects of glyphosate in pure culture growth of different types of fungi showed that the chemical inhibited fungi growth, but only at very high concentrations (Dill et al. 2010). 
Table 1: Glyphosate growth inhibition on a variety of fungal species (Dill et al. 2010).

\begin{tabular}{lc}
\hline Fungi Genus & EC90 $\left(\mu \mathrm{gg}^{-1}\right.$ or $\left.\mathrm{ppm}\right)$ \\
\hline Septoria & $<100$ \\
Pseudocercosporella & $<100$ \\
Botrytis & $<100$ \\
Phytophthora & 1000 \\
Rhizoctonia & 1000 \\
Fusarium & 1000 \\
Gaeumannomyces & 1000 \\
Puccinia (rust) & 5000 \\
Pyricularia & 5000 \\
\hline
\end{tabular}

\subsubsection{Carbaryl}

Carbaryl (1-naphthol N-methylcarbamate) is manufactured by Bayer Company under the name of Sevin®. The chemical was first registered in the United States in 1959. Carbaryl is a wide-spectrum carbamate insecticide that can be used to regulate over 100 types of insect species. This insecticide is used for various types of crop production including grain crops, fruit and vegetables crops, and crop producing trees (EPA, 2004). It is applied to the entire crop plant surface in order to deter herbivory by insects. Because of its ability to control many insects, it has become popular and widely used among the farming community (Hassanzadeh et al. 2010). While Sevin ${ }^{\circledR}$ is the main product manufactured with carbaryl as the active ingredient, the chemical appears in more than 1500 products produced by over 290 formulators (Hassanzadeh et al. 2010).

Carbaryl functions by disrupting the nervous system of insects. It works by inhibiting the enzyme acetyl cholinesterase (AChE). Acetyl cholinesterase is an enzyme that controls the reaction that processes acetylcholine into choline after it has been utilized to transmit impulses between nerves (Cox, 1993). The presence of AChE is responsible for the smooth transmission of nerve impulses. Without the normal function of $\mathrm{AChE}$, muscle control is lost, leading to rapid muscle compulsions, paralysis, and 
eventually death (Cox, 1993). Carbaryl has been proven to be lethal on many non-target insects. The manufacturer recommends that the product not be sprayed while plants are flowering. Misuse by the consumer has caused issues with honey bee populations. Bees exposed to the substance cannot survive (Cornell, 1993).

Carbaryl has a short residual lifetime on crops. This insecticide is slowly taken up and metabolized by the plant; it is then degraded through hydrolysis. Its insecticidal properties are continually active for 3-10 days after application (Cornell, 1993). Carbaryl is readily degraded in the soil through contact with sunlight and bacterial decomposition. The half-life in aerobic soil is around 7 days, and 28 days in anaerobic soil. It can be transported through soil runoff because it is bound by organic matter (Cornell, 1993).

\subsubsection{D-limonene}

The active ingredient in the organic herbicide used for my research is Dlimonene. The herbicide is called Avenger Organics@ Natural Weed Killer. It is Organic Materials Review Institute (OMRI) certified, meaning that it is allowed for use in organic production and processing in operations certified as United States Department of Agriculture (USDA) organic (OMRI, 2016).

Avenger Organics $@$, like Roundup ${ }^{\circledR}$, is a post emergence, non-selective herbicide. The active ingredient d-limonene is citrus oil. The application of this substance to weeds naturally strips away the waxy plant cuticle causing dehydration and eventually death. This substance is comparable to leading synthetic herbicides making it a top choice for organic farmers (Avenger Organics, 2015). Citrus oil is non-toxic and biodegradable. Additionally, it has the potential to control a wide variety of weeds. This particular organic herbicide is considered more effective than other options in the market including 
herbicides containing vinegar (acetic acid), clove oil, or fatty acid soaps. Avenger Organics@ claims that their product is equally as effective and faster acting than most comparable synthetics on the market (Avenger Organics, 2015). Citrus oil is biodegradable and should degrade quickly before having effects on soil microorganisms. However, there has not been any published research on this herbicide.

\subsubsection{Neem Oil}

Neem oil has been used for pest control for thousands of years. This is derived from natural oil that occurs in the seed of the neem tree (Azadirachta indica) which is native to India and the Indian subcontinent. There are two active ingredients (Azadirachtin and Clarified Hydrophobic Extract) that can be used to control pests on agricultural crops (EPA, 2001). These substances can be used to ward off a wide variety of pests including white flies, moth larvae, mites, aphids, and other such organisms (EPA, 2001). Bayer NATRIA® Neem Oil is the product tested in this experiment. NATRIA® Neem Oil, like Avenger Organics@ Weed Killer is OMRI certified and readily available to the public and on an industrial farm scale.

Neem oil is a biopesticide that is widely used on organic farms as an alternative to non-natural chemical pesticides. This natural pesticide is rapidly broken down through a combination of light and soil microbial activity. The half-life of this product in soil is anywhere from 3-44 days depending on environmental conditions (Bond et al. 2012). This product has little to no detrimental effects on non-target organisms. Neem oil is practically non-toxic to mammals, bees, birds, and plants; it is moderately toxic to fish and aquatic animals (Bond et al. 2012). 
The main active ingredient in neem oil is azadirachtin which acts as a steroid-like tetranortriterpenoid. Tetranortriterpenoid is a chemical compound class that mimics a hormone present in insects called ecdysones (major molting hormone) that controls the regulation of insect pupation. Application of azadirachtin causes an interruption in the development and pupation stage of insects, which has very detrimental effects on their life cycle (Shannag et al. 2013).

Pesticides that are natural and of botanical origin are sought after because of their low toxicity and high rate of biodegradability, making them ideal to be incorporated into integrated pest management practices (IPM). Neem oil is becoming a key insecticide in today's growing market for organic and sustainably grown produce (Shannag et al. 2013). Although neem oil has been marketed to suppress many types of insects, field and greenhouse studies show that the efficacy of this product is variable. While neem oil works to inhibit developmental stages of the insect, it has many detrimental effects including impacts on feeding behavior, reproduction growth, and overall fitness and mobility (Shannag et al. 2013). The efficacy of this product can be attributed to environmental factors. Neem oil is highly susceptible to photodegradation once sprayed onto the plant with a half-life of only 1-2.5 days on the plant leaf (Bond et al. 2012). Soil treatment is under study because of the short half-life on the plant. Neem oil in the soil may prolong effectiveness and lessen instability. However, it is imperative to test its effects on soil microorganisms that are crucial for soil and plant health.

\subsection{Abelmoschus esculentus}

Aberlmoschus esculentus, also known by its common name okra, is a staple crop in Miami-Dade County. Okra is an annual plant part of the hibiscus family. Individual 
plants of this crop can get very large ranging anywhere from 1-2.5 meters tall depending on the variety. The plant bears yellow flowers that give rise to the okra pod or fruit (Christman, 2007). The flower is very attractive showing a pale yellow or cream color with a purple center. This particular plant has large spiny leaves and a thick semi-woody stem with few branches. Okra will continue to bloom throughout maturity and continually produce fruit (Christman, 2007).

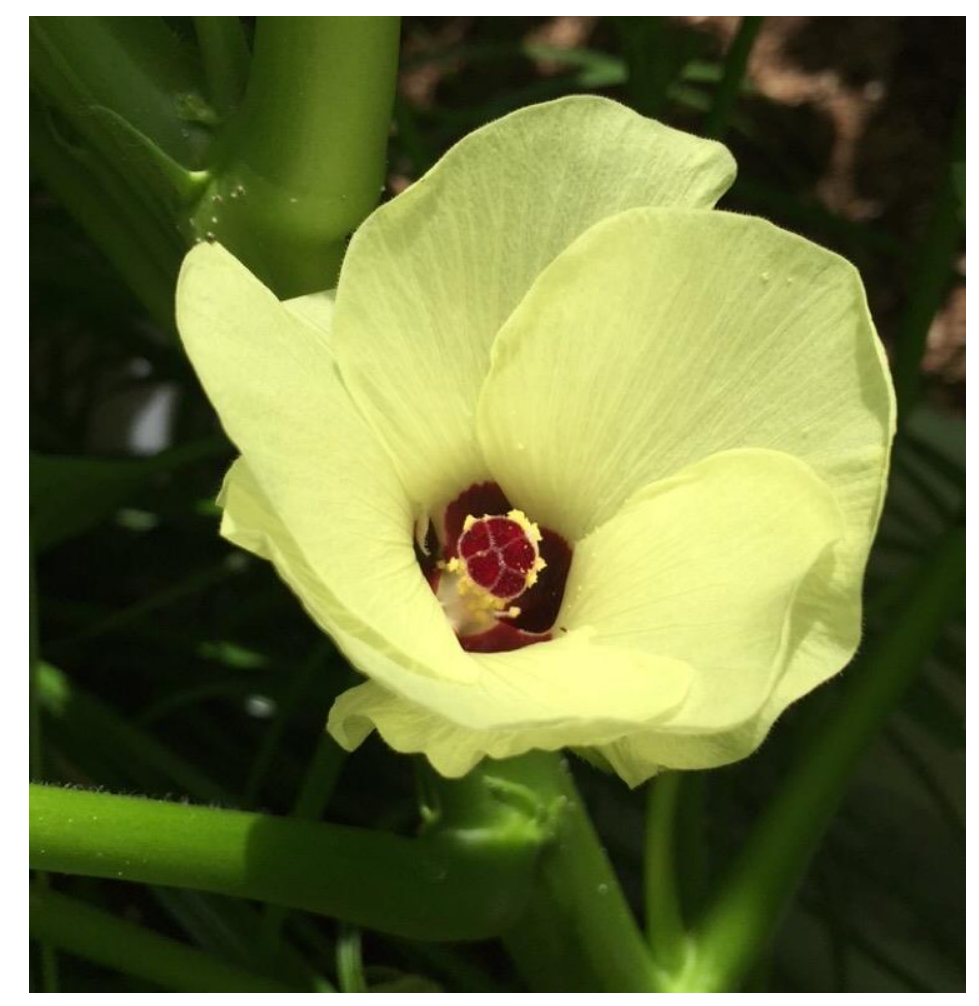

Figure 2: Okra flower

Annually, 1000 to 1500 acres is dedicated to okra production in Miami-Dade County (Klassen et al. 2013). The most popular varieties for planting in South Florida are Annie Oakley II, Clemson Spineless, Cajun Delight, and Emerald (Klassen et al. 2013). Okra is native to the old world tropics originating from West Africa. It is thought that okra was brought to the North American continent through slave trafficking. Okra is 
a well suited crop for South Florida, especially during the summer when it is too hot and humid for most other crops (Christman, 2007).

In Miami, okra can be grown in gravel or marl soil and is seeded directly into the ground. Seed planting depth should be from 1-2.5 cm deep. Recommended spacing is $3.5-10 \mathrm{~cm}$ in between plants and about 1 meter in between rows. The crop can be grown any time of the year in South Florida but is usually planted after the winter vegetable crop in order to be harvested from early spring and well into late fall (Klassen et al. 2013). Okra is very fast growing and is ready to harvest in about 60-70 days after germination. Pods are ideal for picking when they are about 5-7.5 cm long and still tender. If they grow past this point and become large, they gain a woody texture and become inedible (Smith et al. 2003). Okra should be harvested about every two days to avoid inedible pods and insure continual fruit production.

Okra prefers an acidic soil with a $\mathrm{pH}$ between 5.8- 6.5 for optimal fertility levels. Okra will grow well in nutrient rich soils amended with organic matter. It is recommended that the plants be watered uniformly in the morning hours. They should be watered sufficiently until the soil is moistened to around a depth of $15 \mathrm{~cm}$ (Smith et al. 2003).

The variety of okra used in this experiment is known as Gold Coast Okra. It is a variety developed in Louisiana in the 1960's. This variety produces mildly sweet, spineless light green pods which can grow up to $15 \mathrm{~cm}$ in length. Plants grow from 1.51.8 meters tall and reach maturity around 50 days after germination. It has a welldeveloped root system that is indicative to drought and heat tolerance. It is resistant to 
attack from root knot nematodes which okra is particularly susceptible to (Southern

Exposure Seed Exchange).

In South Florida, there are a few major pests that okra is susceptible to. Melon thrips and aphids scar the outside of the fruit pods. Silverleaf white fly develops and feeds on the okra plant. Plant parasitic nematodes have the potential to wreak havoc on okra roots.

Table 2: A list of recommended insecticide sprays for South Florida and the pests they control (Brown et al. 2015).

\begin{tabular}{|c|c|c|c|c|c|c|c|c|c|c|}
\hline Pest & Neem $^{d e}$ & Spinosad & $\mathrm{Bt}^{20}$ & Carbaryl $^{d}$ & Malathion $^{d}$ & Pyrethroids ${ }^{\mathrm{h} d}$ & Soap & $\begin{array}{l}\text { Hort. } \\
\text { Oilce }\end{array}$ & Imidacloprid ${ }^{d}$ & Acetamiprid $^{d}$ \\
\hline Aphids & $\mathrm{x}$ & & & & $\mathrm{x}$ & & $\mathrm{x}$ & $x$ & $\mathrm{x}$ & $\mathrm{x}$ \\
\hline Armyworm & & $\mathrm{x}$ & $\mathrm{x}$ & & & $\mathrm{x}$ & & & & \\
\hline Bean leafroller & & $\mathrm{x}$ & $\mathrm{x}$ & & & $\mathrm{x}$ & & & & \\
\hline Cabbage looper & & $\mathrm{x}$ & $\mathrm{x}$ & & $\mathrm{x}$ & $\mathrm{x}$ & & & & \\
\hline $\begin{array}{l}\text { Colorado } \\
\text { potato beetle }\end{array}$ & & $\mathrm{x}$ & & & & & & & $\mathrm{x}$ & $x$ \\
\hline $\begin{array}{l}\text { Corn earworm/ } \\
\text { fruitworm }\end{array}$ & & $\mathrm{x}$ & $\mathrm{x}$ & & & $\mathrm{x}$ & & & & \\
\hline $\begin{array}{l}\text { Cowpea } \\
\text { curculio }\end{array}$ & & & & $\mathrm{x}$ & & $\mathrm{x}$ & & & & $\mathrm{x}$ \\
\hline $\begin{array}{l}\text { Cucumber } \\
\text { beetle }\end{array}$ & $x$ & & & $x$ & $x$ & $x$ & & & & $x$ \\
\hline $\begin{array}{l}\text { Diamondback } \\
\text { moth caterpillar }\end{array}$ & & $\mathrm{x}$ & $\mathrm{x}$ & & & & & & & \\
\hline Flea beetle & & & & $\mathrm{x}$ & $\mathrm{x}$ & $\mathrm{x}$ & & & $x$ & $\mathrm{x}$ \\
\hline Leafminers & & $\mathrm{x}$ & & & & & & & & \\
\hline Leafhoppers & & & & $\mathrm{x}$ & & & & & $\mathrm{X}$ & $\mathrm{x}$ \\
\hline $\begin{array}{l}\text { Melonworm, } \\
\text { pickleworm }\end{array}$ & & $\mathrm{x}$ & $\mathrm{x}$ & & $\mathrm{x}$ & $\mathrm{x}$ & & & & \\
\hline $\begin{array}{l}\text { Mexican bean } \\
\text { beetle }\end{array}$ & & & & $x$ & $\mathrm{x}$ & $x$ & & & & $x$ \\
\hline Spider mites & $\mathrm{x}$ & & & & & & & $\mathrm{x}$ & & \\
\hline $\begin{array}{l}\text { Squash vine } \\
\text { borer }\end{array}$ & & & $x$ & & & $\mathrm{x}$ & & & & \\
\hline Stink bugs & & & & & & $x$ & & & & $x$ \\
\hline Thrips & & $\mathrm{x}$ & & & & & & & $\mathrm{x}$ & $\mathrm{x}$ \\
\hline $\begin{array}{l}\text { Tomato } \\
\text { hornworm, } \\
\text { pinworm }\end{array}$ & & $\mathrm{X}$ & $x$ & & & $\mathrm{x}$ & & & & \\
\hline Whiteflies & $\mathrm{x}$ & & & & & $\mathrm{x}$ & $\mathrm{x}$ & $x$ & $x$ & $x$ \\
\hline
\end{tabular}




\section{METHODOLOGY \\ 3.1 Site Description}

The study was conducted at two sites. The first site is Possum Trot Tropical Fruit Nursery in Homestead (21105 SW 150th Ave Miami, FL 33187 (Coordinates:

$25.568108,-80.434988)$. This 40 acre farm consists of a variety of tropical fruit trees inter-planted together, creating a diverse system. No artificial pesticides are applied. Additionally, no fertilizer is used other than the occasional application of chicken manure when needed. This farm is in the process of receiving its organic certification from the USDA.

The second site is an adjacent conventional farm called The Girls Home (22200 SW 152nd Ave Miami, FL 33170 Coordinates: 25.560190, -80.439038). This site serves as an example of the standard conventional farm where: inputs include synthetic chemical pesticide, tillage is practiced, and crops are grown in a monocultural setting.

\subsection{Field Trial}

At both the two sites, plots were prepared by removing overlying grass then tilling the soil with a rototiller. After tilling, one truckload of soil (approximately $4.6 \mathrm{~m}^{3}$ ) was delivered to each site to ensure that the soils at both sites were the same. 


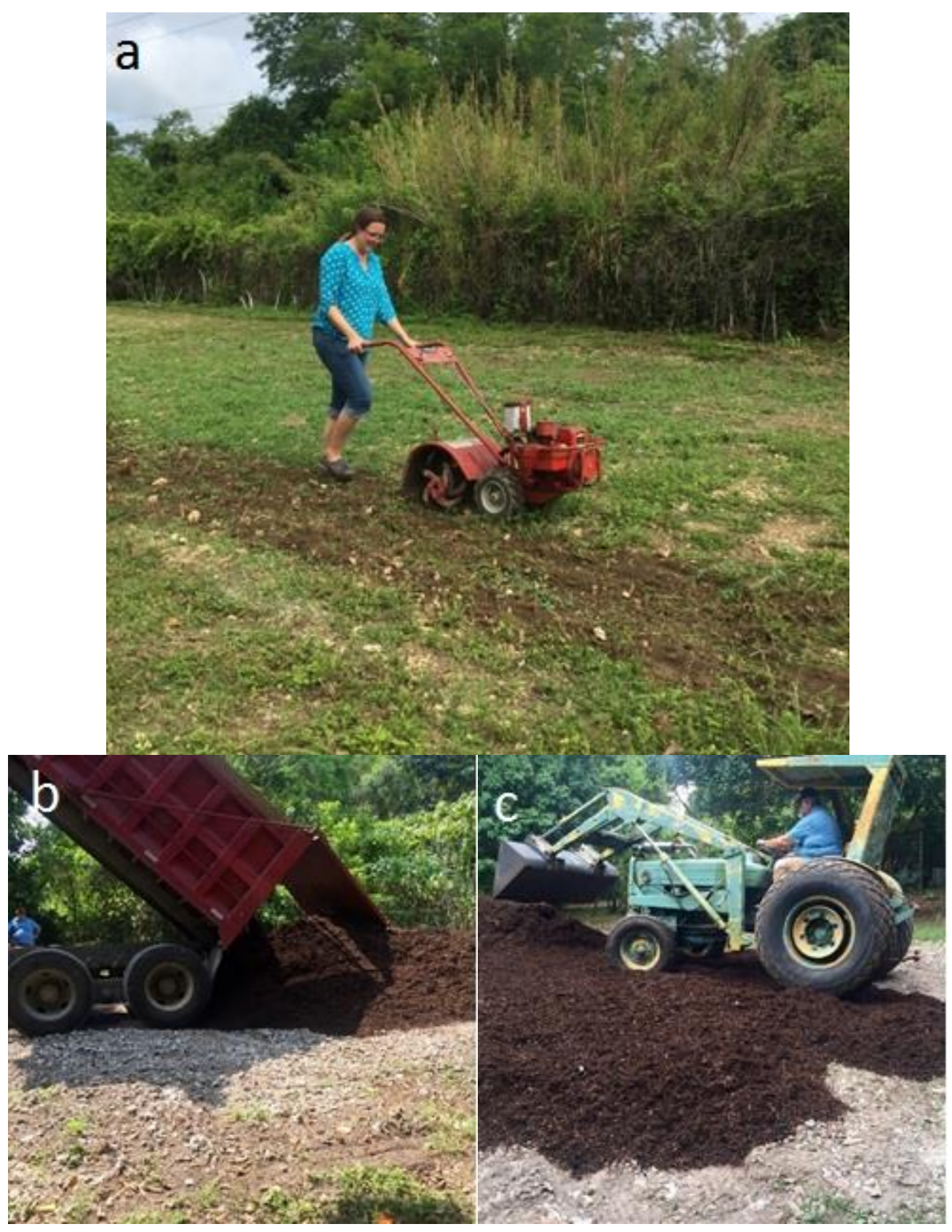

Figure 3: (a) Rototilling grass and surface soil (b) soil delivery (c) leveling out of soil

Cinderblocks were laid in a $6.1 \times 9.1$ meter rectangle at each site to create two raised beds. At each site, the plots were divided into four treatments; herbicide only, insecticide only, combination of herbicide and insecticide, and a control which had no spray treatment. These treatment areas were arranged randomly using a random number 
generator. Plastic barriers were installed to prevent spray drift between adjacent treatments.

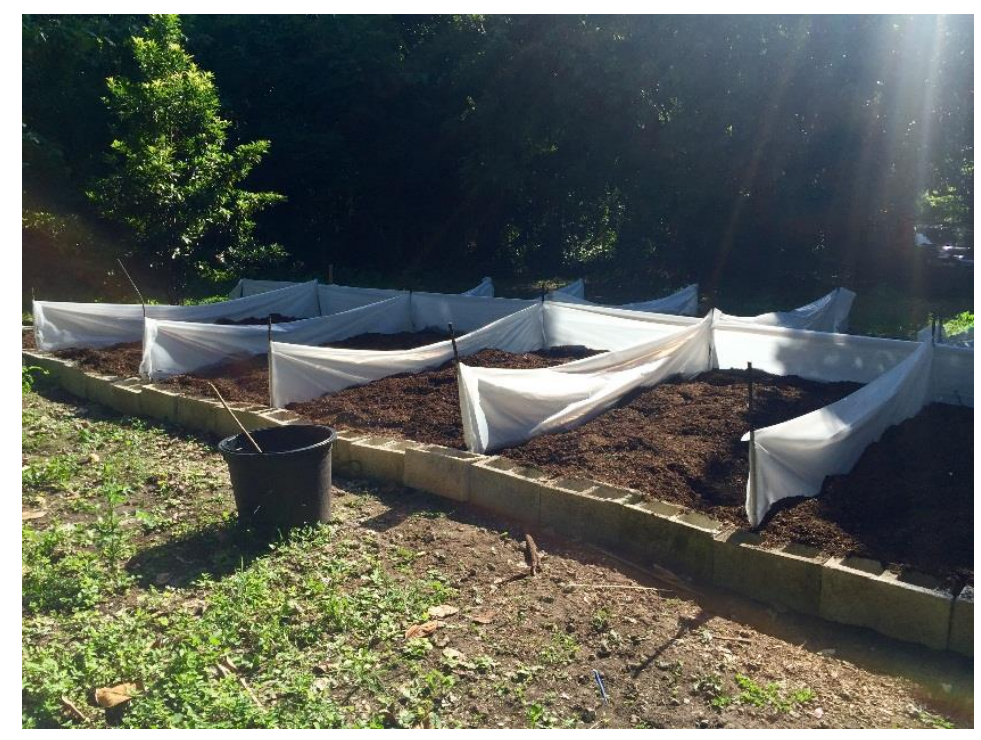

Figure 4: The finished plots with plastic separators

The four treatments were replicated three times resulting in 12 plots at each farm and 24 total plots. Each plot was $3.5 \times 6.1$ meters and was split into four treatments, making each treatment plot $1.5 \times 3.5$ meters. Once the subplots were separated, about 4.7 liters of USDA organic chicken manure was mixed into the surface soil as fertilizer in each treatment plot.

\section{Abelmoschus esculentus (okra) (Gold Coast Okra, Southern Exposure Seed} Exchange, Mineral, Virginia) plants were grown at both sites. At the organic site, neem oil and D- Limonene were applied. At the conventional site, glyphosate and carbaryl were applied.

Each site was inoculated with mycorrhizal fungi to ensure a robust and diverse presence of fungi for root colonization. Every seed received the same dose of liquid inoculant (about $5 \mathrm{ml}$ ). Nature's Solution Mycorrhizae (Nature Technologies Intl., 
Novato, California) was used as the inoculant and contains a mix of fungal species including five types of ectomycorrhizal fungi (Pisolithus tinctorius, Rhizopogan villosullus, Rhizopogon amylopogon, Rhizopogon fulvigleba, Rhizopogon luteolus) and six types of endomycorrhizal fungi (Glomus mosseae, Glomus intraradices, Glomus dussi, Glomus clarum, Glomus deserticola, Glomus migroaggregatum).

Soil and root samples were collected multiple times during the experiment. Fiftyone seeds were planted seven inches apart in each treatment area for a total of 1224 seeds. The plots were equally watered daily for one hour. Spraying of treatments herbicides/pesticides occurred twice in this 60 day period; once at 30 days after planting and once at 45 days after planting. Glyphosate and citrus oil were sprayed on weeds growing in the plots until they were coated while carbaryl and neem oil were sprayed directly on the okra crop until coated. Weeds were allowed to grow freely in the plots between applications. Control plots were not weeded. Before planting, preliminary soil samples were taken for analysis. Additionally, rhizosphere soil and root samples were collected 3 times; $\mathrm{T}_{0}: 30$ days after planting (before first spray), $\mathrm{T}_{1}: 45$ days after planting (before second spray), and finally $\mathrm{T}_{2}$ : at full maturity at 66 days after planting. Three plants from each treatment were sacrificed for root, stem, and leaf samples at each of the three sampling dates for a sample size of nine plants per treatment per sampling. At the time of sampling, plants were randomly selected from each plot using a random number generator. The entire plant was exhumed, including the roots, using a shovel. Each sample was then placed in a pre-labeled plastic bag and brought back to the lab. During plant growth weekly measurements were made of plot light intensity, soil moisture, soil $\mathrm{pH}$, and soil temperature using a digital meter (Digital 4-Way Soil Meter, Sunleaves, 
Bloomington, Indiana) . At full maturity, okra fruit was harvested and weighed to determine crop yield.

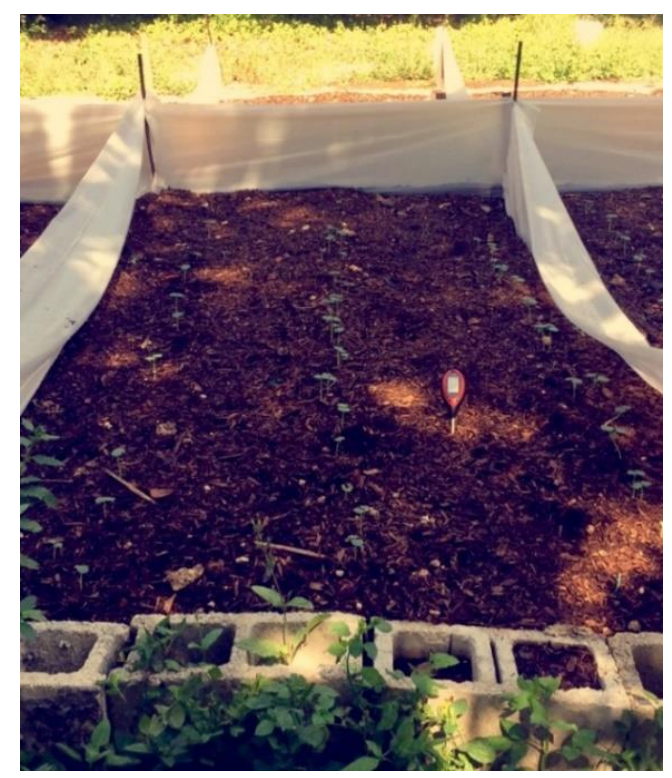

Figure 5: Using soil meter to take field measurements

\subsection{Potted Trial}

The field trial was compared to a more highly controlled shade house, potted trial at the Florida International University (FIU) organic garden. Okra was inoculated with the same $5 \mathrm{ml}$ of mycorrhizae inoculant as the field trial. The seeds were started in starter trays to ensure that equal amounts of inoculant were provided to each seed. Seedlings were transplanted into 45 one gallon pots all filled with the same garden potting soil. Five pots acted as the $T_{0}$ sample taken at 30 days, and the remaining 40 pots were sprayed after that sampling. Ten pots were sprayed with each of the four treatments, in this trial there were no combination pots. At $\mathrm{T}_{1}$ (45 days) 20 pots were taken for analysis and the other 20 were left for their second spray. At $\mathrm{T}_{2}$ (66 days) the remaining 20 pots were taken for analysis. All of the methods used in the potted trial such as timing and method of spray were the same as the field trial. 


\subsection{Laboratory Methods}

The soil and root samples were analyzed at FIU's soils lab. Subsamples of collected soil were dried at $30^{\circ} \mathrm{C}$, ground, and sieved through a $2 \mathrm{~mm}$ sieve while a separate subsample was stored at $4^{\circ} \mathrm{C}$ for biological analysis. Remaining soil, stem, and leaf samples were air dried and stored in air tight containers until analysis of the physical and chemical properties listed below.

Table 3: Analyses performed on soil and root samples at the 3 sampling periods.

\begin{tabular}{|c|c|c|c|}
\hline $\begin{array}{l}\text { Preliminary Soil } \\
\text { Analysis }\end{array}$ & $\begin{array}{l}\mathrm{T}_{0} \text { Soil and Root } \\
\text { Analysis ( } 30 \text { days } \\
\text { after germination) }\end{array}$ & $\begin{array}{l}\mathrm{T}_{1} \text { Soil and Root } \\
\text { Analysis ( } 45 \text { days } \\
\text { after germination) }\end{array}$ & $\begin{array}{l}\mathrm{T}_{2} \text { Soil and Root } \\
\text { Analysis (60 days } \\
\text { after germination) }\end{array}$ \\
\hline Total C,N,P & Root Mass Ratio & Root Mass Ratio & Root Mass Ratio \\
\hline pH (Field) & Stem Mass Ratio & Stem Mass Ratio & Stem Mass Ratio \\
\hline $\begin{array}{l}\text { Organic Matter } \\
\text { Content }\end{array}$ & Leaf Mass Ratio & Leaf Mass Ratio & Leaf Mass Ratio \\
\hline \multirow[t]{3}{*}{ Soil Moisture } & $\begin{array}{l}\text { Leaf Nutrient } \\
\text { Status }(C, N, P)\end{array}$ & $\begin{array}{l}\text { Leaf Nutrient } \\
\text { Status }(C, N, P)\end{array}$ & $\begin{array}{l}\text { Leaf Nutrient } \\
\text { Status }(C, N, P)\end{array}$ \\
\hline & $\begin{array}{l}\text { Mycorrhizal Root } \\
\text { Colonization } \\
\text { Percentage }\end{array}$ & $\begin{array}{l}\text { Mycorrhizal Root } \\
\text { Colonization } \\
\text { Percentage }\end{array}$ & $\begin{array}{l}\text { Mycorrhizal Root } \\
\text { Colonization } \\
\text { Percentage }\end{array}$ \\
\hline & & & Okra Yield (g) \\
\hline
\end{tabular}

\subsubsection{Root, Stem, and Leaf Mass Ratio}

Plant samples were thoroughly washed to ensure no remaining soil particles or insects were left on the roots, stems, or leaves. Each sample was then separated, the stem was cut from the roots, and the leaves were cut from the stem. Stems, roots, and leaves were each put into their own brown paper bag and labeled. They were then dried at $70^{\circ} \mathrm{C}$ for 72 hours and weighed $( \pm 0.0001 \mathrm{~g})$. 


\subsubsection{Total Carbon and Nitrogen (Soil and Leaf)}

Dried, ground (mortar and pestle) soil and leaf samples were analyzed for TC and TN by dry combustion with a LECO CN Analyzer (St. Joseph, Michigan).

\subsubsection{Total Phosphorus (Soil and Leaf)}

Total P in the plant tissue samples were analyzed following the USEPA (1983) method colorimetrically with the SEAL Analytical AQ2 Discrete Auto Analyzer (Mequon, Wisconsin).

Sample Preparation

Oven dried samples were finely ground with a mortar and pestle. Between 0.017$0.021 \mathrm{~g}$ of sample was added to $20 \mathrm{ml}$ glass scintillation vial with Teflon Cap. $0.2 \mathrm{ml}$ of $0.17 \mathrm{M} \mathrm{MgSO}_{4}$ was added to each vile. The vials were then heated in the oven overnight at $70^{\circ} \mathrm{C}$ uncapped. The vials were then removed from the oven and placed in the furnace at $500{ }^{\circ} \mathrm{C}$ for 4 hours. Once the samples had been ashed, $5 \mathrm{ml}$ of $0.2 \mathrm{~N} \mathrm{HCL}$ was added to each vial and then capped tightly. The vials were then heated in the oven for 30 minutes at $80^{\circ} \mathrm{C}$. Ten $\mathrm{ml}$ of deionized water (DIW) was added to each vial. They were then capped tightly, vigorously shaken, and left overnight to settle.

\section{$\underline{\text { Standard Solution Preparation }}$}

Phosphate working standard solutions were prepared starting with a phosphate stock standard solution of $4.394 \mathrm{~g}$ Potassium dihydrogen orthophosphate diluted to 11 with DIW. From there, four working standard solutions were made with concentrations $\mathrm{mg} \mathrm{P} / 1$ of $0,0.1,0.4,0.5$, and 1 . 


\section{Running the AQ2}

The machine was turned on. After 30 minutes, the daily startup was conducted and water baselines were recorded. Reagents were added to the machine; wedge 1 was the phosphate color reagent, wedge 2 was the ascorbic acid, and wedge 3 was the CCV or 0.5 phosphate standard. Two hundred $\mu 1$ of sample solution was added to its own sample cup and diluted with $1800 \mu$ l of DIW for a 10x dilution. Duplicate samples were added in after every 10 samples and standards were added after every 20 samples. The sample tray locations were inputted into the computer scheduling sheet and the machine was run until all samples were tested.

\subsubsection{Soil Organic Matter Content}

Loss on Ignition Method by Storer 1984

The weight of a crucible was taken and 4-5 g of oven dry soil was added. The crucible was then placed in a muffle furnace at $500{ }^{\circ} \mathrm{C}$ for 5 hours. The furnace was then turned off and samples were left to cool overnight. The samples were then reweighed and the post ignition weight was recorded. Organic matter percent $=($ pre ignition weight post ignition weight / pre ignition weight)*100

\subsubsection{Soil Moisture Content}

Gravimetric Method

An aluminum tin was weighed and weight was recorded. A soil sample of about

$10 \mathrm{~g}$ was added to the tin as a wet weight. The sample was the placed in an over to dry for 24 hours at $100^{\circ} \mathrm{C}$. The samples were removed from the oven and the dry weight was recorded. $\%$ soil moisture $=100 *(($ wet weight - dry weight $) /$ dry weight $)$ 


\subsubsection{Clearing and Staining Root Samples for Arbuscular Mycorrhizal Fungi Percent Colonization}

The degree of mycorrhizal colonization in the root samples was performed following a modified method by McGonigle et al. (1990).

The roots of each plant sample were carefully washed in a $2 \mathrm{~mm}$ sieve to remove all remaining soil particles. Twenty five $1.5 \mathrm{~cm}$ long root fragments were removed for processing for each sample. Each set of 25 roots was placed in its own micro centrifuge tube and submerged in $1.5 \mathrm{ml}$ of $10 \% \mathrm{KOH}$. They were then placed in the oven at $70{ }^{\circ} \mathrm{C}$ for 2 hours. Once out of the oven each sample is rinsed twice in DIW. Since the roots were very clean and already white, there was no need for bleaching. The roots were then stained by adding a $0.5 \%$ Trypan blue/ lactoglycerol solution to each sample, enough to cover all the roots in the tube. They were then placed in the oven at $70{ }^{\circ} \mathrm{C}$ for 30 minutes. After taken out of the oven, the samples were thoroughly washed so no excess blue stain remained. Each set of 25 roots received its own slide. Each root was placed horizontally in a drop of lactoglycerol. Each root was examined at under a microscope and recorded as colonized or not colonized. Qualification for colonization was the visual presence of any three structures: hyphae, vesicles, or arbuscules. Percent colonization was then calculated by dividing the number of colonized roots by 25 .

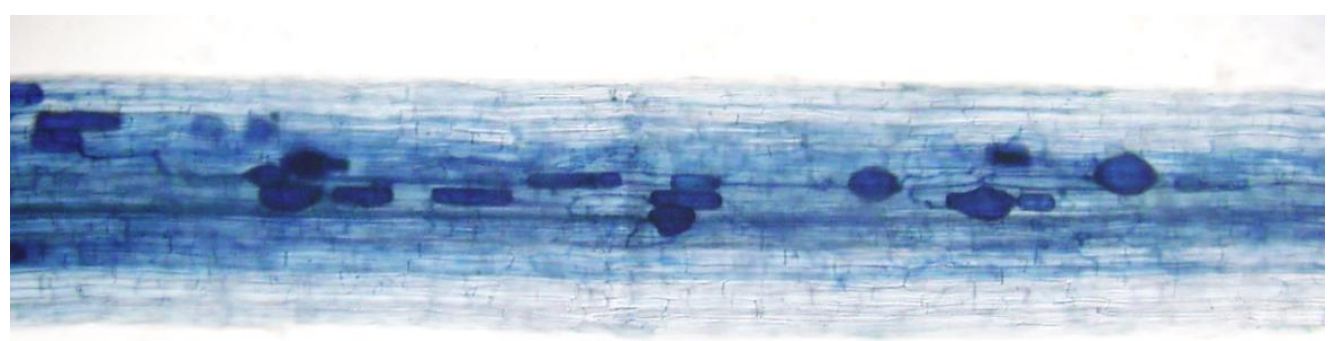

$50.0 \mu \mathrm{m}$

Figure 6: Example of mycorrhizal root colonization 


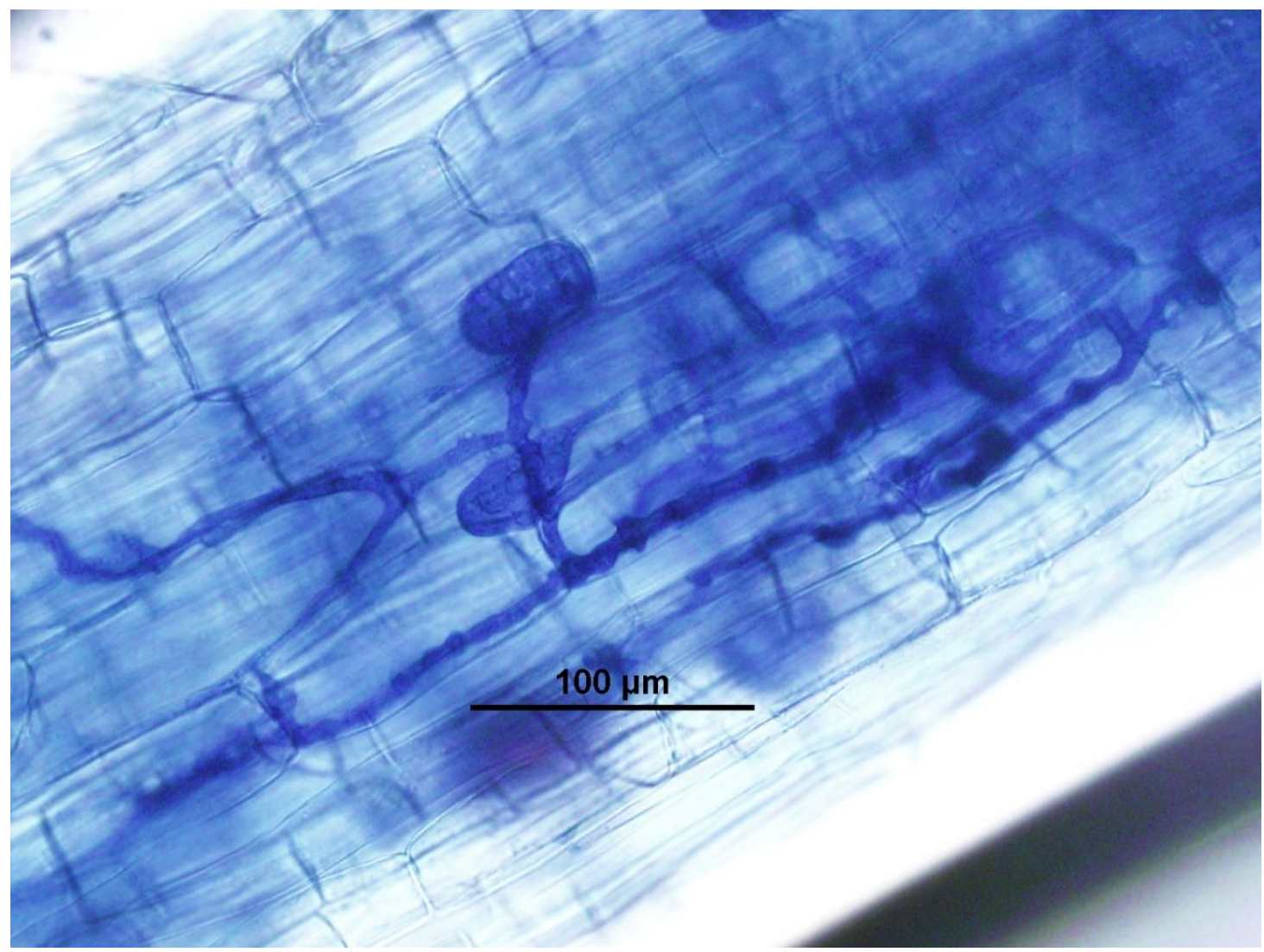

Figure 7: A close up example of vesicle and hyphae structures

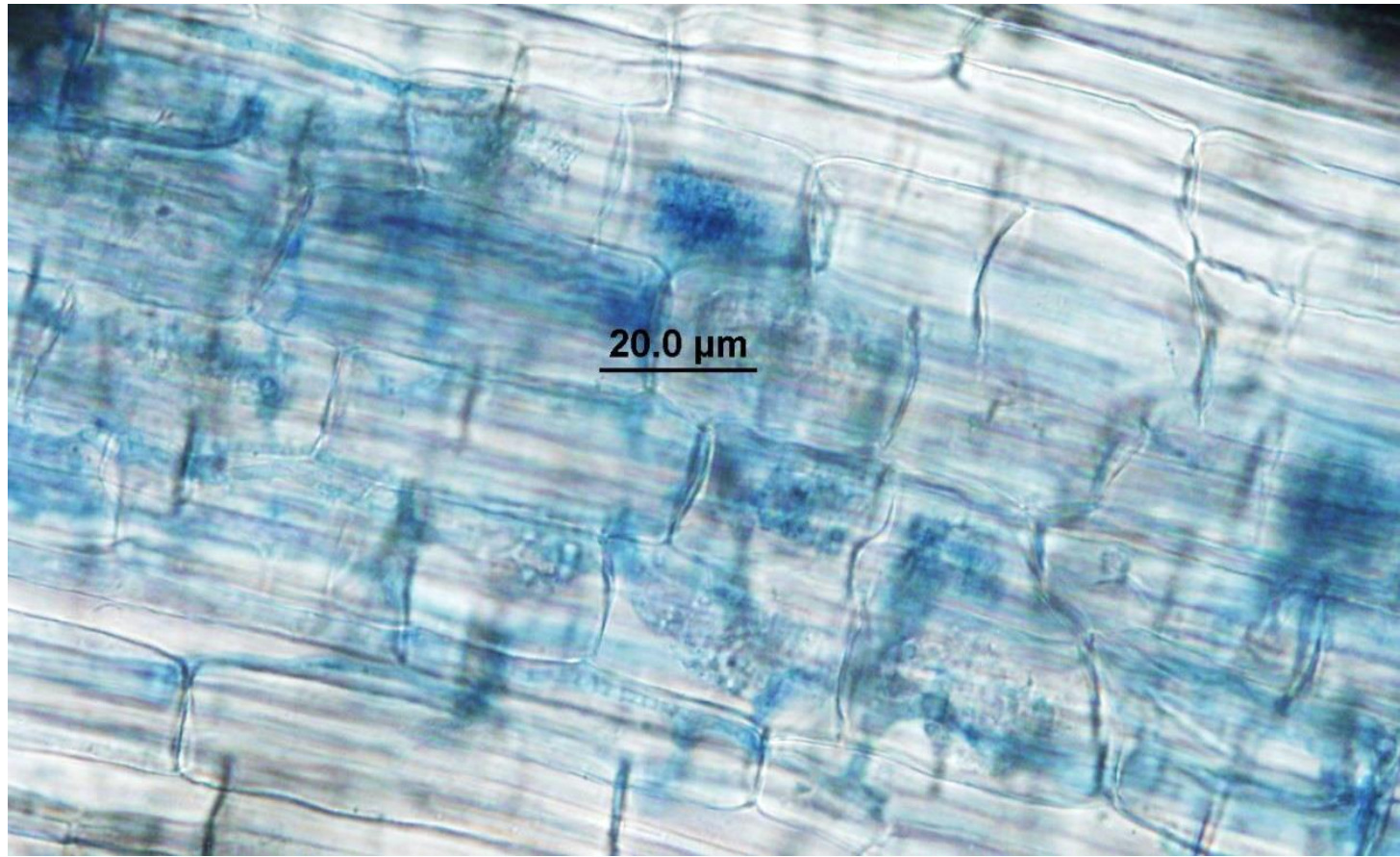

Figure 8: A close up example of arbuscules inside the root 


\subsection{Statistical Analysis}

All data was analyzed with SPSS statistical software (version 23). One-way ANOVA tests were performed to compare statistical means. Posthoc comparisons were made to show significance between treatments. Univariate analysis of Variance was also conducted. For research purposes, in order for statistical power to be acceptable, results from $T_{1}$ (45 days) and $T_{2}$ (66 days) were combined when running statistical tests. $T$ tests were run to ensure that $T_{1}$ and $T_{2}$ were similar enough to be combined. The $T$ test results were different between a couple factors, but similar enough to warrant amalgamation. Correlations between factors and $\mathrm{T}$ tests are included in the appendix. Data was considered significant when $p<0.05$ and marginally significant when $0.05 \leq \mathrm{p}<0.1$.

\section{RESULTS}

\subsection{Preliminary Soil Analysis}

Preliminary soil analysis was conducted to get an idea of the soil status before any amendments or treatments were applied. The soil delivered to both sites was similar in composition being that it was from the same soil company. A composite soil sample was used to extract and count spores. The spore count for a $50 \mathrm{~g}$ sample was 5 from the 250 $\mu \mathrm{m}$ sieve, 26 from the $150 \mu \mathrm{m}$ sieve, and 285 from the $38 \mu \mathrm{m}$ sieve for a total of 316 spores. The organic matter content was an average of $41.90 \% \pm 0.17 \%$ from the organic site and $40.74 \% \pm 0.03 \%$ from the synthetic site. The moisture content showed an average of $61.80 \% \pm 3.60 \%$ at the organic site and $55.96 \% \pm 3.45 \%$ at the synthetic site. The total phosphorus at the organic site was an average of $3.21 \pm 0.1 \mathrm{mg} \mathrm{g}-1 \mathrm{dw}$ and 3.08 $\pm 0.18 \mathrm{mg} \mathrm{g}-1 \mathrm{dw}$ at the synthetic site. The total soil carbon at the organic site had an 
average of $190.66 \pm 66.9 \mathrm{mg} \mathrm{g}-1 \mathrm{dw}$, while the synthetic site had an average of $224.33 \pm$ $24.42 \mathrm{mg}$ g- $1 \mathrm{dw}$. The total soil nitrogen at the organic site was an average of $8.22 \pm 0.21$ mg g-1 dw, the synthetic site had an average of $9.95 \pm 0.74 \mathrm{mg} g-1 \mathrm{dw}$. The $\mathrm{pH}$ from the field meter showed an average of $5.8 \pm 0.35$ at the organic site and $5.4 \pm 0.26$ at the synthetic site. The soil temperature at the time of planting was $38 \pm 9.47^{\circ} \mathrm{C}$ at the organic site and $39 \pm 3.58{ }^{\circ} \mathrm{C}$ at the synthetic site.

\subsection{Growth Parameters}

At each sampling time 72 plants were sacrificed for analysis (36 from each site, 9 from each treatment). The dry weight of stem, root, and leaf was compiled for each plant. As expected there was an increase in biomass over time from sampling $\mathrm{T}_{0}$ at 30 days to sampling $\mathrm{T}_{2}$ at 66 days (Fig. 9). The increase in overall biomass occurred at each site, both of which had a similar growth pattern. The first sampling at 30 days showed that both sites started off similar and then diverged as time went on with the synthetic site producing more overall biomass than the organic site. 


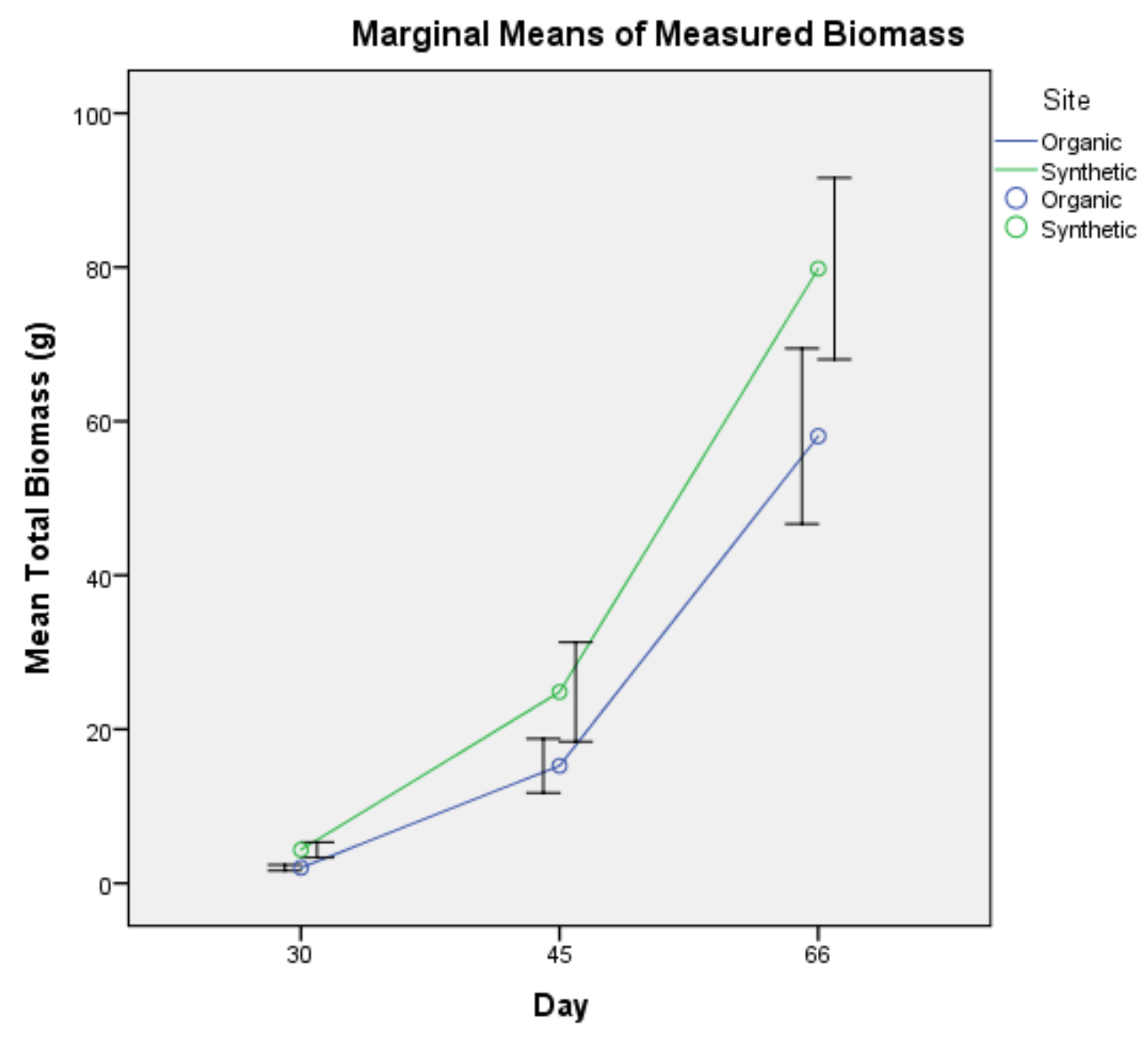

Error bars: +/- $2 \mathrm{SE}$

Figure 9: A graph depicting the means of total dry weight biomass at each site regardless of treatment.

(Fig. 10) displays the total mean dry weight of the stem and roots of the two sites over time, regardless of treatment. The graph is intended to show the biomass results without the leaf matter included in order to ensure that difference in herbivory between the sites did not interfere with results. (Fig. 10) closely follows the pattern of (Fig. 9) which includes the total biomass of root, stem, and leaf weights. 


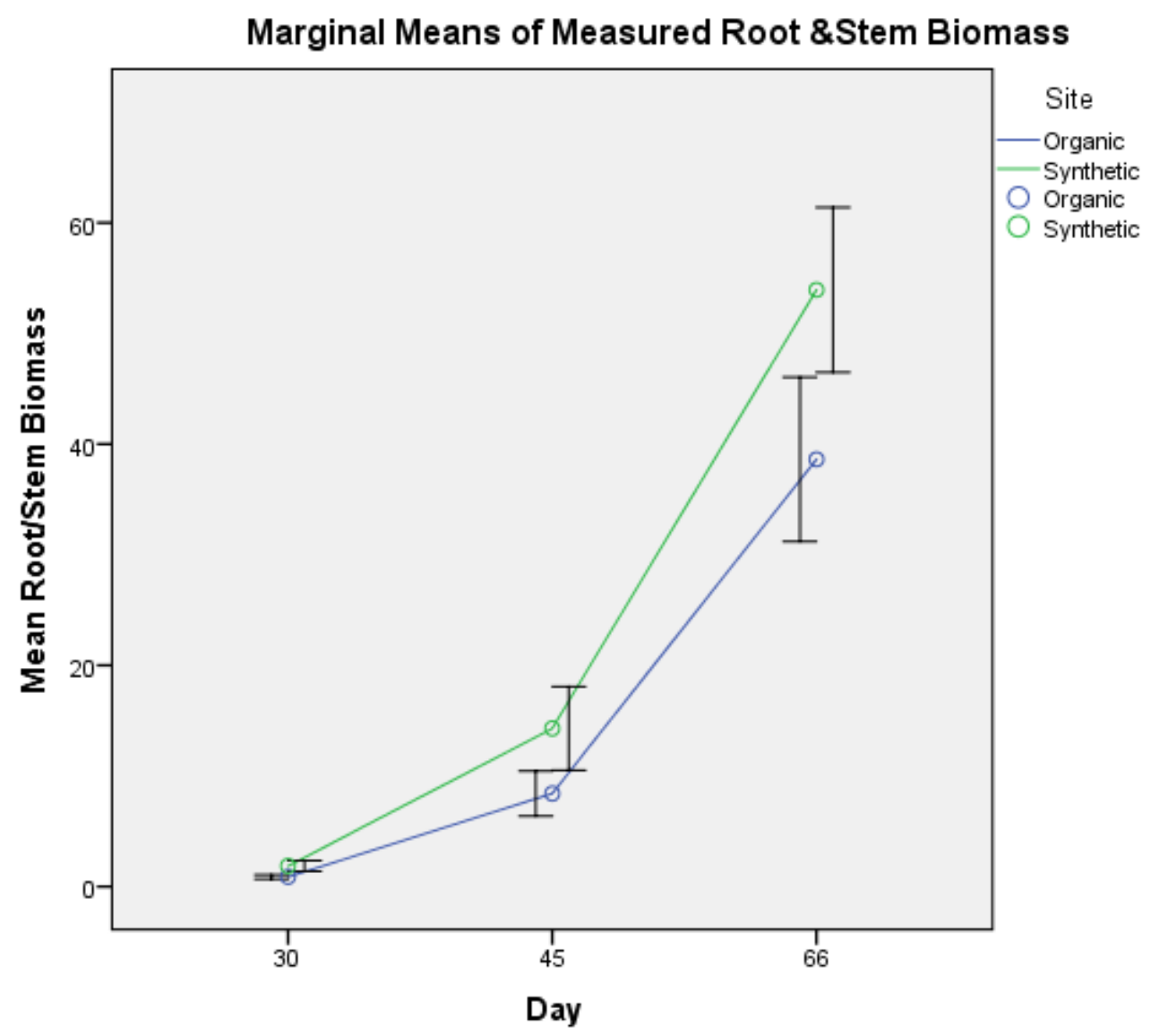

Error bars: $+/-2 \mathrm{SE}$

Figure 10: A graph depicting the means of stem and root dry weight biomass at each site regardless of treatment.

There was a distinct difference in biomass between sites at $\mathrm{T}_{2}$. As a result, sunlight readings from the soil meter were taken into consideration. Table 4 shows significant correlations between sunlight and total biomass, total phosphorus, $\mathrm{C}: \mathrm{N}$ ratio, C:P ratio, and yield. (Fig. 11) displays the measured means of light intensity by taking into consideration light readings from each treatment plot at each time and averaging them. This shows that the organic site consistently had less light than the synthetic site. 
Table 4: Sunlight correlation

\begin{tabular}{ccccccc}
\hline & Total & RI\% & Total P & C:N & C:P & Yield \\
& Biomass & & & & \\
\hline $\begin{array}{c}\text { Pearson } \\
\text { correlatio } \\
\text { n }\end{array}$ & $.266^{* *}$ & .031 & $-.255^{* *}$ & $.484^{* *}$ & $.284^{* *}$ & $.387^{* *}$ \\
$\begin{array}{c}\text { Sig. (2- } \\
\text { tailed) }\end{array}$ & .000 & .645 & .000 & .000 & .000 & .001 \\
$\mathrm{~N}$ & 216 & 216 & 216 & 216 & 216 & 72
\end{tabular}

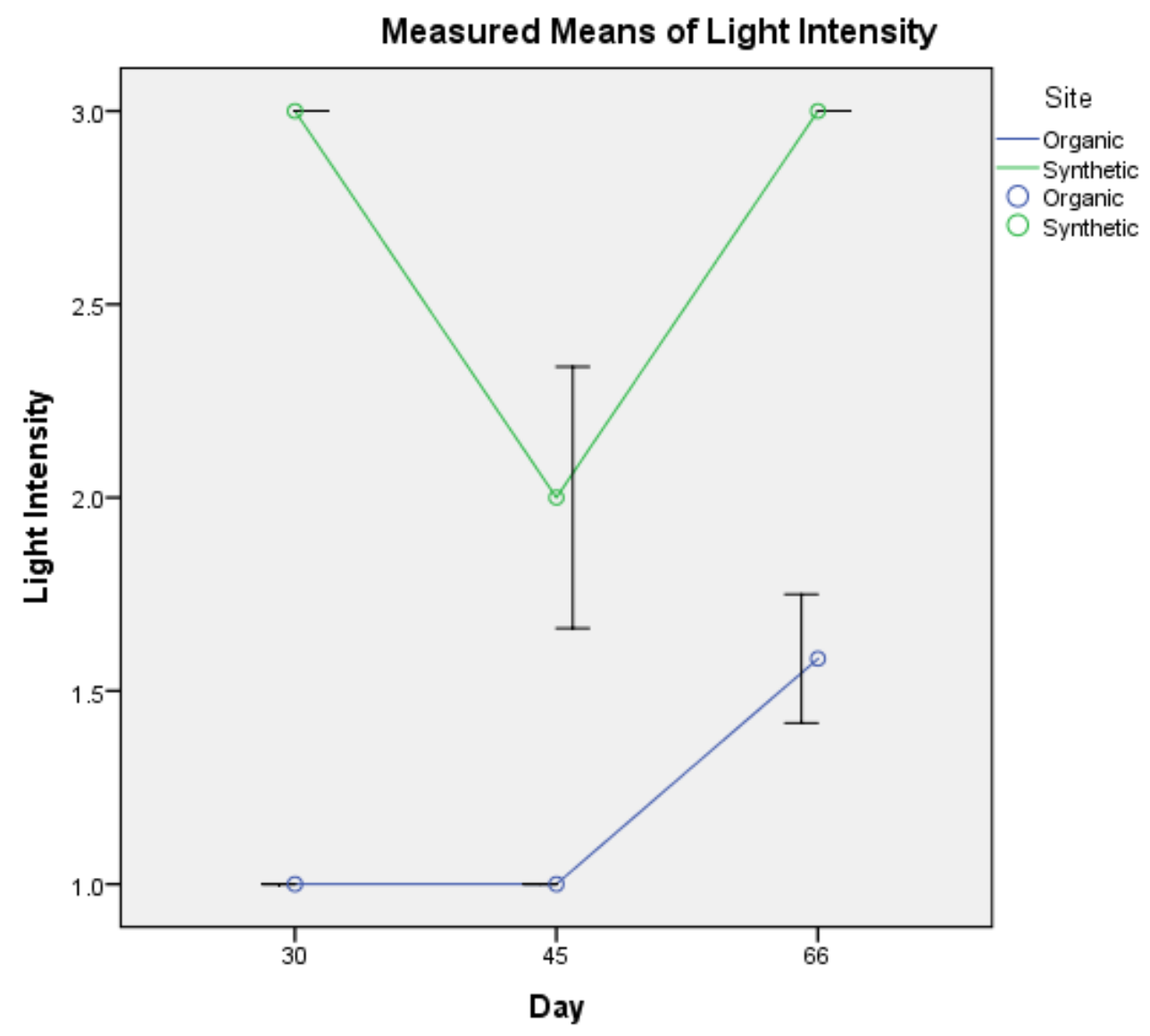

Error bars: +/- 2 SE

Figure 11: Sunlight intensity measurements from each of the three sampling dates at both sites. 


\subsection{Root Colonization}

Table 5 provides a summary of an ANOVA conducted to compare the root colonization percentage means of each site overall, including all treatments and then each treatment individually.

Table 5: Root colonization ANOVA results for $T_{1} \& T_{2}$ for each site comparing the means of different treatments.

$\%$ Colonization $\mathrm{n} \quad \mathrm{df} \quad \mathrm{F}$ value $\mathrm{P}$ value

\begin{tabular}{|c|c|c|c|c|c|}
\hline Organic Site & $30 \pm 2$ & 72 & 3,68 & 0.55 & 0.650 \\
\hline Control & $33 \pm 5$ & 18 & & & NS \\
\hline Herbicide & $28 \pm 4$ & 18 & & & NS \\
\hline Insecticide & $32 \pm 5$ & 18 & & & NS \\
\hline Combination & $25 \pm 5$ & 18 & & & NS \\
\hline Synthetic Site & $40 \pm 3$ & 72 & 3,68 & 6.626 & 0.001 \\
\hline Control & $48 \pm 6$ & 18 & & & $\mathrm{a}$ \\
\hline Herbicide & $54 \pm 4$ & 18 & & & $\mathrm{a}$ \\
\hline Insecticide & $36 \pm 5$ & 18 & & & $a b$ \\
\hline Combination & $25 \pm 4$ & 18 & & & $b$ \\
\hline
\end{tabular}

\subsubsection{Root Colonization between Both Sites}

(Fig. 12) shows the difference between the root colonization percentages at both sites over the three sampled time points, regardless of treatment. The organic site started out with higher root colonization and then declined steadily throughout the sampling periods. The synthetic site started out with a lower root colonization percentage, increased at the second sampling point, and then decreased again at the third sampling. 


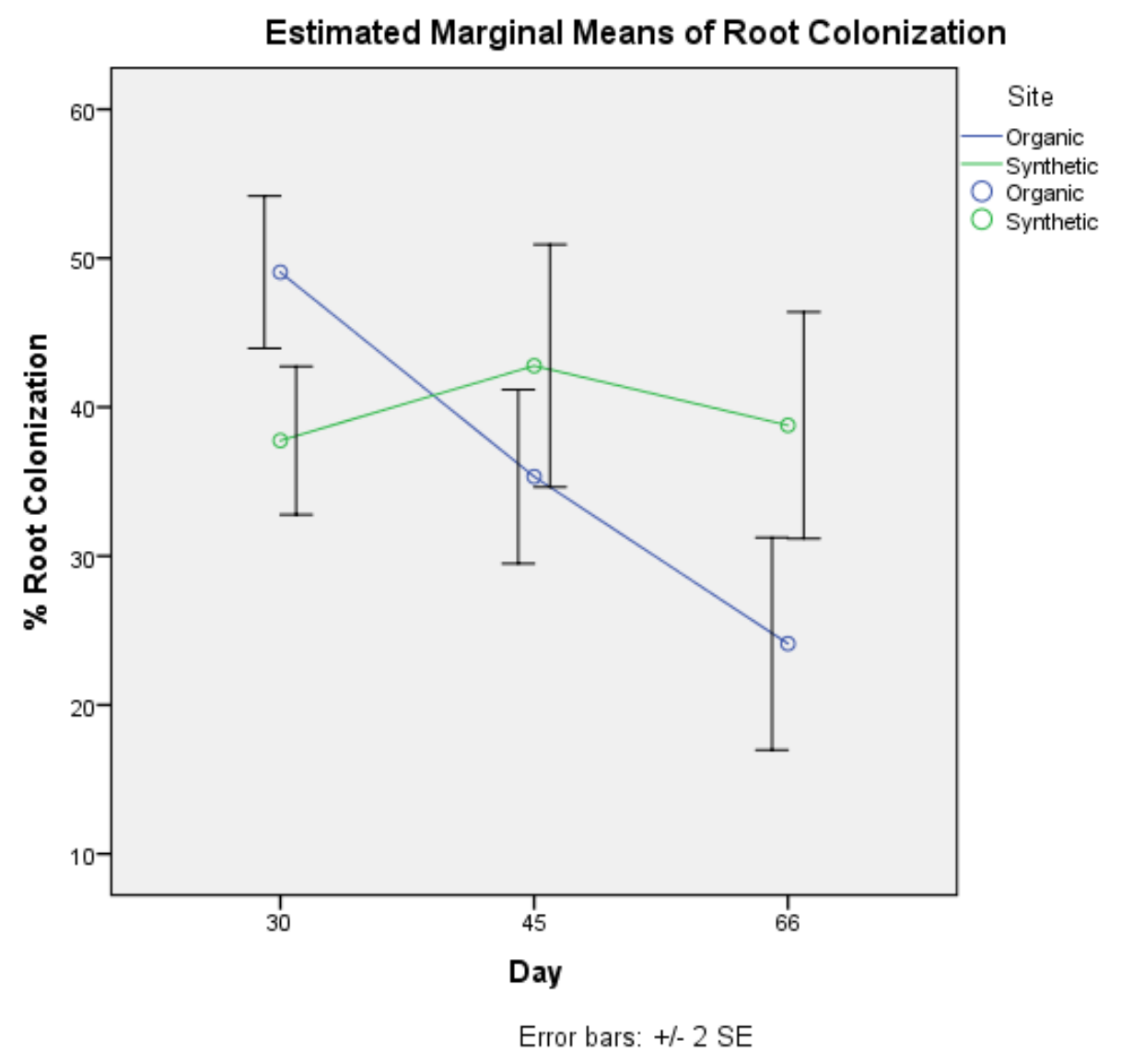

Figure 12: A line graph depicting the relationship of mean root colonization percentage for both sites by sampling time (day) regardless of treatment.

\subsubsection{Organic Site}

The root colonization percentage results for the organic site showed that the mean root colonization did not vary much between treatments. The control treatment did have the highest root colonization while the combination treatment had the lowest. There was no significant difference between treatments with root colonization at this site. 


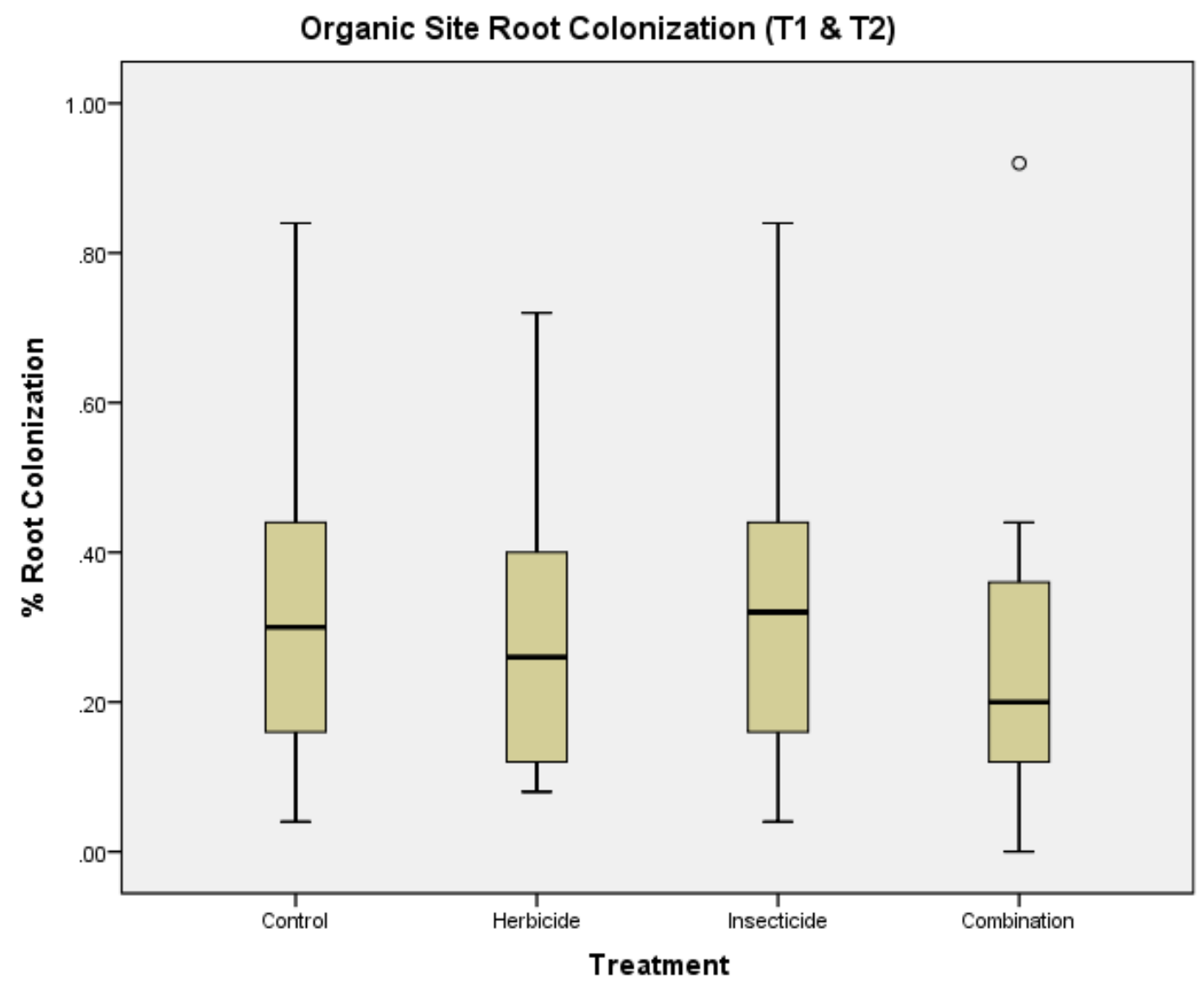

Figure 13: A boxplot showing average root colonization percentage at the organic site with $T_{1}$ and $T_{2}$ averages combined.

\subsubsection{Synthetic Site}

The root colonization percentage results for the synthetic site did display differences in mean root colonization between treatments. The control was significantly different than the combination treatment $(\mathrm{P}<0.007)$. The herbicide differed marginally from the insecticide treatment $(\mathrm{P}<0.076)$. The combination treatment was also significantly different than the herbicide treatment $(\mathrm{P}<0.001)$. 


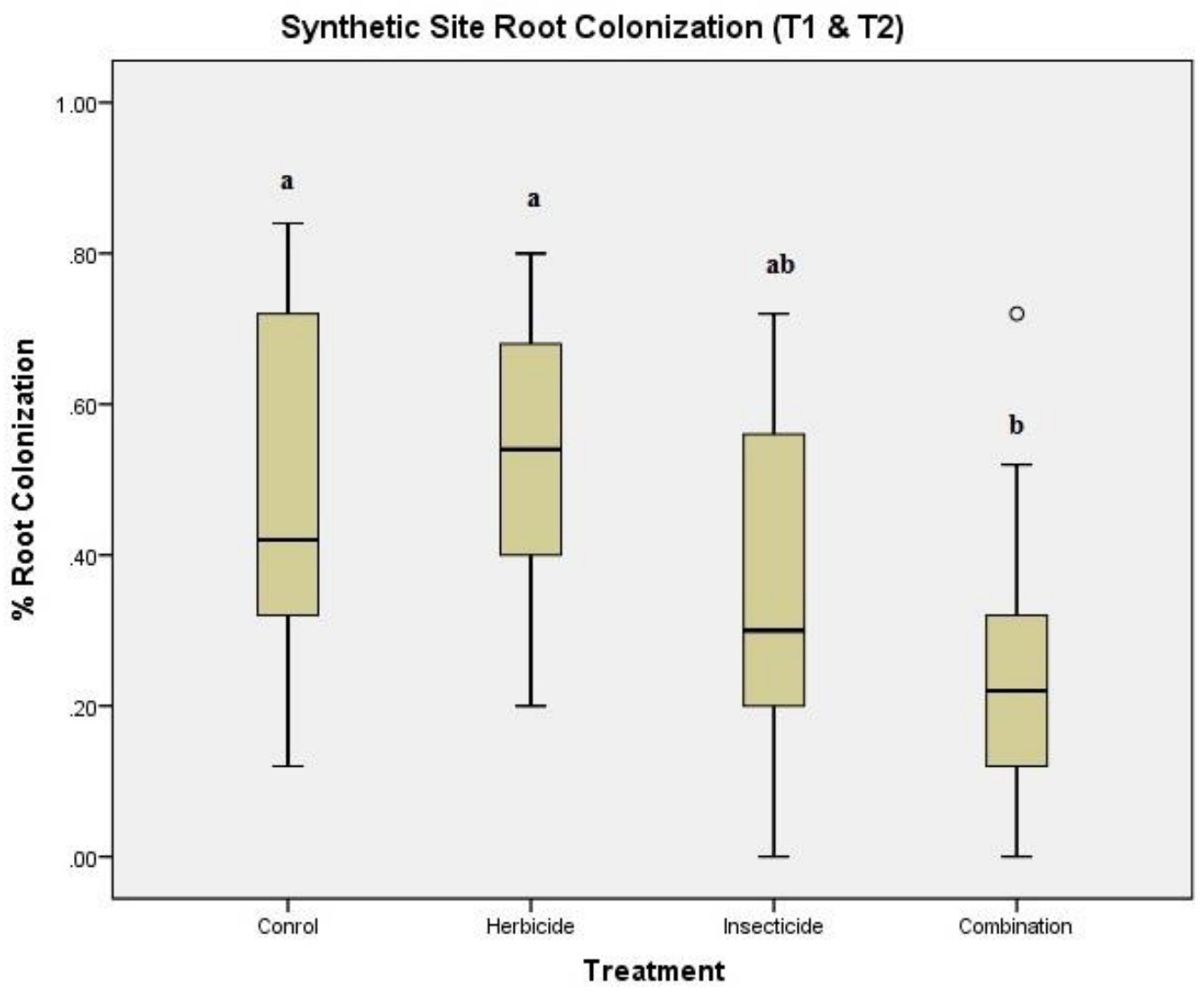

Figure 14: A boxplot presenting average root colonization percentage at the synthetic site with $T_{1}$ and $\mathrm{T}_{2}$ averages combined.

\subsection{Phosphorus Concentration (Leaf Matter)}

Table 6 provides a summary of an ANOVA conducted to compare the total phosphorus concentration means of each site overall, including all treatments and then each treatment individually. 


\begin{tabular}{llllll}
\hline & Total P & $\mathrm{n}$ & $\mathrm{df}$ & F value & P value \\
& & & & & \\
\hline Organic Site & $\mathbf{6 . 4 0} \pm \mathbf{0 . 1 1}$ & $\mathbf{7 2}$ & $\mathbf{3 , 6 8}$ & $\mathbf{4 . 7 0 1}$ & $\mathbf{0 . 0 0 5}$ \\
Control & $6.54 \pm 0.18$ & 18 & & & $\mathrm{ab}$ \\
Herbicide & $6.19 \pm 0.20$ & 18 & & & $\mathrm{ab}$ \\
Insecticide & $5.92 \pm 0.17$ & 18 & & & $\mathrm{a}$ \\
Combination & $6.95 \pm 0.26$ & 18 & & & $\mathrm{~b}$ \\
Synthetic Site & $\mathbf{4 . 6 5} \pm \mathbf{0 . 1 4}$ & $\mathbf{7 2}$ & $\mathbf{3 , 6 8}$ & $\mathbf{0 . 2 2 1}$ & $\mathbf{0 . 8 8 1}$ \\
Control & $4.74 \pm 0.35$ & 18 & & & NS \\
Herbicide & $4.71 \pm 0.31$ & 18 & & & NS \\
Insecticide & $4.68 \pm 0.21$ & 18 & & & NS \\
Combination & $4.45 \pm 0.19$ & 18 & & & NS
\end{tabular}

Table 6: Total phosphorus ANOVA results for $T_{1} \& T_{2}$ for each site comparing the means of different treatments.

\subsubsection{Total Phosphorus between Sites}

(Fig. 15) shows the difference between the total phosphorus concentrations at both sites over the three sampled time points, regardless of treatment. The organic site showed much higher phosphorus concentrations in the leaves then the synthetic site overall. The organic site phosphorus did increase over time but did not show a large difference in concentration within the time points. The synthetic site started out with high levels of phosphorus, proceeded to drop down drastically at 45 days, and then came back up at 66 days. 


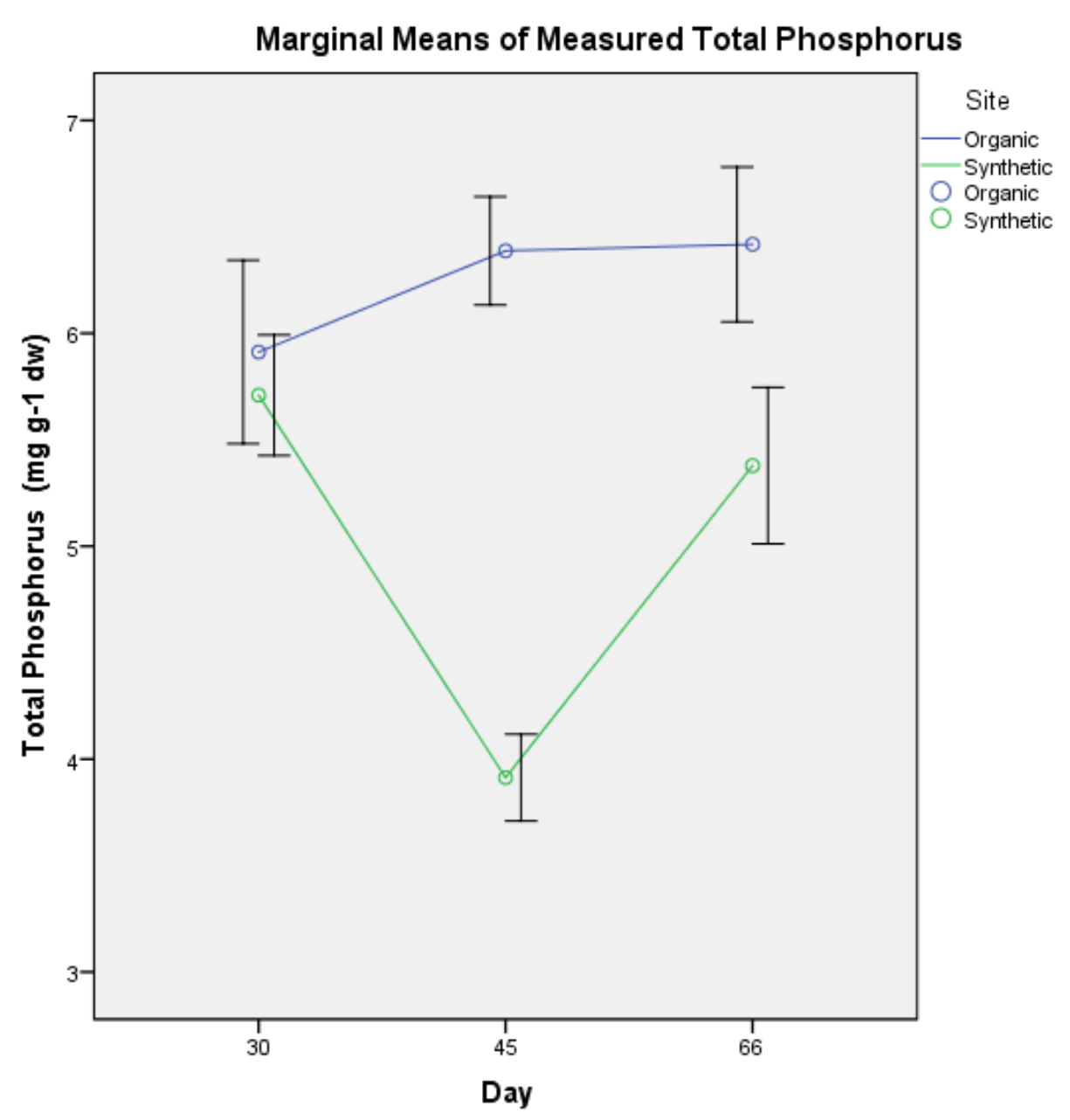

Error bars: +/- 2 SE

Figure 15: A line graph depicting the relationship of the mean total phosphorus concentrations for both sites regardless of treatment.

\subsubsection{Organic Site}

The total phosphorus results for the organic site displayed differences between treatments for the mean phosphorus concentration in the leaves. The post hoc analysis showed that there was a significant difference between the herbicide and combination treatment $(\mathrm{P}<0.052)$ and the insecticide and combination treatment $(\mathrm{P}<0.004)$. 


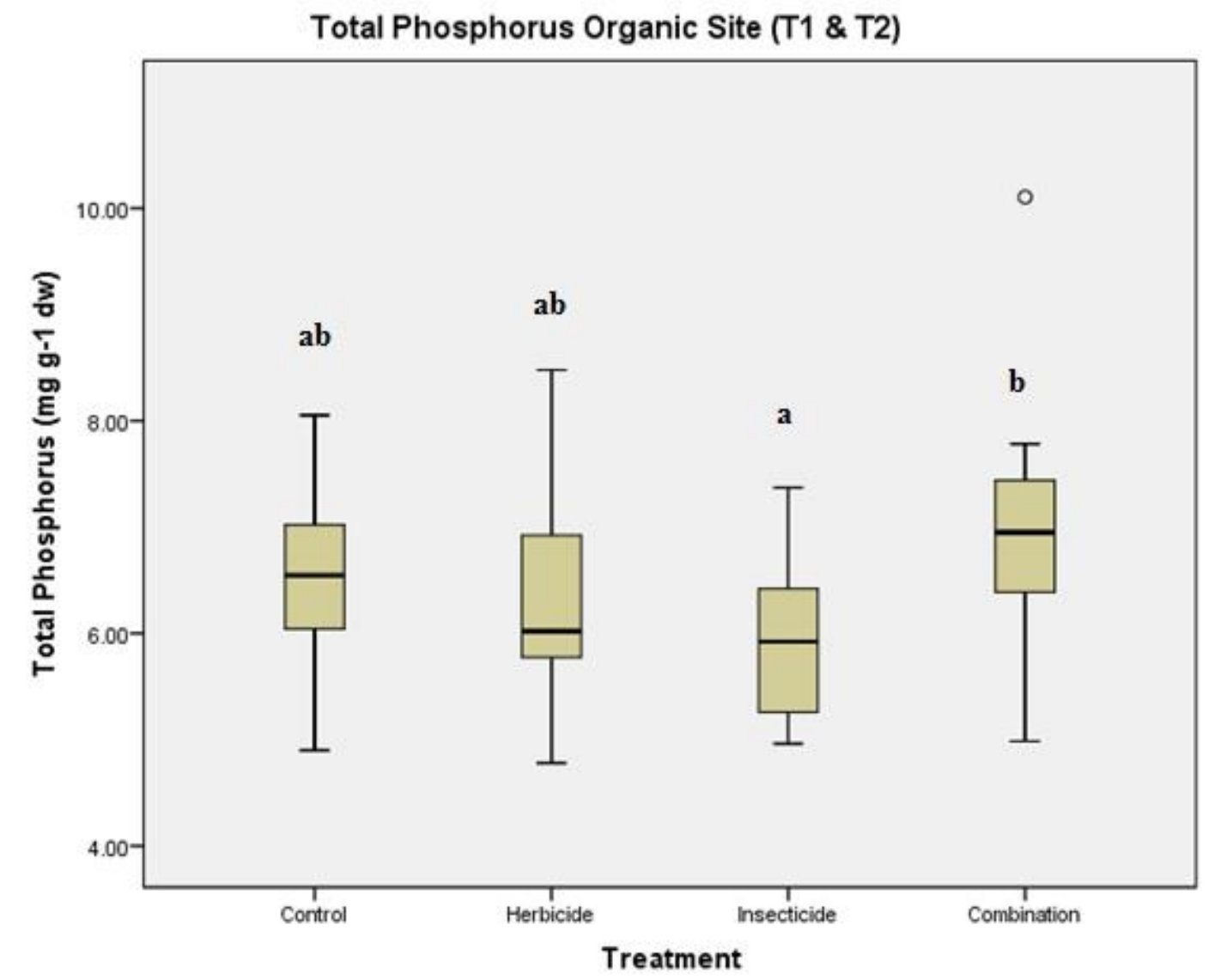

Figure 16: A boxplot depicting the average total phosphorus measurements at the organic site with $\mathrm{T}_{1}$ and $\mathrm{T}_{2}$ averages combined.

\subsubsection{Synthetic Site}

The total phosphorus results for the synthetic site displayed only small differences between treatments for the mean phosphorus concentration in the leaves. The post hoc analysis displays that there was no significant difference between any of the treatments at the synthetic site. 


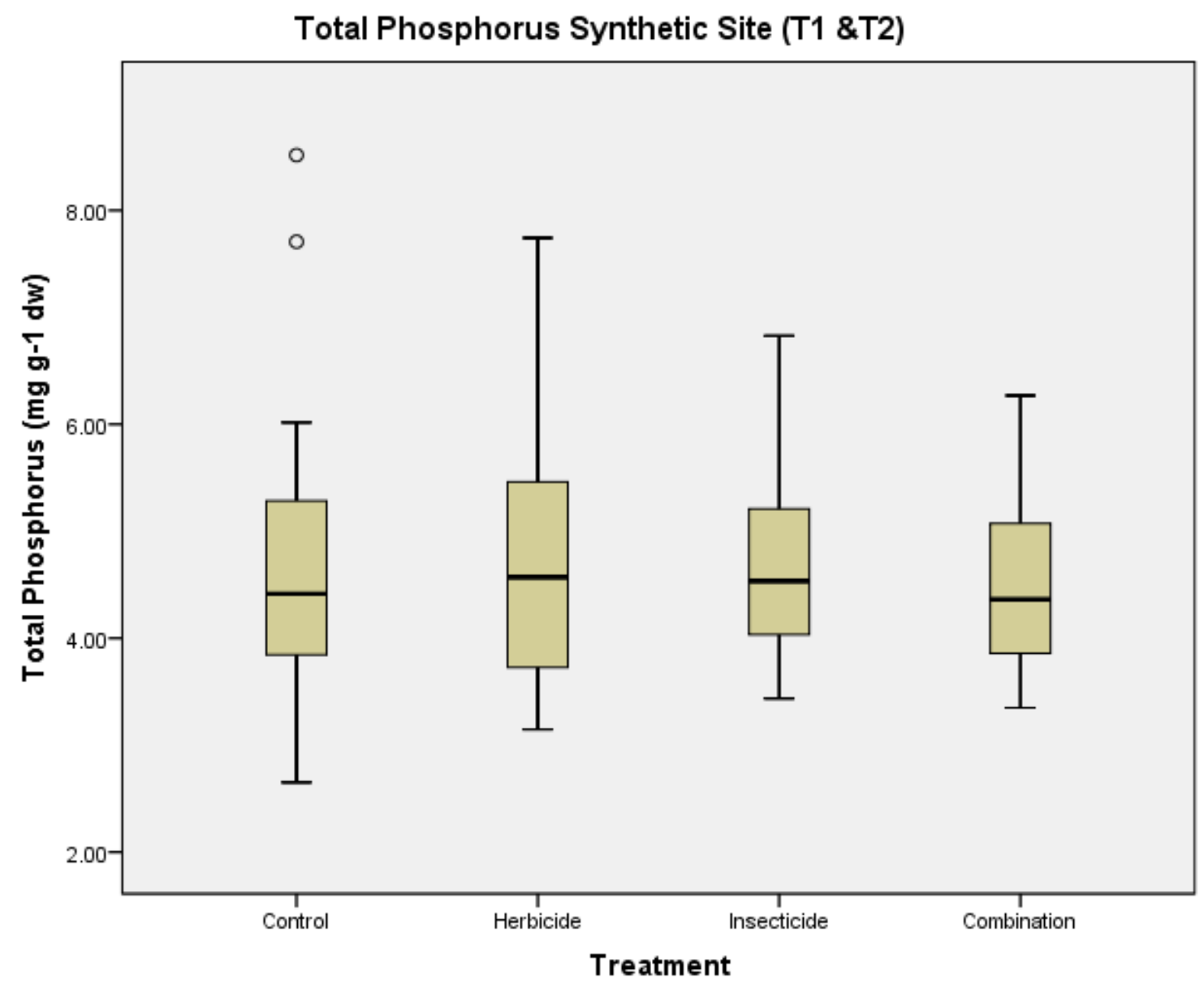

Figure 17: A boxplot displaying the average total phosphorus measurements at the synthetic site with $\mathrm{T}_{1}$ and $\mathrm{T}_{2}$ averages combined.

\subsection{Carbon Nitrogen Ratio}

Table 7 provides a summary of an ANOVA conducted to compare the calculated C:N ration means of each site overall, including all treatments and then each treatment individually. 
Table 7: C:N ratio ANOVA results for $T_{1} \& T_{2}$ for each site comparing the means of different treatments.

\begin{tabular}{llllll}
\hline & $\begin{array}{l}\text { C:N Ratio } \\
\text { (mol/mol) }\end{array}$ & $\mathrm{n}$ & $\mathrm{df}$ & F value & P value \\
\hline Organic Site & $\mathbf{1 0 . 6 6} \pm \mathbf{0 . 1 6}$ & $\mathbf{7 2}$ & $\mathbf{3 , 6 8}$ & $\mathbf{2 . 5 1 7}$ & $\mathbf{0 . 0 6 5}$ \\
Control & $10.07 \pm 0.35$ & 18 & & & $\mathrm{a}$ \\
Herbicide & $10.89 \pm 0.20$ & 18 & & & $\mathrm{a}$ \\
Insecticide & $11.18 \pm 0.32$ & 18 & & & $\mathrm{~b}$ \\
Combination & $10.50 \pm 0.33$ & 18 & & & $\mathrm{a}$ \\
Synthetic Site & $\mathbf{1 3 . 1 7} \pm \mathbf{0 . 1 4}$ & $\mathbf{7 2}$ & $\mathbf{3 , 6 8}$ & $\mathbf{1 . 3 9 3}$ & $\mathbf{0 . 2 5 3}$ \\
Control & $13.65 \pm 0.31$ & 18 & & & NS \\
Herbicide & $13.03 \pm 0.27$ & 18 & & & NS \\
Insecticide & $12.92 \pm 0.29$ & 18 & & & NS \\
Combination & $13.08 \pm 0.22$ & 18 & & & NS
\end{tabular}

\subsubsection{C:N ratio between Both Sites}

(Fig. 18) shows the difference between the $\mathrm{C}: \mathrm{N}$ ratios at both sites over the three sampled time points, regardless of treatment. The synthetic site showed a higher C:N ratio in the leaves then the organic site overall. The organic site $\mathrm{C}: \mathrm{N}$ ratio did increase gradually over time. The synthetic site had an increased C:N ration between 30 days and 45 days but gradually decreased between 45 days and 66 days. 


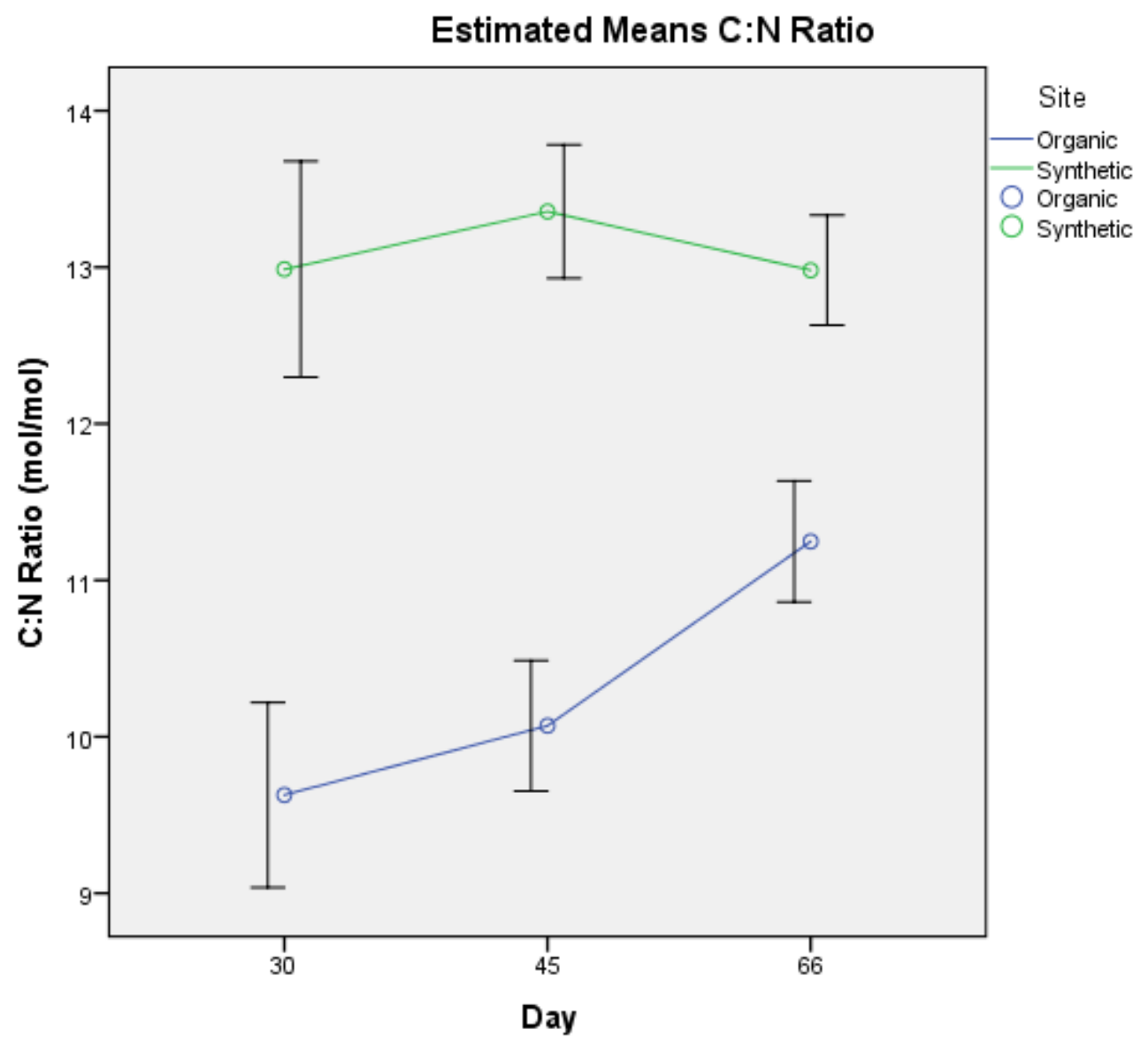

Error bars: +/- $2 \mathrm{SE}$

Figure 18: A line graph depicting the relationship of the mean $\mathrm{C}: \mathrm{N}$ ratio for both sites regardless of treatment.

\subsubsection{Organic Site}

The $\mathrm{C}: \mathrm{N}$ ratio results for the organic site did display some difference between treatments. The post hoc analysis displays that there was marginally significant difference between the control treatment and the insecticide treatment $(\mathrm{P}<0.065)$. 


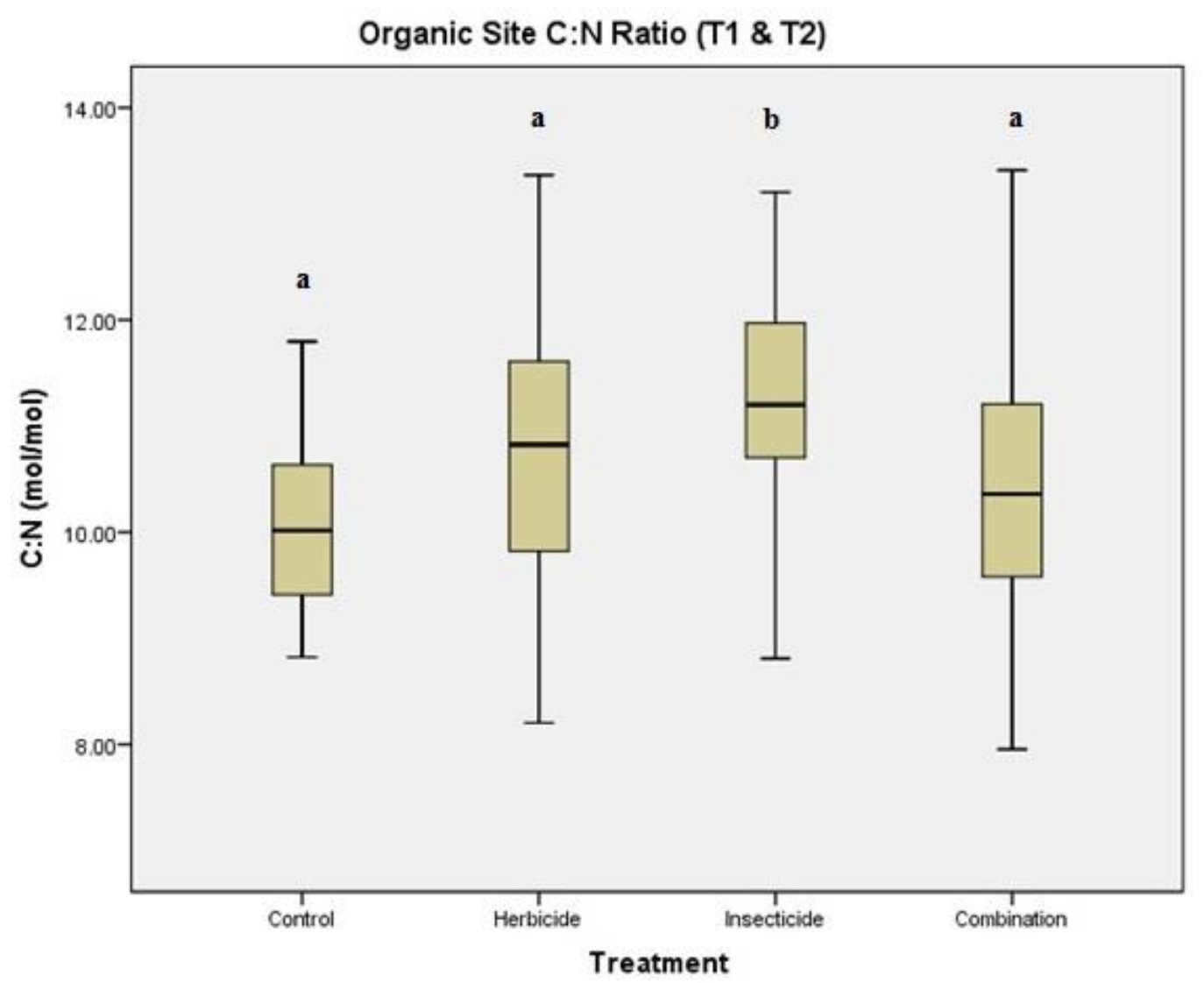

Figure 19: A boxplot showing the $C: N$ ratio between treatments at the organic site with $T_{1}$ and $T_{2}$ averages combined.

\subsubsection{Synthetic Site}

The C:N ratio results for the synthetic site displayed minor differences between treatments. The post hoc analysis displays that there was no significant difference between treatments at the synthetic site. 


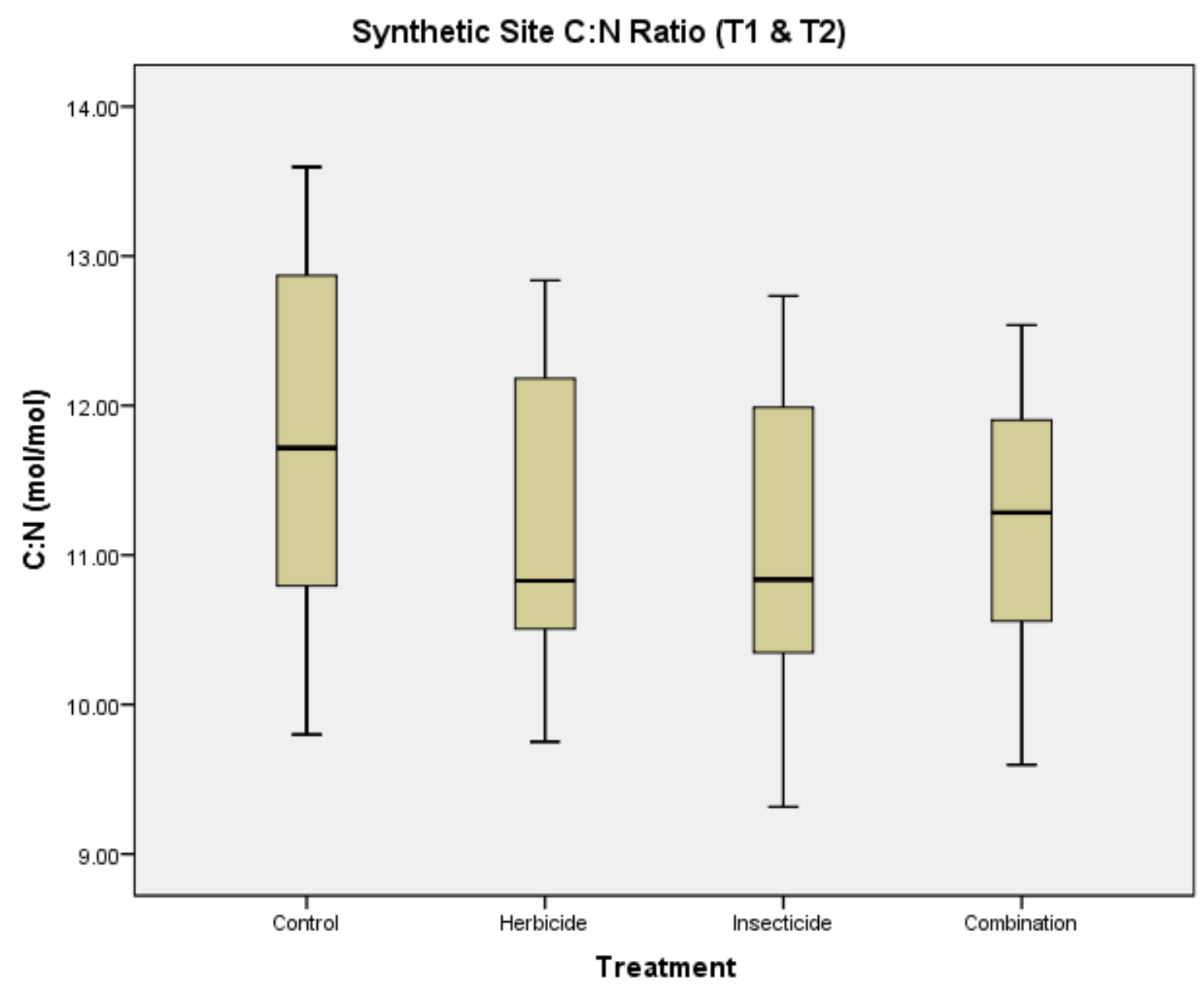

Figure 20: A boxplot displaying the $\mathrm{C}: \mathrm{N}$ ratio between treatments at the synthetic site with $\mathrm{T}_{1}$ and $\mathrm{T}_{2}$ averages combined.

\subsection{Carbon Phosphorus Ratio}

Table 8 provides a summary of an ANOVA conducted to compare the calculated C:P ration means of each site overall, including all treatments and then each treatment individually. 
Table 8: C:P ratio ANOVA results for $T_{1} \& T_{2}$ for each site comparing the means of different treatments.

\begin{tabular}{llllll}
\hline & $\begin{array}{l}\text { C:P Ratio } \\
(\mathrm{mol} / \mathrm{mol})\end{array}$ & $\mathrm{n}$ & $\mathrm{df}$ & F value & P value \\
\hline Organic Site & $\mathbf{1 7 5 . 9 0} \pm \mathbf{0 . 1 6}$ & $\mathbf{7 2}$ & $\mathbf{3 , 6 8}$ & $\mathbf{4 . 0 5 5}$ & $\mathbf{0 . 0 1 0}$ \\
Control & $171.73 \pm 5.27$ & 18 & & & $\mathrm{a}$ \\
Herbicide & $180.62 \pm 5.86$ & 18 & & & $\mathrm{a}$ \\
Insecticide & $189.01 \pm 5.73$ & 18 & & & $\mathrm{a}$ \\
Combination & $162.22 \pm 6.01$ & 18 & & & $\mathrm{~b}$ \\
Synthetic Site & $\mathbf{2 5 5 . 4 7} \pm \mathbf{6 . 6 6}$ & $\mathbf{7 2}$ & $\mathbf{3 , 6 8}$ & $\mathbf{0 . 1 3 9}$ & $\mathbf{0 . 9 3 7}$ \\
Control & $257.43 \pm 17.06$ & 18 & & & $\mathrm{NS}$ \\
Herbicide & $253.55 \pm 15.00$ & 18 & & & $\mathrm{NS}$ \\
Insecticide & $249.57 \pm 10.24$ & 18 & & & $\mathrm{NS}$ \\
Combination & $261.33 \pm 10.80$ & 18 & & & $\mathrm{NS}$
\end{tabular}

\subsubsection{C:P Ratio Between Sites}

(Fig. 21) shows the difference between the C:P ratios at both sites over the 3 sampled time points, regardless of treatment. Both sites started out with similar C:P ratios. The synthetic site spiked at 45 days while the organic site decreased. At 66 days the synthetic site fell while the organic site slightly increased. 


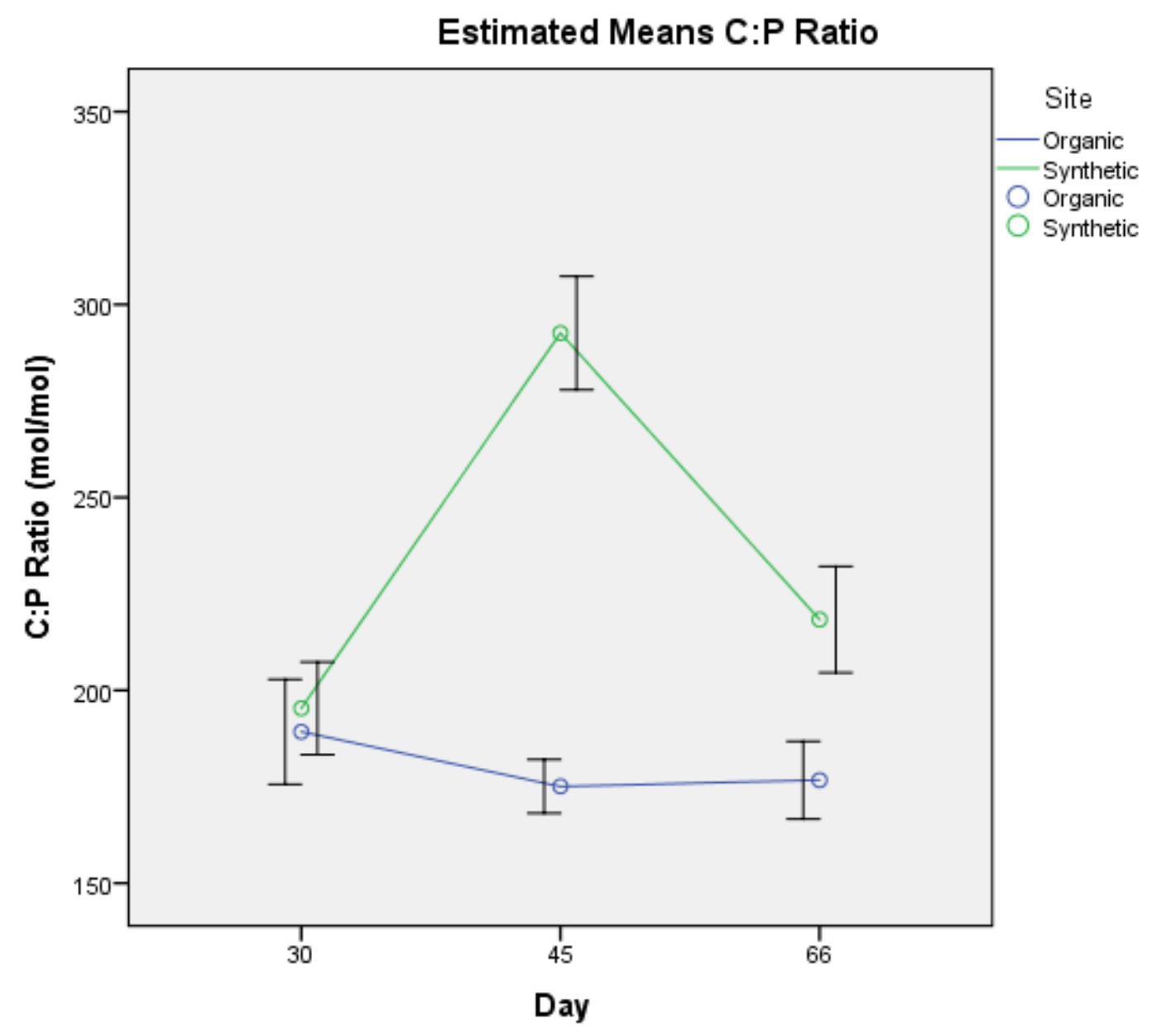

Error bars: +/- 2 SE

Figure 21: A line graph depicting the relationship of the mean C:P ratio (leaf matter) for both sites regardless of treatment.

\subsubsection{Organic Site}

The C:P ratio results for the organic site did show some difference between treatments. The post hoc analysis showed a significant difference between the insecticide treatment and the combination treatment $(\mathrm{P}<0.008)$. 


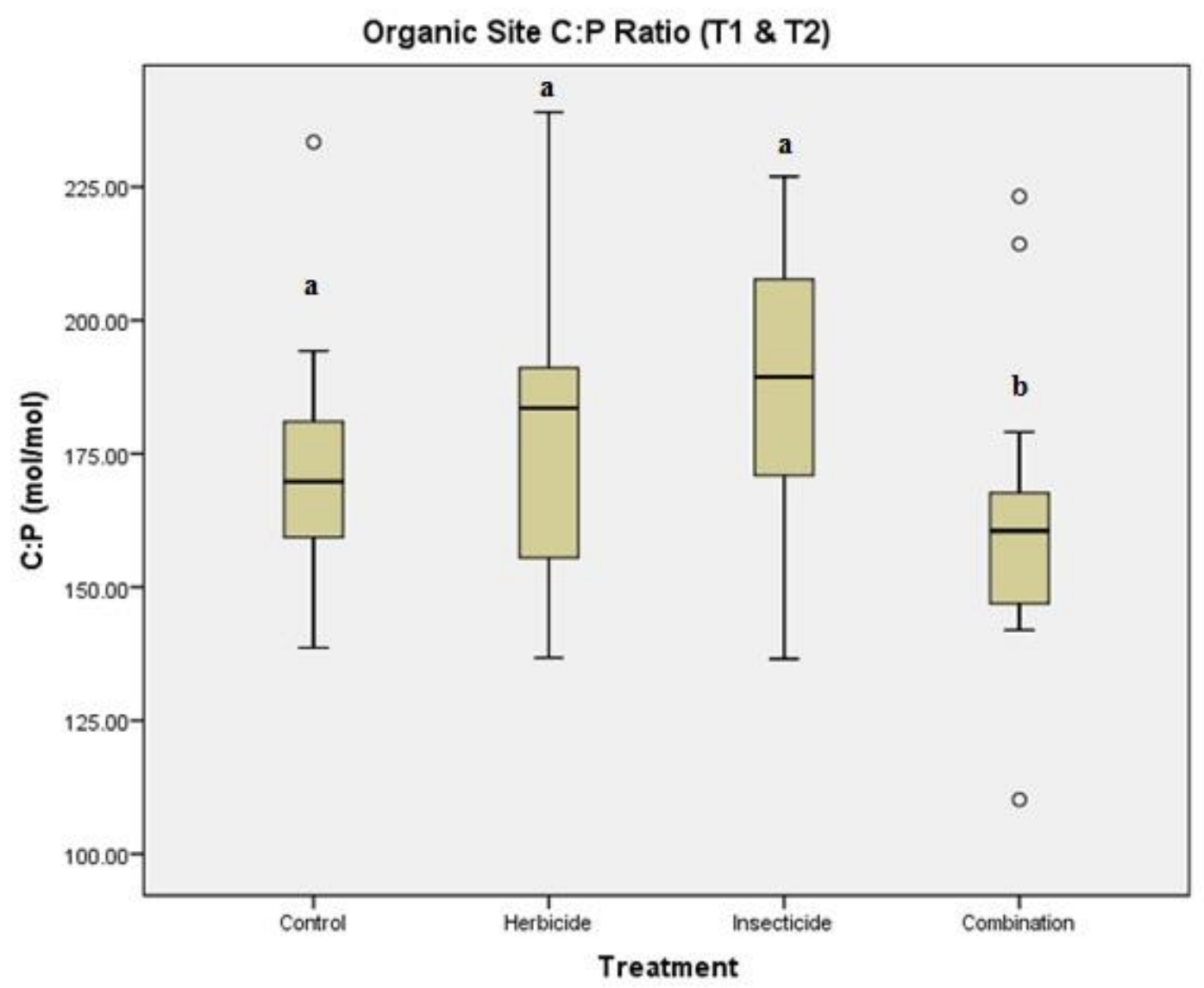

Figure 22: A boxplot depicting the $C: P$ ratio between treatments at the organic site with $T_{1}$ and $T_{2}$ averages combined.

\subsubsection{Synthetic Site}

The C:P ratio results for the synthetic site displayed minor differences between treatments. The post hoc analysis displays that there was no significant difference between treatments at the synthetic site. 
Synthetic Site C:P Ratio (T1 \& T2)

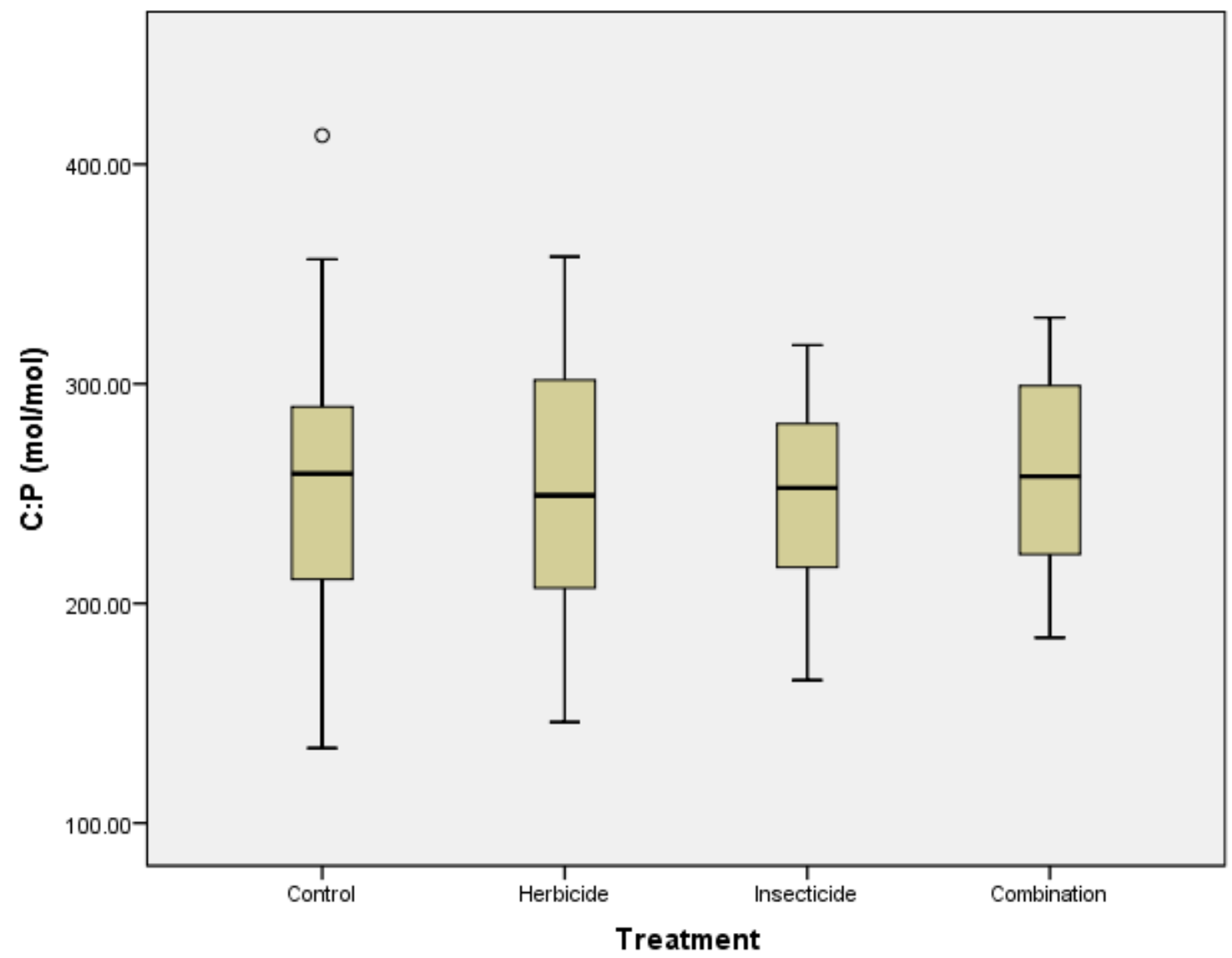

Figure 23: A boxplot showing the $\mathrm{C}: \mathrm{P}$ ratio between treatments at the synthetic site with $\mathrm{T}_{1}$ and $\mathrm{T}_{2}$ averages combined.

\subsection{Fruit Yield \& Herbivory}

The fruit yield for the organic site did show varied results. The herbicide treatment harbored the most fruit with a mean yield of $0.83 \mathrm{~g}$, while the insecticide treatment had none at all. The control treatment showed $0.10 \mathrm{~g}(0.73 \mathrm{~g})$ less than the herbicide treatment and the combination $(0.09 \mathrm{~g})$ was the lowest out of the treatments that bore fruit. Overall, there was a small amount of fruit measured from this site with the highest treatment only yielding a mean of a little less than a gram. 
The fruit yield for the synthetic site showed much more obvious results than the organic site. The fruit yield was varied between treatments with the control having the highest mean yield of $43.61 \mathrm{~g}$. The combination treatment had the second highest mean yield, just slightly under the control with $41.67 \mathrm{~g}$. The insecticide treatment had a mean yield of $26.14 \mathrm{~g}$ and the herbicide treatment had the lowest mean yield with $11.96 \mathrm{~g}$.

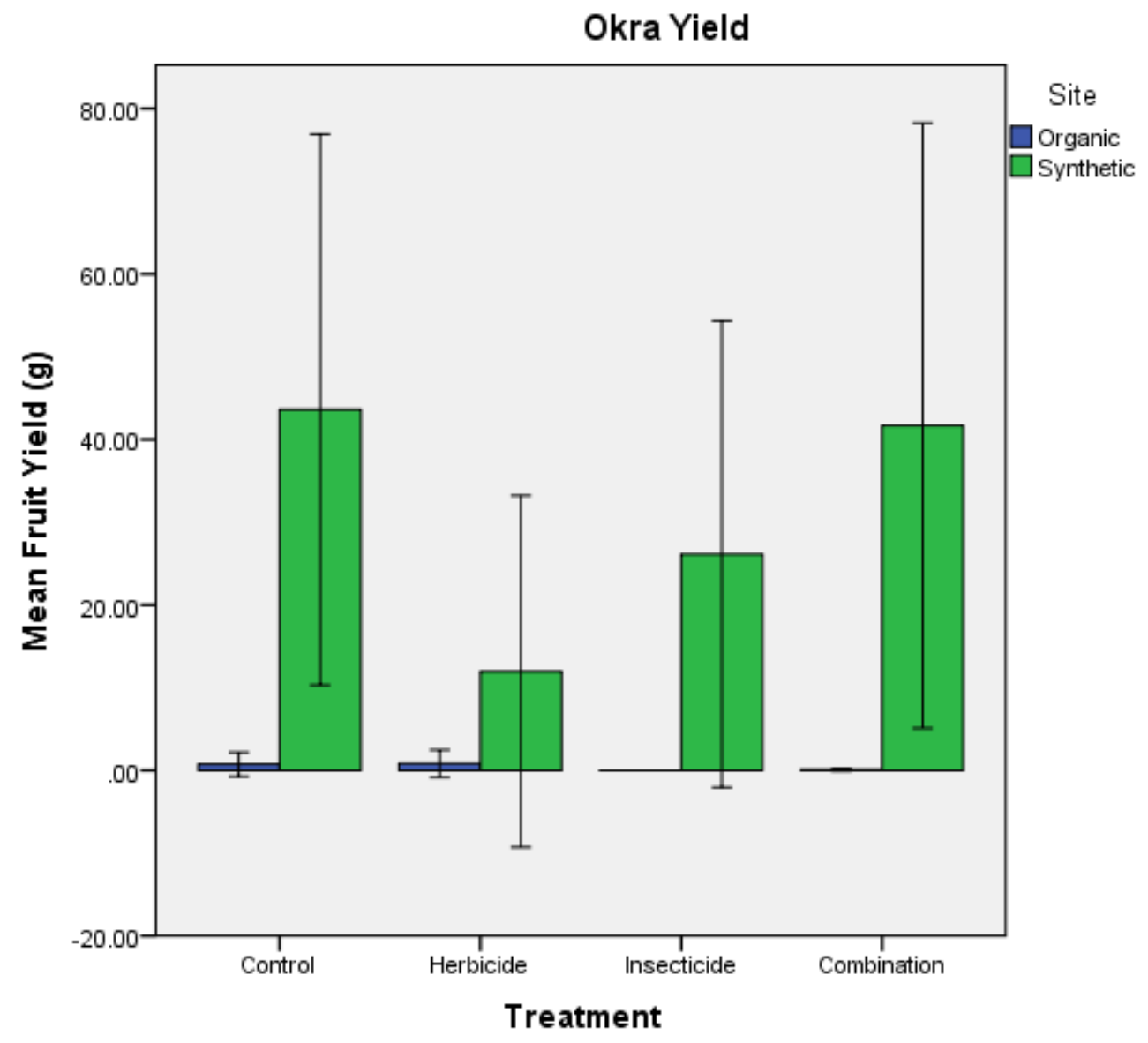

Error bars: +/- $2 \mathrm{SE}$

Figure 24: A bar graph depicting the fruit yield means at the organic and synthetic site at $T_{2}$.

(Fig. 25) below displays the interaction between the okra plant samples and herbivorous insects at the organic site. There was a great amount of herbivory that may have affected plant growth. 


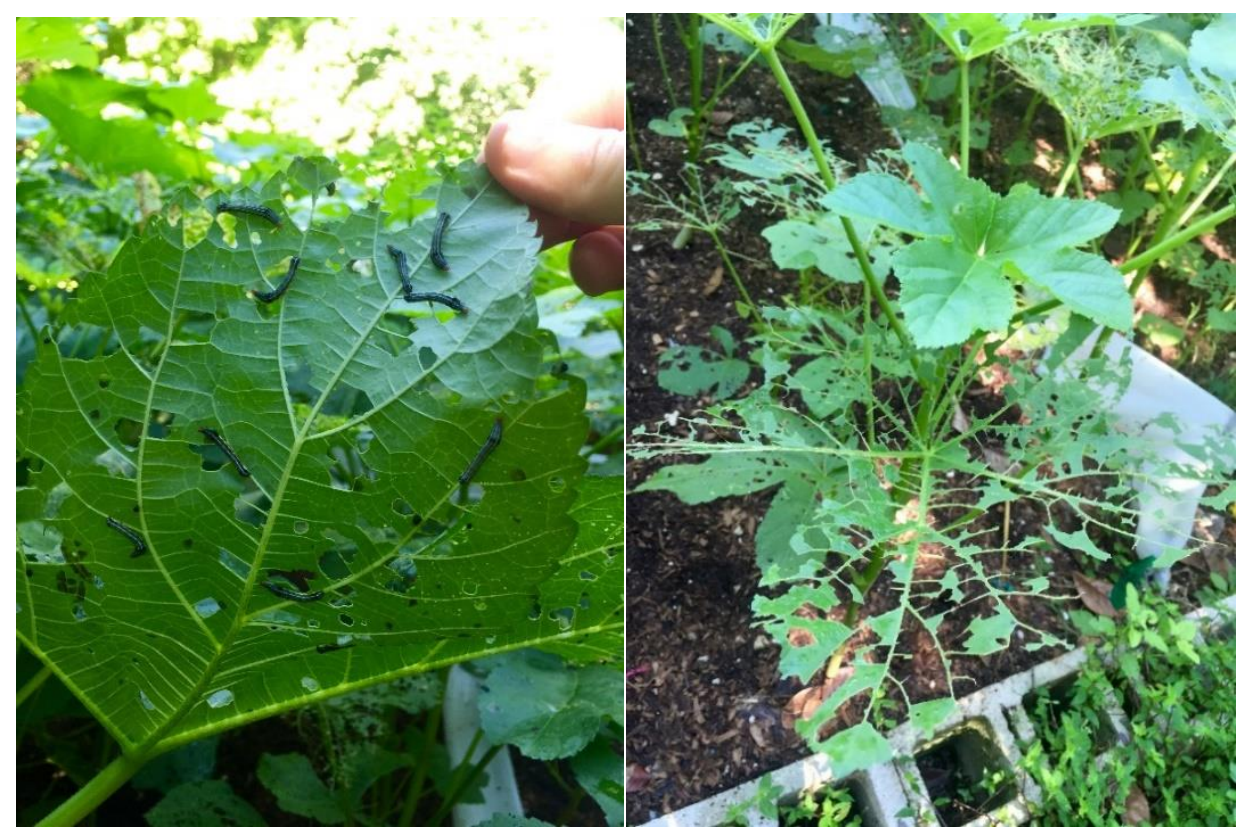

Figure 25: Images displaying the intense herbivory at the Possum Trot organic site.

\subsection{Potted Trial Results}

The root colonization results of the potted trial for the combined times of $\mathrm{T}_{1}$ and $\mathrm{T}_{2}$ display varied results. The control treatment displayed the highest root colonization percentage with a mean of $93 \%$. The Avenger Organics@ herbicide treatment had a mean root colonization percentage of $70 \%$. The Roundup ${ }^{\circledR}$ synthetic herbicide treatment had a mean root colonization of $50 \%$. The NATRIA® Neem Oil organic insecticide showed a mean root colonization percentage of $81 \%$, while the synthetic Sevin ${ }^{\circledR}$ insecticide shows a mean root colonization percentage of $71 \%$. 


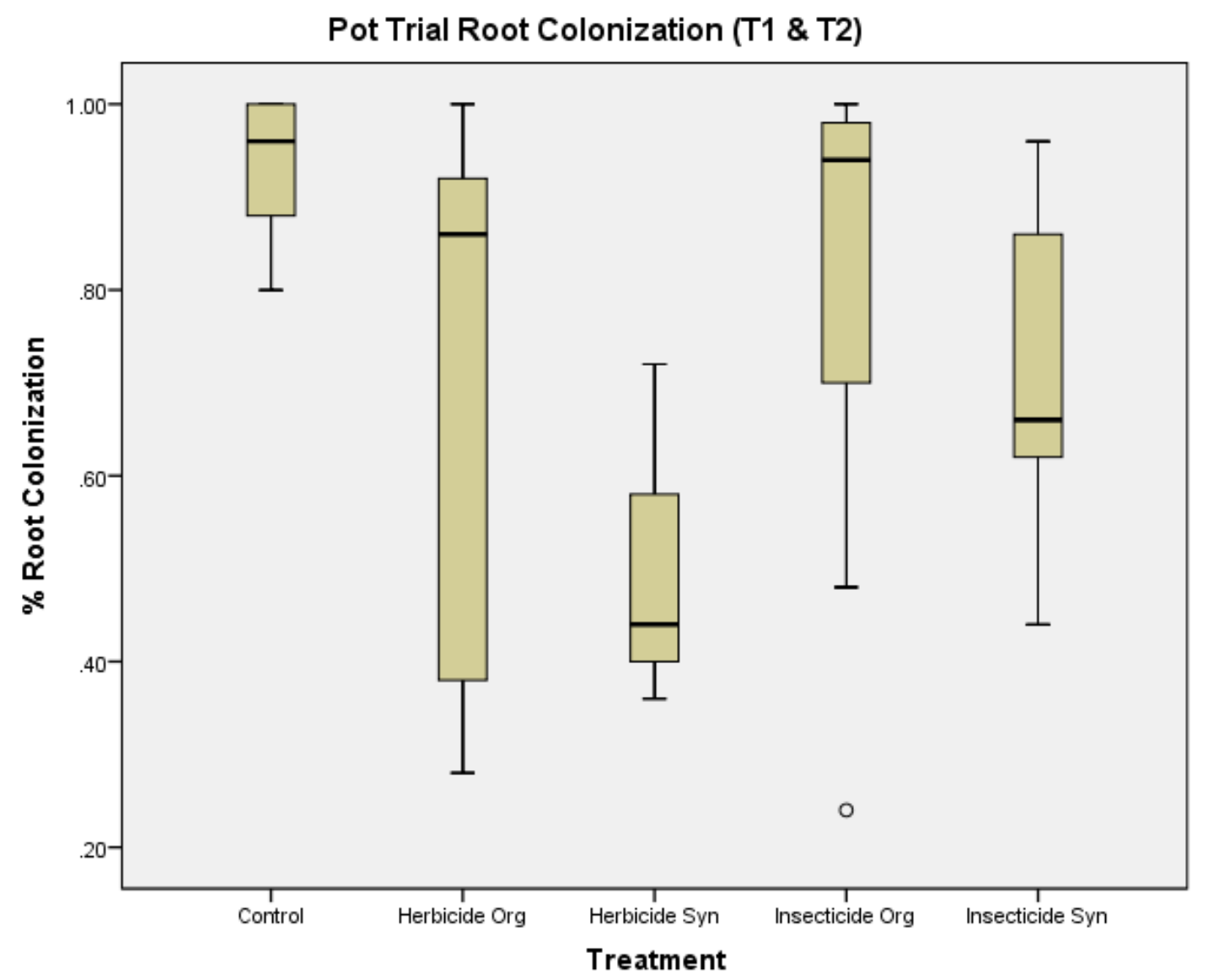

Figure 26: A boxplot showing the mean root colonization for each treatment in the potted trial with $\mathrm{T}_{1}$ and $\mathrm{T}_{2}$ averages combined.

The mean total phosphorus results show varied results within the potted trial. The control treatment displayed an average of $4.02 \mathrm{mg} \mathrm{g}-1 \mathrm{dw}$ of total phosphorus in the leaf samples. The organic herbicide had an average total phosphorus $3.78 \mathrm{mg} \mathrm{g}-1 \mathrm{dw}$, while the synthetic herbicide showed an average total phosphorus of $4.03 \mathrm{mg} \mathrm{g}$ - 1 dry weight. The neem oil organic insecticide showed an average total phosphorus of $3.97 \mathrm{mg}$ g- 1 dry weight, while the synthetic insecticide displayed an average of $4.40 \mathrm{mg} \mathrm{g}-1$ dry weight. 


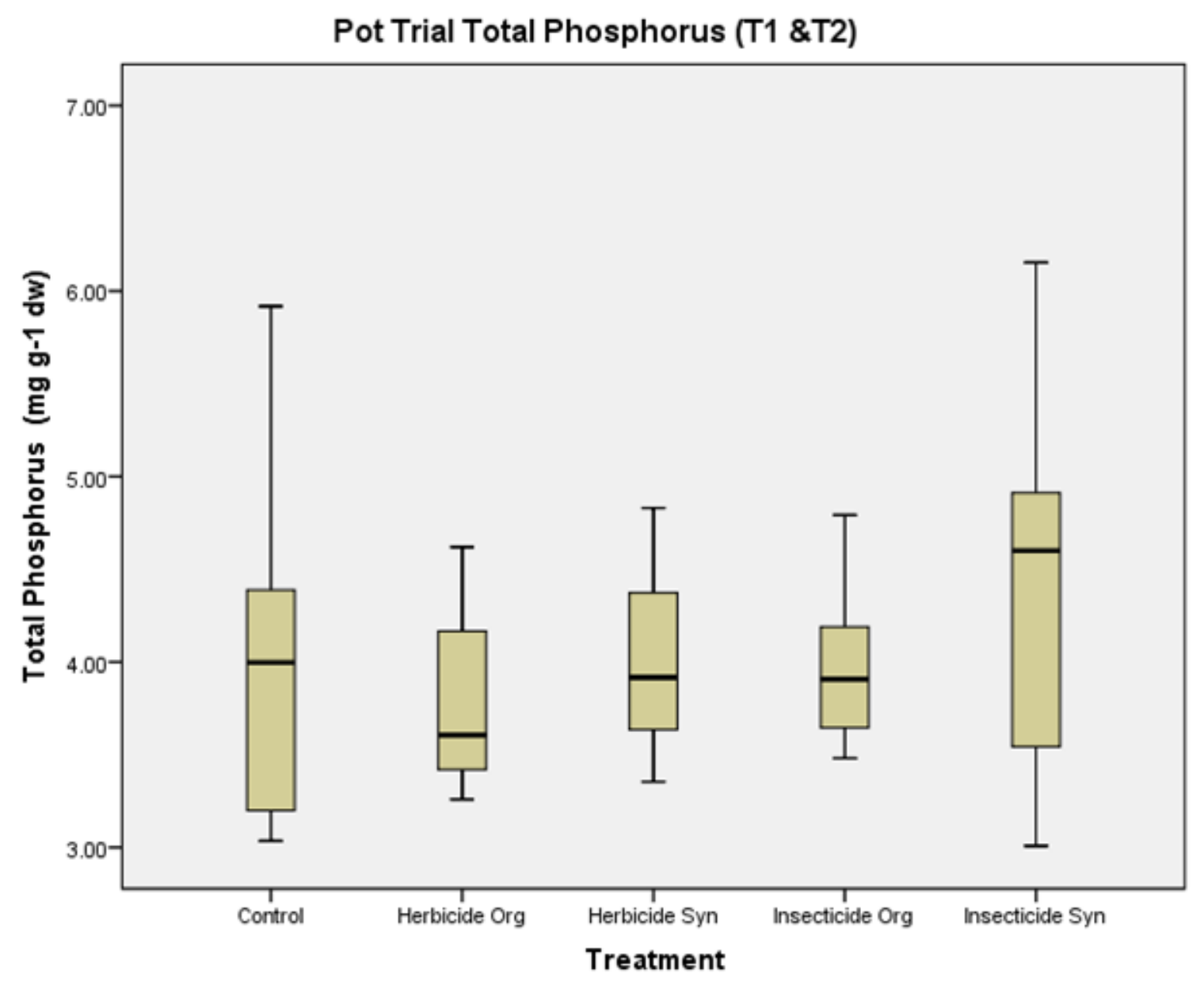

Figure 27: A boxplot displaying the total phosphorus in $\mathrm{mg} \mathrm{g}-1 \mathrm{dw}$ of the leaf samples from each treatment with $T_{1}$ and $T_{2}$ averages combined.

The results for the $\mathrm{C}: \mathrm{N}$ ratio in the potted trial show drastic differences. The control treatment displayed a mean of $18.72(\mathrm{~mol} / \mathrm{mol})$, the organic herbicide treatment had a mean of $18.01(\mathrm{~mol} / \mathrm{mol})$, the synthetic herbicide had a mean of $14.57(\mathrm{~mol} / \mathrm{mol})$, the organic insecticide had a mean of $17.24(\mathrm{~mol} / \mathrm{mol})$, and the synthetic insecticide had a mean of $17.29(\mathrm{~mol} / \mathrm{mol})$. 


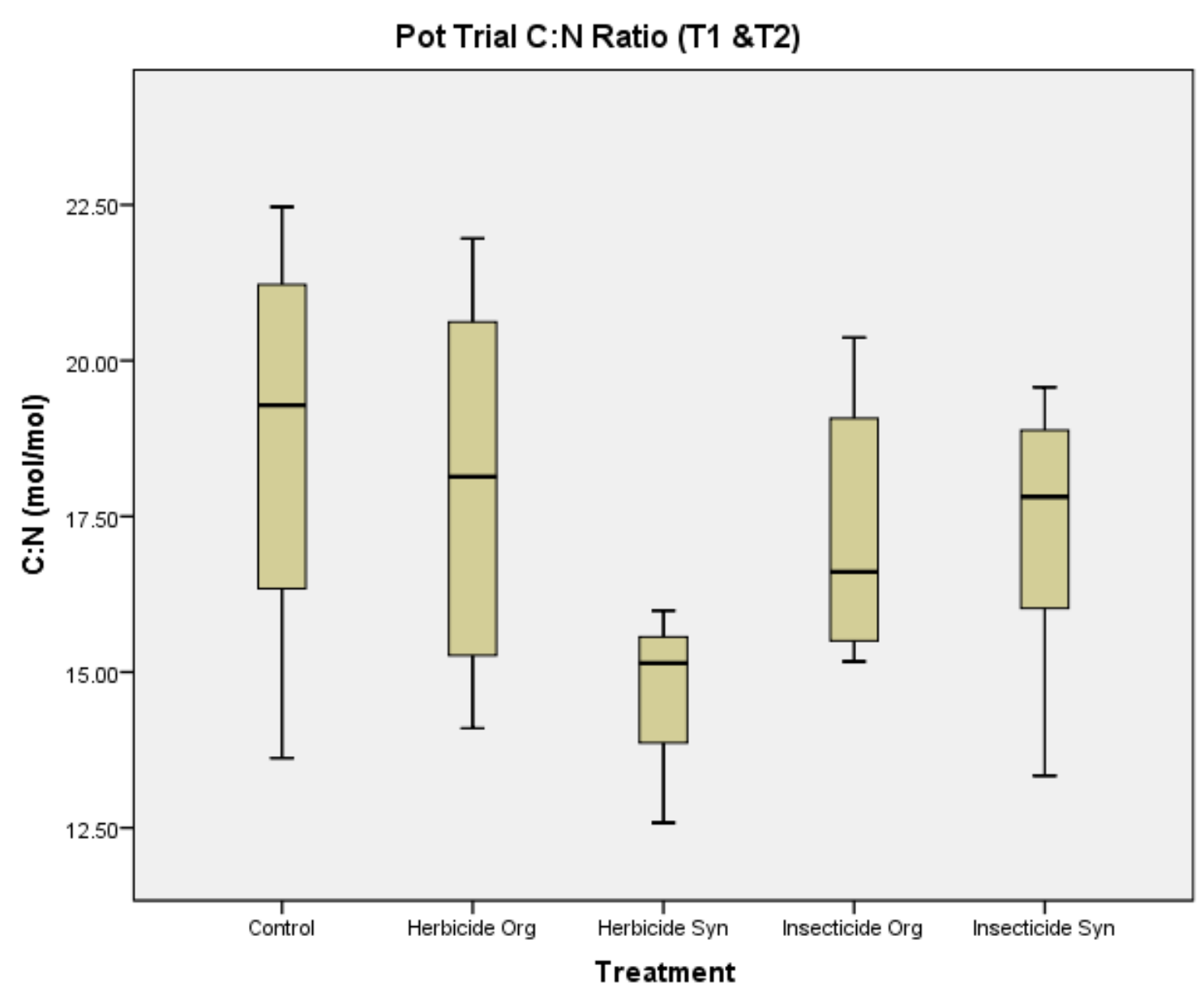

Figure 28: A boxplot displaying the $\mathrm{C}: \mathrm{N}$ ratio for the potted trial with $\mathrm{T}_{1}$ and $\mathrm{T}_{2}$ averages combined.

The results for the C:P ratio in the potted trial showed some differences between the treatments. The control treatment displayed a mean of $280.30(\mathrm{~mol} / \mathrm{mol})$, the organic herbicide treatment had a mean of $290.50(\mathrm{~mol} / \mathrm{mol})$, the synthetic herbicide had a mean of $273.21(\mathrm{~mol} / \mathrm{mol})$, the organic insecticide had a mean of $274.41(\mathrm{~mol} / \mathrm{mol})$, and the synthetic insecticide had a mean of 258.17 ( $\mathrm{mol} / \mathrm{mol})$. 


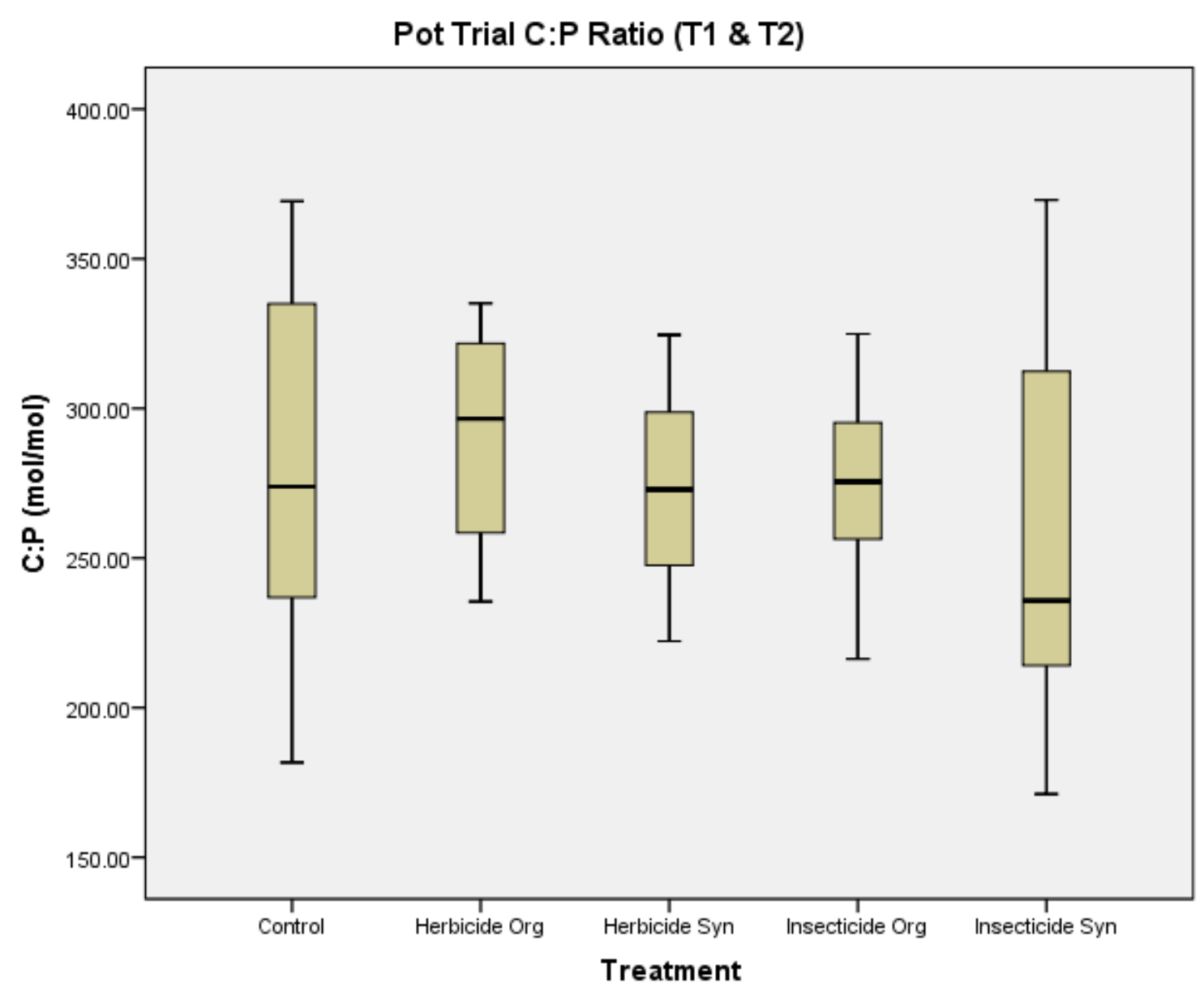

Figure 29: A boxplot depicting the $C: P$ ratio for the pot trial with $T_{1}$ and $T_{2}$ averages combined.

\section{DISCUSSION}

\subsection{Hypothesis 1}

The results of this study partially support my first hypothesis that the synthetic treatments (glyphosate and carbaryl) would have the greatest negative effect on mycorrhizal root colonization and overall leaf nutrient status. Table 5 displays the root colonization statistics for the field trial. The glyphosate and control treatments showed no significant difference. It is possible that, because the control treatment plots were full of weeds and the glyphosate treatment had no weeds, the weeds may have interfered with 
the colonization of AMF in the control treatment and carbaryl plots. The weeds present at the synthetic site mainly consisted of purple nutsedge (Cyperus rotundus). Purple nutsedge can be colonized by AMF, but has been shown to possess a non-functional relationship with endomycorrhizal fungi (Muthukumar et al. 1997). Koske et al. 1997 found that roots of the purple nutsedge contained vesicles and hyphal structures, but lacked arbuscules.

The carbaryl treatment had the second lowest root colonization percentage, just above the combination treatment. As per hypothesis 1 , the combination treatment did have the most negative effect on root colonization percentage. The combination treatment shows the effect of the carbaryl, but also may show the true effect of the glyphosate treatment. These chemicals in combination seem to have a severe effect on the ability for mycorrhiza to colonize the roots of plants.

The potted trial conducted at the FIU garden shade house displayed varied results as compared to the field trial. The results from the potted trial are very definitive in the differences between the treatments. The glyphosate treatment resulted in a mean root colonization of $50 \%$ and the carbaryl treatment $71 \%$, as compared to the control treatment that had a mean root colonization of $93 \%$. The potted trial was more controlled than the field trial for the following reasons: Each plant was contained in the same size pot as the others, they were all at the same site under the same light and temperature conditions, there was little exposure to herbivorous pests, and the seeds were started in starter trays which made inoculation of AMF more precise.

The results of the potted trial show a severe negative effect of glyphosate spray on AMF colonization potential (Fig. 26). While this result may not correspond with the field 
trial results from the glyphosate plot, the combination plot did reflect a more negative effect on mycorrhizal root colonization than just carbaryl alone. Although glyphosate is recognized as having little to no fungicidal or bactericidal tendencies, researchers have discovered that this may not be factual. Feng et al. 2005, inoculated glyphosate resistant wheat and soybean crops with stripe rust fungus (Puccinia striiformisf. sp.tritic) and Asian soybean rust (Phakopsora pachyrhizi). The researchers applied glyphosate to the infected crops and found that the chemical actually controlled the leaf rust disease in both cases, even at low concentrations. This result may be due to the inhibition of fungal EPSPS (Feng et al. 2005). Plants that are infected with Asian soybean rust and treated with glyphosate demonstrate a buildup of shikimic acid which is a sign of the inhibition of the plants EPSPS directly related to glyphosate application (Dill et al. 2010). If detrimental fungus can be controlled by glyphosate application to the plant, it is likely that glyphosate contact with beneficial soil fungi may have an inhibitory effect on their ability to proliferate and sustain relationships with plant roots.

There has been limited research conducted on carbaryl and its interaction with the proliferation and colonization of mycorrhizal fungi. This chemical has a half-life of 7 days in aerobic soil settings. It is possible that the carbaryl or other ingredients in the Sevin ${ }^{\circledR}$ spray have some type of negative relationship with mycorrhizae as shown in the field study conducted.

The second part of hypothesis 1 assumes that the synthetic treatments would have negative effects on leaf nutrients status on the plants treated with these chemicals. Mycorrhizal fungi help plants with different types of nutrient uptake. However, the transfer of phosphorus is their primary function. For this reason, total phosphorus is 
generally linked to presence of mycorrhizae colonization in the plant root. There was no significant difference between any of the treatments at the synthetic site in total phosphorus concentration. Additionally, the $\mathrm{C}: \mathrm{N}$ and $\mathrm{C}: \mathrm{P}$ ratios showed no significant difference between treatments at the synthetic site as well. This data displays that, although there was a difference in root colonization from treatment to treatment, this had no effect on the nutrient uptake of the plants. This may be an indication of there being little nutrient stress on the plants. Therefore, the AMF didn't need to be present in order for nutrient uptake to occur.

Although the sample size in the potted trial was too low to reflect significant difference between treatments when analyzed with a one way ANOVA, the results showed stark differences. The glyphosate and carbaryl treatments had lower root colonization percentages, but higher total phosphorus concentrations than the organic treatment, and, in the case of the carbaryl treatment, the total phosporus was higher than in the control. The C:N ratio results showed that the glyphosate treatment had a much lower C:N ratio than the rest, and the carbaryl was similar to the other treatments. It is surprising that the $\mathrm{C}: \mathrm{N}$ ratio in the glyphosate treatment was so much lower than the other treatments, meaning these plants were more efficient in taking up nitrogen than the others. This result is unexpected considering the low root infection percentages in this treatment and overall fitness of the samples. The total C:P ratio results show that the glyphosate had a C:P ratio below the control and the carbaryl treatment was much lower than the control. These results may be due to stress on the plants causing them to overcompensate with nutrient uptake. 
(Fig. 24) displays the mean fruit yield from each treatment at the synthetic site showing the control had the highest yield and the glyphosate treatment had the lowest. In this case, the fruit yield represents the fruit production for the entire plot, not just the sampled plants. The difference in fruit yield per treatment in this case clearly showed that the glyphosate alone did have a negative effect on fruit set overall. The carbaryl treatment had a yield which was higher than the glyphosate treatment, but lower than the combination. This result shows that the benefit of combining two sprays to combat herbivorous insects and weeds may outweigh the negative effect of interference with mycorrhizal colonization. The control treatment with no spray still outperformed all of the 3 sprayed treatments in yield.

\subsection{Hypothesis 2}

The results of this study partially support my second hypothesis in which the organic treatments (citrus oil and neem oil) would have little to no effect on mycorrhizal root colonization and overall leaf nutrient status. At the organic site, there was no significant difference in root colonization percentages between any of the treatments. Additionally, the potted trial results showed that the mean root colonization percentage for the citrus oil was $70 \%$ and the neem oil was $81 \%$, the control was $93 \%$. This can be attributed to both of the active ingredients in these products being non-toxic and highly biodegradable with relatively short half-lives. The products may degrade so quickly that they don't have time or the ability to mobilize far enough to affect the mycorrhizal relationships in the surrounding soil.

The significantly greater total phosphorus concentrations in the leaves in the control treatment of the organic site relative to the citrus oil or neem oil treatments would 
suggest that either of the treatments reduced the ability of the Okra plants to obtain phosphorus. However, the combined treatment, where both citrus and neem oil were applied, resulted in greater total phosphorus in the leaves. These results don't seem to be correlated with the root colonization percentage results for this site considering that the combination treatment had the lowest root infection percentage but the highest total phosphorus leaf concentrations. Similarly the neem oil treatment had the second highest root colonization percentage, but the lowest total phosphorus concentration.

The potted trial phosphorus results (Fig. 27), shows the control with a high total phosphorus concentration while neem oil was just under the control and the citrus oil mean was below the neem oil. These results correspond with the root colonization percentage for the potted trial. Because the potted trial was in a more controlled atmosphere, the results correlate more than the field trial. The AMF infection may have played a more significant role in nutrient uptake in the potted environment due to less available nutrients in the soil than in the field trial. The field trial soil was high in organic matter (around 40\%), and, because the experiment took place in the summer months, it is very possible that a high decomposition rate added a significant amount of nutrients in to the system. When nutrients are more available in the soil, AMF play less of a role in phosphorus transfer.

The C:N ratio at the organic site showed a marginally significant difference between the control and the neem oil treatment (Fig. 19). The control treatment was the most efficient in nitrogen nutrient uptake. The neem oil treatment was significantly different than the control treatment and displayed the least efficiency in nitrogen uptake as determined by leaf nutrient concentrations. The $\mathrm{C}: \mathrm{P}$ ratio at the organic site showed a 
difference between the neem oil and combination treatments (Fig. 22). The combination was the most efficient in phosphorus uptake, followed by the control. The phosphorus data as compared to the root colonization percentage shows results that are seemingly opposite to the expected outcome, and the remaining nutrient results show little difference between the treatments.

In the case of the organic field study, it seems as though nutrient results are situational. The organic plot was somewhat shaded causing the plants to not grow to their full potential. Furthermore, there was a noteworthy amount of insect herbivory taking place at this site throughout the experiment. Neem oil was sprayed as an insecticide. However, because of the experimental design that was executed in this experiment, the plants were not sprayed as often as they would be in a normal agricultural setting. Generally, plants would be sprayed with insecticide soon after they emerge and start developing their first true leaves. Because of the experimental parameters of this study, it was crucial that the mycorrhizae have time to establish themselves before the plants could be sprayed. For this reason, excess herbivory or weed growth may have occurred, causing stress to the plants at either site. Additional stress through lack of sunlight and enhanced herbivory (Fig. 25) could have played a major role in the uptake of nutrients and colonization of mycorrhizae.

(Fig. 24) displays the fruit yield for the organic site. Although there was a small amount of fruit yield, it was negligible. Due to the issues at this site with sunlight and herbivory, the mean yield for each plot did not exceed $1 \mathrm{~g}$ and the insecticide plots actually produced no yield at all. 
In the potted trial, the $\mathrm{C}: \mathrm{N}$ and $\mathrm{C}: \mathrm{P}$ ratios showed that the neem oil treatment was the most successful in nitrogen and phosphorus uptake followed by the citrus oil and then then control.

\subsection{Hypothesis 3}

The third hypothesis states that the synthetic chemical sprays will have a greater negative effect on mycorrhizal colonization and overall plant health then the organic sprays. By the end of the experiment, it was clear that the synthetic site had more successful plant growth than the organic site. This suggests that, contrary to the original hypothesis, use of synthetic chemicals have a more beneficial effect on okra growth than their organic counterparts. However, there were differences in environmental factors between the two sites that may have skewed the results in a way that didn't reflect the treatment applied. At the start of this experiment, the intention was to statistically compare the two field sites. It was expected that, because they were so close in proximity, climatic factors would be very similar. If all other inputs were the same including soil, fertilization, inoculation and seeding, and amount of water supplied, the sites should have been comparable. However, the sites did end up being different from one another. Possum Trot is an organic tropical nursery which mostly consists of trees with very little openings for sunlight. The area in which the plot was established was the sunniest area at

the farm. Yet, at some points in the day, the plot was still shaded due to the positioning of the trees, even though the area around the plot had been trimmed (Fig. 11). At the Girls Home site, the plot was in open and direct sunlight throughout the entire day. Okra is a sun loving plant and it is crucial to have full sunlight in order to exhibit ideal growth. Sunlight affected most of the factors in this experiment displayed by table 4, which 
shows sunlight correlated with every tested factor with the exception of root infection. Additionally, at Possum Trot, there was substantially more herbivory taking place than at the Girls Home site. This may be attributed to the density of trees and herbaceous plants on the farm and lack of any chemical sprays on the landscape. The Girls Home farm is very open; the mangoes grown on this land were far from the experimental plot and were chemically treated.

When comparing results at the two sites, the differences are very obvious. (Fig. 9) displays the means of each site in total biomass at the 3 sample points. Both sites follow a similar growth pattern but they begin to diverge after 30 days. By the end of the experiment, it was clear that the synthetic site had more successful plant growth than the organic site which is quite possibly due to environmental factors and not the actual treatment applied. (Fig. 12) shows the overall root colonization for both sites regardless of treatment. The organic site actually started out with a high level of root infection and then dropped down over time while the synthetic site stayed at a more steady percentage of root colonization overtime. Table 5 shows that the root colonization for each treatment at the synthetic site were generally higher than the organic site. While these results may not be comparable, the potted results for root colonization show clear differences. The citrus oil had a very high root infection percentage overall and is close to the control while the glyphosate treatment is noticeably lower than the citrus oil and all of the other treatments. The neem oil treatment was closest to the control and the carbaryl treatment had the second lowest colonization above the glyphosate. Although there was no statistical analysis performed for this trial, I believe that, with a large enough sample size, these results would be statistically substantiated. 
(Fig. 15) shows the total phosphorus results between the two sites overtime regardless of treatment. It is clear that the phosphorus levels in the leaf matter were much higher throughout the experiment in the organic site. This may have occurred because the plants underwent more stress at the organic site and the mycorrhizae may have been working to supply the plants with substantial nutrients to help them survive. The phosphorus results for the potted trial shows minimal difference in total phosphorus between treatments (Fig. 27) and actually doesn't correspond much with the percent root colonization data.

The C:N ratio comparison (Fig. 19) demonstrations that the organic site had a lower $\mathrm{C}: \mathrm{N}$ ratio overall than the synthetic site. (Fig. 22) which displays the C:P ratio, shows similar results; the organic site was lower than the synthetic. This result, along with the total phosphorus comparison, shows that, although the plants at the organic site weren't as successful in growth and fruit yield as the synthetic site, they were more efficient in nutrient uptake than those at the synthetic site. This may be correlated to the spray not having much effect on the AMF's ability to colonize and function in the root. This result may have also occurred because the plants at the synthetic site did have more biomass than those at the organic site. Therefore, their nutrients may have been more diluted throughout the plant instead of concentrated like the plants at the organic site.

The potted trial showed that the glyphosate treatment actually had the most efficient nitrogen uptake (Fig. 28), followed by the neem oil treatment and then the citrus oil. The control treatment showed the least efficiency in nitrogen uptake. While mycorrhizae do assist in nitrogen transfer, it is not their main function. Consequently, the influence is minimal. The C:P ratio results (Fig. 29) from the potted trial indicate that the 
carbaryl treatment was the most efficient in phosphorus uptake which was also reflected in the total phosphorus results. The glyphosate treatment along with the neem oil and citrus oil were very close in C:P ratios with some variation.

Overall, when comparing the organic and synthetic sprays, it was difficult to conclude that any of the treatments were more detrimental than the other due to the site difference and small sample size in the potted trial. When considering that there was significant differences between the control treatments and the synthetic sprays, especially the carbaryl and combination treatments, there is a clear distinction showing that the control plots had higher colonization percentages. The organic site showed no significant differences between the organic treatments and the control.

\section{CONCLUSION}

The results of this study exhibited that there is some relationship between spray applied and the amount of mycorrhizal colonization that occurs in the plant root and possibly the mycorrhizal forming potential in the surrounding soil. The organic sprays showed little negative effect on root colonization. The carbaryl and combination treatments in the field study showed the greatest detrimental effect on colonization while glyphosate showed the worst effect in the potted study.

In order for this study to end with more conclusive results, there are some changes that can be implemented. A potted study should be conducted with a larger sample size for each treatment before the field study in order to have data to compare to the results in the field. In the field experiment, both plots should be at the same location to ensure little to no environmental differences, allowing for more control. Additionally, a larger sample 
size is needed for stronger statistical power. Ideally, at least 30 plants per treatment per time would be used. With such a large sample size, it may be more efficient to test the effect of fewer chemicals at once.

This experiment was designed to emulate a farm setting. While field studies are not always ideal as a result of uncontrollable factors, it is important to understand the interactions that occur most closely to the likely scenario of crop growth and chemical usage. Many farmers and land managers use pesticides to control pests and ensure ideal growth and fruit yield. Since the establishment of the National Research Conservation Service (NRCS), formally known as the U.S. Soil Conservation Service, farmers have become continuously more aware of the best management practices for soil conservation and even receive incentives for executing conservation practices on their land. The beneficial relationship between mycorrhizal fungi and most commercial crops is well known in the farming community and has even sparked a lucrative business in commercial mycorrhizal inoculant production.

This research can be valuable to the farming and food production community. Organic and sustainable farming systems are gaining popularity. With demand for organic produce comes the opportunity to make significant profit. It is crucial for organic farmers to know if the inputs they are using could be hurting their yield, especially since these systems are usually as low input as possible. Farming is a very high risk industry with many unknowns such as environmental conditions and market prices. Fewer and fewer people are willing to risk their livelihood getting into farming. Scientific studies like this one play a crucial role in assisting those who take on the burden of feeding the United States and the globe. 


\section{REFERENCES}

Abd-Alla, M. H., S. A. Omar, and S. Karanxha. 2000. The impact of pesticides on arbuscular mycorrhizal and nitrogen-fixing symbioses in legumes. Applied Soil Ecology 14:191-200.

Akhtar, M.S., Siddiqui, Z.A., 2008. Arbuscular Mycorrhizal Fungi as Potential Bioprotectants Against Plant Pathogens, in: Mycorrhizae: Sustainable Agriculture And Forestry. Springer.

Altieri, M. A. 1999. The ecological role of biodiversity in agroecosystems. Agriculture, Ecosystems \& Environment 74:19; 19-31; 31.

Arias-Estévez, M., E. López-Periago, E. Martínez-Carballo, J. Simal-Gándara, J. Mejuto, and L. García-Río. 2008. The mobility and degradation of pesticides in soils and the pollution of groundwater resources. Agriculture, Ecosystems \& Environment 123:247-260.

Azadirachtin (121701) Clarified Hydrophobic Extract of Neem Oil (025007) Fact Sheet, 2001. Environmental Protection Agency. URL

https://www3.epa.gov/pesticides/chem_search/reg_actions/registration/fs_g-127_01oct-01.pdf

Bond, C.; Buhl, K.; Stone, D. 2012. Neem Oil General Fact Sheet; National Pesticide Information Center, Oregon State University Extension Services.

Brown, S.P., Treadwell, D., Stephens, J.M., Webb, S., 2015. Florida Vegetable Gardening Guide. University of Florida IFAS. URL http://edis.ifas.ufl.edu/pdffiles/vh/vh02100.pdf

Brundrett, M., Bougher, N., Dell, B., Grove, T., Malajczuk, N., 1996. Working with mycorrhizas in forestry and agriculture. Australian Centre for International Agricultural Research, Canberra, ACT.

Carbaryl: General Fact Sheet, 2003.. National Pesticide Information Center. URL http://npic.orst.edu/factsheets/carbgen.pdf

Carbaryl,1993. Extension Toxicology Network. URL http://pmep.cce.cornell.edu/profiles/extoxnet/carbaryl-dicrotophos/carbaryl-ext.html.

Cerdeira, A. L., and S. O. Duke. 2006. The Current Status and Environmental Impacts of Glyphosate-Resistant Crops: A Review. Journal of Environmental Quality 35:163358. 
Christman, S., 2007. Abelmoschus esculentus Plant Profile. Abelmoschus esculentus. URL http://floridata.com/plants/malvaceae/abelmoschus esculentus/951.

Cox, C., 1993. The Problems with Sevin. Journal of Pesticide Reform 13.

Dill, G.M., Sammons, D., Feng, P.C.C., Kohn, F., Kretzmer, K., Mehrsheikh, A., Bleeke, M., Honneger, J.L., Farmer, D., Wright, D., Padgette, S.R., 2010. Glyphosate: Discovery, Development, Applications, and Properties. Wiley, Hoboken, NJ.

Dodd, J. C., and P. Jeffries. 1989. Effects of herbicides on three vesicular-arbuscular fungi associated with winter wheat (Triticum aestivum L.). Biology and fertility of soils. 7:113-119.

Druille, M. 2013. Glyphosate reduces spore viability and root colonization of arbuscular mycorrhizal fungi. Applied Soil Ecology : a section of agriculture, ecosystems \& environment 64:99; 99-103; 103.

Druille, M., M. Omacini, R. A. Golluscio, and M. N. Cabello. 2013. Arbuscular mycorrhizal fungi are directly and indirectly affected by glyphosate application. Applied Soil Ecology. : 143-149.

Feng, P. C. C., and Baley. 11. Glyphosate inhibits rust diseases in glyphosate-resistant wheat and soybean. Proceedings of the National Academy of Sciences - PNAS 102:17290; 17290 .

Hassanzadeh, N., N. Bahramifar, and A. Esmaili-Sari. 2010. Residue content of carbaryl applied on greenhouse cucumbers and its reduction by duration of a pre-harvest interval and post-harvest household processing. Journal of the Science of Food and Agriculture 90:2249-2253.

Jeffries, P., S. Gianinazzi, S. Perotto, K. Turnau, and J. Barea. 2003. The contribution of arbuscular mycorrhizal fungi in sustainable maintenance of plant health and soil fertility. Biology and Fertility of Soils 37:1-16.

Koske, R. E., and Gemma. 08. Mycorrhizae in Hawaiian angiosperms: a survey with implications for the origin of the native flora. American Journal of Botany 79:853; 853.

Lazaruk, L. W., G. Kernaghan, S. E. Macdonald, and Damase Khasa. 2005. Effects of partial cutting on the ectomycorrhizae of Picea glauca forests in northwestern Alberta. Canadian Journal of Forest Research 35:1442-1454.

Levitan, L., I. Merwin, and J. Kovach. 1995. Assessing the relative environmental impacts of agricultural pesticides: the quest for a holistic method. Agriculture, Ecosystems \& Environment 55:153-168. 
Li, Y.C., Klassen, W., Lamberts, M., Olczyk, T., n.d. Okra Production in Miami-Dade County, Florida. University of Florida IFAS Extension. URL https://edis.ifas.ufl.edu/pdffiles/tr/tr00900.pdf

McGonigle TP, Miller MH, Evans DG, Fairchild GL, Swan JA (1990) A new method which gives an objective measure of colonization of roots by vesicular-arbuscular mycorrhizal fungi. New Phytol 115:495-501

Muthukumar, T., and Udaiyan. 01. Influence of native endomycorrhiza, soil flooding and nurse plant on mycorrhizal status and growth of purple nutsedge (Cyperus rotundus L.). Agriculture, Ecosystems \& Environment 61:51; 51.

Savin, M. C., L. C. Purcell, A. Daigh, and A. Manfredini. 2009. Response of Mycorrhizal Infection to Glyphosate Applications and P Fertilization in Glyphosate-Tolerant Soybean, Maize, and Cotton. Journal of Plant Nutrition 32:1702-1717.

Sawers, R.J.H., Gutjahr, C., Paszkowski, U., 2008. The Molecular Components of Nutrient Exchange in Arbuscular Mycorrhizal Interactions, in: Yang, S.-Y. (Ed.), Mycorrhizae: Sustainable Agriculture and Forestry. Springer.

Shannag, H.K., Capinera, J.L., Freihat, N.M., 2013. Use of neem-based insecticides against southern armyworm. Trends in Entomology 9.

Siddiqui, Z.A., Pichtel, J., 2008. Mycorrhizae: An Overview, in: Mycorrhizae: Sustainable Agriculture And Forestry. Springer.

Smith, P., Polomski, B., Shaughnessy, D., 2009. Okra. HGIC 1313 : Extension:Clemson University:South Carolina. URL http://www.clemson.edu/extension/hgic/plants/vegetables/crops/hgic1313.html.

Smith, S. E., \& Read, D. J. (2008). Mycorrhizal symbiosis (3rd ed.). Boston, MA: Academic Press.

s, S. D., and S. U. Khan. 1992. Uptake of Atrazine by Hyphae of Glomus VesicularArbuscular Mycorrhizae and Root Systems of Corn (Zea mays L.). Weed Science 40:161-170.

Székács, A., Darvas, B., 2012. Forty Years with Glyphosate, in: Herbicides - Properties, Synthesis And Control of Weeds.

Tanentzap, A. J., A. Lamb, S. Walker, and A. Farmer. 2015. Resolving conflicts between agriculture and the natural environment. PLoS Biology 13:.

Tate, R.L., 2000. Soil microbiology (2nd ed.). Wiley, New York. 
USEPA. 1983. U S Environmental Protection Agency. Rev. March 1983. Method 200.7. Methods for Chemical Analysis of Water and Wastes. (EPA-600 4-79-020) EnvironmentalMonitoring and Support Laboratory, Office of Research and Development, Cincinnati, OH45268

van der Heijden, Marcel G. A. 2008. The unseen majority: soil microbes as drivers of plant diversity and productivity in terrestrial ecosystems. Ecology Letters 11:296; 296-310; 310.

van der Werf, H. M. 1996. Assessing the Impact of Pesticides on the Environment. Agriculture Ecosystems and Environment 60:81.

Who We Are, n.d. Organic Materials Review Institute. URL http://www.omri.org/about.

$\mathrm{Xu}, \mathrm{S}$., n.d. Environmental Fate of Carbaryl. Environmental Monitoring \& Pest Management. URL http://www.cdpr.ca.gov/docs/emon/pubs/fatememo/carbaryl.pdf 


\section{APPENDICIES}

Paired Samples Correlations

\begin{tabular}{|ll|r|r|r|}
\hline & $\mathrm{N}$ & Correlation & \multicolumn{1}{c|}{ Sig. } \\
\hline Pair 1 & $\begin{array}{l}\text { O Biomass 1 \& O } \\
\text { Biomass 2 }\end{array}$ & 36 & .076 & .658 \\
Pair 2 & S Biomass 1 \& S & & & \\
& Biomass 2 & 36 & .095 & .583 \\
Pair 3 & RI 01 \& RI 0 2 & 36 & .270 & .111 \\
Pair 4 & RI S1 \& RI S 2 & 36 & .467 & .004 \\
Pair 5 & OTP 1 \& OTP 2 & 36 & .280 & .098 \\
Pair 6 & STP1 \& S TP 2 & 36 & -.303 & .073 \\
Pair 7 & OC:N 1 \& O C:N 2 & 36 & .582 & .000 \\
Pair 8 & SCN1 \& S CN 2 & 36 & .145 & .400 \\
Pair 9 & OCP 1 \& O CP 2 & 36 & .345 & .040 \\
Pair 10 & SCP1 \& S CP 2 & 36 & -.248 & .145 \\
\hline
\end{tabular}


Correlations

\begin{tabular}{|c|c|c|c|c|c|c|c|c|c|c|}
\hline & & Day & Light & $\begin{array}{c}\text { Total } \\
\text { Biomass }(\mathrm{g})\end{array}$ & $\begin{array}{c}\text { Root/Stem } \\
\text { Biomass }\end{array}$ & Root Infection & $\begin{array}{c}\text { Total P (mg } \\
\mathrm{g}-1 \mathrm{dw})\end{array}$ & $\mathrm{C}: \mathrm{N}(\mathrm{mol}: \mathrm{mol})$ & $\mathrm{C}: \mathrm{P}(\mathrm{mol}: \mathrm{mol})$ & Fruit Yield (g) \\
\hline \multirow[t]{3}{*}{ Day } & Pearson Correlation & 1 & $.156^{x}$ & $.762^{\mathrm{nx}}$ & $.780^{\mathrm{kn}}$ & $-.236^{\mathrm{Nn}}$ & .052 & $.158^{x}$ & .007 & ${ }^{\circ}$ \\
\hline & Sig. (2-tailed) & & .022 & .000 & .000 & .000 & .443 & .020 & .920 & .000 \\
\hline & $\mathrm{N}$ & 216 & 216 & 216 & 216 & 216 & 216 & 216 & 216 & 72 \\
\hline \multirow[t]{3}{*}{ Light } & Pearson Correlation & $.156^{n}$ & 1 & $.266^{* \pi}$ & $.273^{\mathrm{kn}}$ & .031 & $-.255^{\mathrm{N}}$ & $.484^{\prime \prime}$ & $.248^{\pi n}$ & $.387^{2 \pi}$ \\
\hline & Sig. (2-tailed) & .022 & & .000 & .000 & .645 & .000 & .000 & .000 & .001 \\
\hline & $\mathrm{N}$ & 216 & 216 & 216 & 216 & 216 & 216 & 216 & 216 & 72 \\
\hline \multirow[t]{3}{*}{ Total Biomass (g) } & Pearson Correlation & $.762^{\mathrm{kx}}$ & $.266^{\mathrm{kn}}$ & 1 & $.996^{\mathrm{kx}}$ & $-.167^{x}$ & .011 & $.223^{\mathrm{kn}}$ & .022 & .189 \\
\hline & Sig. (2-tailed) & .000 & .000 & & .000 & .014 & .873 & .001 & .743 & .112 \\
\hline & $\mathrm{N}$ & 216 & 216 & 216 & 216 & 216 & 216 & 216 & 216 & 72 \\
\hline \multirow[t]{3}{*}{ Root/Stem Biomass } & Pearson Correlation & $.780^{\pi \times}$ & $.273^{\text {nx }}$ & $.996^{\mathrm{Nx}}$ & 1 & $-.162^{x}$ & .019 & $.228^{\prime \prime}$ & .012 & $.236^{*}$ \\
\hline & Sig. (2-tailed) & .000 & .000 & .000 & & .017 & .781 & .001 & .862 & .046 \\
\hline & $\mathrm{N}$ & 216 & 216 & 216 & 216 & 216 & 216 & 216 & 216 & 72 \\
\hline \multirow[t]{3}{*}{ Root Infection } & Pearson Correlation & $-.236^{\mathrm{Nn}}$ & .031 & $-.167^{x}$ & $-.162^{x}$ & 1 & -.028 & .011 & .060 & -.044 \\
\hline & Sig. (2-tailed) & .000 & .645 & .014 & .017 & & .681 & .870 & .380 & .716 \\
\hline & $\mathrm{N}$ & 216 & 216 & 216 & 216 & 216 & 216 & 216 & 216 & 72 \\
\hline \multirow[t]{3}{*}{ Total P (mg g-1 dw) } & Pearson Correlation & .052 & $-.255^{x \pi}$ & .011 & .019 & -.028 & 1 & $-.333^{\mathrm{xn}}$ & $-.944^{\mathrm{xx}}$ & -.187 \\
\hline & Sig. (2-tailed) & .443 & .000 & .873 & .781 & .681 & & .000 & .000 & .116 \\
\hline & $\mathrm{N}$ & 216 & 216 & 216 & 216 & 216 & 216 & 216 & 216 & 72 \\
\hline \multirow[t]{3}{*}{$\mathrm{C}: \mathrm{N}(\mathrm{mol}: \mathrm{mol})$} & Pearson Correlation & $.158^{n}$ & $484^{\mathrm{kn}}$ & $.223^{\mathrm{kn}}$ & $.228^{\mathrm{kn}}$ & .011 & $-.333^{\mathrm{nn}}$ & 1 & $.356^{\mathrm{N}}$ & $.518^{\pi x}$ \\
\hline & Sig. (2-tailed) & .020 & .000 & .001 & .001 & .870 & .000 & & .000 & .000 \\
\hline & $\mathrm{N}$ & 216 & 216 & 216 & 216 & 216 & 216 & 216 & 216 & 72 \\
\hline \multirow[t]{3}{*}{$\mathrm{C}: \mathrm{P}(\mathrm{mol}: \mathrm{mol})$} & Pearson Correlation & .007 & $.248^{\mathrm{nn}}$ & .022 & .012 & .060 & $-.944^{\mathrm{N}}$ & $.356^{n=}$ & 1 & .171 \\
\hline & Sig. (2-tailed) & .920 & .000 & .743 & .862 & .380 & .000 & .000 & & .151 \\
\hline & $\mathrm{N}$ & 216 & 216 & 216 & 216 & 216 & 216 & 216 & 216 & 72 \\
\hline \multirow[t]{3}{*}{ Fruit Yield (g) } & Pearson Correlation & ${ }^{\circ}$ & $.387^{\mathrm{kn}}$ & .189 & $.236^{\star}$ & -.044 & -.187 & $.518^{\mathrm{xn}}$ & .171 & 1 \\
\hline & Sig. (2-tailed) & .000 & .001 & .112 & .046 & .716 & .116 & .000 & .151 & \\
\hline & $\mathrm{N}$ & 72 & 72 & 72 & 72 & 72 & 72 & 72 & 72 & 72 \\
\hline
\end{tabular}

*. Correlation is significant at the 0.05 level (2-tailed).

**. Correlation is significant at the 0.01 level (2-tailed).

c. Cannot be computed because at least one of the variables is constant. 